\title{
Developing an analytical framework for understanding the emergence of de-professionalisation in health, social care and education sectors
}

\begin{abstract}
Nigel Malin ${ }^{1}$
Abstract: This article aims to develop an analytical framework for understanding the context in which a process of de-professionalisation exists within an employment culture dominated by capitalism, globalisation and inequality. It specifically focuses upon experiences arising in health, social care and education sectors typifying that found within the British Welfare State during late modernity. Different theoretical definitions are presented to introduce an argument for a multi-dimensional approach. For example de-professionalisation may cover the removal from professional control, influence, manipulation or a destabilisation of a conventional mode of professionalisation and professional ties. Alternatively it may embody causation to appear unprofessional; or to discredit or deprive of professional status; also privately may be experienced as a weakening of status, respect or tendency away from a position of strength or equal status and be associated with measures for lessening the need for specialist knowledge and expertise. This analysis is based on a review of recent policy and practice evidence to support the notion that de-professionalisation may be defined through a lens of 'cuts to services' and job insecurity. It includes a case study covering the strike by NHS junior doctors which it is argued has had an impact on the image of 'doctors as professionals', resulting in a potential loss of public trust. De-professionalisation may be defined by financial cuts to staff training and through critiquing models of current training; or by a lowering of morale, a demoralisation or pervasive denigration of the workforce. Lastly this process may be considered as an outcome of low productivity in the workplace where a rise in low-skilled jobs becomes blamed for static wages. Increases in productivity come about as a result of deploying better raw materials, better trained or educated labour or better machines. Ordinary workers seem to have enjoyed few of the benefits of economic growth.
\end{abstract}

Keywords: ideological roots of de-professionalisation; neo-liberalism, Taylorism/PostFordism; health, social care and education providers; service cutbacks; reductions in training; workforce morale and productivity

1. Professor Emeritus in Social Policy, University of Sunderland, UK

Address for correspondence: malinnigel@gmail.com

Date of first (online) publication: 12th October 2017 


\section{Introduction}

Throughout the UK austerity appears to be failing as an economic idea: the deficit reduction continues but is expected to no longer dominate the present Conservative Government's agenda. It is clear for example that in the 2017 General Election voters protested about the fact that their wages bought them less than a decade ago; about the meanest increases in health spending since the NHS began; about the cuts in spending per pupil in education; about food banks, lack of 'affordable' housing and rising inequality. Reducing inequalities requires anti-austerity policies such as more progressive taxation of incomes and wealth; a higher minimum wage and/ or enforcement of a real living wage; more social housing; free prescriptions for most people; a more egalitarian distribution of income and wealth and universal provision of high quality social services that reflect the value attached to the worth and contributions of all citizens. There is a need to ensure that individuals are properly trained and able to undertake particular tasks, and that any differences in rewards are both fair and proportionate. Previous 'reforms' to public services have entailed outsourcing coupled with a dogmatic adherence of the public sector to the purchaser/provider split. This has meant that Local Authorities, the NHS and others no longer directly provide in-house services, but commission them from external private sector providers through competitive tendering, where costs are minimised to win a contract. Most senior economists claim that productivity must rise or quality of life will fall. Unless Government takes urgent action to boost productivity by investing in education, cutting red tape and incentivising research and development, a pattern of slower growth will make it more difficult to reduce excessive inequality. An industrial strategy which focuses on education and training to deal with skills shortages along with technological development which creates conditions for investment and growth now becomes the key policy driver to raise productivity.

\section{Section A.Ideologicalroots of the concept of de-professionalisation}

The above represents this author's broad position statement for introducing a critique of the ideological basis underpinning the concept of de-professionalisation and is intended to provide a context for examining how this may be applied today within UK health, social care and education sectors. A primary aim of this article is to develop an analytic framework for understanding the context in which a process of de-professionalisation exists within an employment culture dominated by capitalism, globalisation and inequality. The argument is that this has become a feature of a deepened marketisation of public welfare systems, extending the logic of competition in everyday life, where the notion of meritocracy appears to contradict 
the principle of equality. Over the past few decades, neo-liberal meritocracy has been characterised by the sheer scale of its attempt to extend entrepreneurial competition into all aspects of everyday life and by the power it has gathered by drawing from twentieth century movements for equality. Meritocracy, rather like social mobility, has been presented as a means of breaking down established hierarchies of privilege.

A starting point is to highlight the social and political roots of de-professionalisation which seem to disregard a 'socially cohesive role' characteristic of a neo-Durkheimian perspective on professions along with a valuing of specialist knowledge, skills and acquired status offered by a neo-Weberian perspective. Drawing on an alternative neo-Marxist framework which emphasises power relations the origins of deprofessionalisation are seen as based on ideas taken from Taylorism (or scientific management) which came to dominate managerial ideas about how best to control alienated labour (Edgell, 2012, pp.57-61). Ideological reference points where the notion of de-professionalisation takes shape include therefore:

- Neo-liberalism as a blend of market individualism and social or state authoritarianism is an ideology where its central pillars are the market and the individual. The principal neo-liberal goal is to 'roll back the frontiers of the state', in the belief that unregulated market capitalism will deliver efficiency, growth and widespread prosperity. This is reflected in a preference for privatisation, economic deregulation, low taxes and anti-welfarism. Neo-liberalism along with deregulated and flexible labour markets have seen power shift too far towards big business and managerial unitarism, detrimental to even minimalist industrial democracy. Individualism as a normative concept, in the form of ethical individualism, implies that society should be constructed so as to benefit the individual, giving priority to the individual's rights, needs or interests. In its most familiar form, egoistical individualism - also called 'market' 'possessive' or 'atomistic' individualism - stresses human self-interestedness and self-reliance.

- Taylorism and Post-Fordism ideas emerged albeit from within an industrial and manufacturing production context embodying principles of work organisation, notably the transfer of all discretion from workers to management and the fragmentation and simplification of tasks, including managerial control over the pace of work. This involved flexible multiskilled work, flexible computer technology, flexible parts and high quality customized products. Both approaches - Taylorism and Fordism - represent distinct branches of managerialism, where the primary goal of Taylorism was to improve efficiency using the existing technology whilst Fordism tended to focus more on replacing labour by machinery and recruiting unskilled workers to attend to the machines.

- Lifelong -Learning has become an ideology which translates into policies focused on the economic imperatives of developing a more productive and efficient workforce. It is an idea informing post-compulsory education and 
training policies, prompted by globalisation and changes in the labour market. These policies are important for economic growth and the well-being of society but their economic objectives are prioritised. Policies focus on improving the skill levels and mix of the existing and future workforce so there is a balance in the supply of, and demand for, skilled labour. Between 1997 and 2010, the Labour Government tried to increase the supply of skilled workers by expanding post-compulsory education, encouraging greater participation, and getting people to take more and higher qualifications. The Coalition (2010-015) along with the subsequent Conservative Governments have planned to increase the demand for skilled workers by focusing on skills rather than qualifications. The connection with de-professionalisation arises most sharply around the concern that such public sector 'cuts' to post-compulsory education in 2010 have shifted more of the cost onto learners and employers (Callender, 2012). As a counter-intuitive, rewarding of specialist skills and expertise characteristic of meritocracy may appear, in one way, to be oppositional to the broad meaning of de-professionalisation which instead draws on the notion of equality.

- Equality is the principle of uniform apportionment; it does not imply identity or sameness. Foundational equality is the idea that human beings are ' born equal' in the sense that their lives are of equal moral value. Formal equality refers to the formal status of individuals in society in terms of their rights and entitlements but it may be described as unjust because it treats unequals equally and therefore fails to reward people in line with their talents and capacities. The de-professionalisation argument comes into play where policies in the workplace may fail to acknowledge any difference between those possessing and those not possessing relevant qualifications and acquired skills.

\section{Section B. Theoretical definitions of de-professionalisation}

De-professionalisation might be described as an output of a process, or as the antithesis of professionalisation, which is an attempt to translate one order of scarce resources - special knowledge and skills - into another - social and economic rewards (Larson, 1977, pp.xvii). This definition of professionalisation tends to be the result of the particular emphasis given to different key aspects of professionalism: status and pay, expertise and standards, values and ethics (Edmond and Price, 2012, p.30). A more nuanced way of examining the concept of professionalisation - and implicitly that of de-professionalisation - is through the lens of 'street-level bureaucracy', an expression coined by Michael Lipsky in an article (1971), elaborated on in 1980, and further updated in 2010 (Lipsky, 2010; see Hupe and Hill, 2015). Lipsky equates the term 'street-level bureaucrat' with 'the public services with which citizens typically interact. In this sense, all teachers, police officers and social 
workers in public agencies are street-level bureaucrats without further qualification' (Lipsky, 2010, p.xvii). He adds that street-level bureaucracy stands for 'public service employment of a certain sort, performed under certain conditions ... Street -level bureaucrats interact with citizens in the course of the job and have discretion in exercising authority' (Lipsky, 2010, p.xvii). The concept embeds both bureaucratic and professional characteristics, and encompasses the development of professional roles in public policy delivery.

Lipsky acknowledges that there may be differences between street-level bureaucrats arising from professional status. He emphasises the common characteristics of street-level bureaucrats despite the diverse nature of the public services workforce to which this term refers - receptionists, benefits clerks, judges, doctors, police officers, social workers, teachers and so on (Lipsky, 2010). Professor of Social Work, Tony Evans $(2015 ; 283)$ claims that this would perhaps make sense if one were to assume the de-professionalisation of staff in street-level bureaucracies. However, while professional workers, across a range of different settings, have seen changes that have constrained their work, they have also seen changes that have increased their power and status. In England, for instance the professional status of social workers has been embedded in law for over a decade (Social Care Act, 2000). Social workers are now registered, and only social workers registered by the professional body can operate as social workers. Furthermore, the number of social workers employed within social services in England has also increased by 24\% in the decade 2000-10 (NHS, 2010). Evans' studies of social work activity have examined the continuing role of 'professionalism' as a factor influencing front-line discretion, concluding that the professional status of social workers has been an important factor in the levels of discretion expected and afforded in their practice. Kate Morris, another social work professor, has researched this area of professionalism in relation to scrutinising both professionals' decision-making and outcomes for children in a variety of comparable neighbourhoods in terms of referral rates and the probability of children ending up being assessed or looked after. An alleged purpose was to establish how poverty and deprivation are understood and responded to by social workers in the frontline of child protection (see Morris et al, 2016).

Many street-level bureaucrats can be considered to be organisational professionals (Evett, 2009), working in public agencies responsible for delivering public policies. Therefore, workers have to deal with standards for doing their work that originate in various sources: public policy, their organisation and their occupation. Whether the process of professionalisation can be fulfilled is likely to depend on the nature of these standards and the way in which they support or maybe oppose each other (van der Aa and van Berkel, 2015). Many of these standards have been changing profoundly over the last decades in ways that potentially affect the promise of professionalism. Expectations regarding public services have been changing as a consequence of changing public policies and new forms of governance. New standards are being set by public policies and managers and trust in established 
occupational standards is not self-evident. The role of occupational standards may change in various ways and may be reduced, resulting in de-professionalisation, which may thwart the promise of professionalism.

A general assessment of recent social policy changes is difficult given differences between welfare states and policy fields. However, scholars on welfare state development (Gilbert, 2002; Taylor-Gooby, 2008; Bonoli and Natali, 2012; Davies, 2017) agree on a number of general changes occurring in social policy fields across countries:

- the alignment of social policy and social protection with economic policies;

- a greater emphasis on the conditionality of welfare state arrangements; and

- especially since the economic crisis of 2008, the reduction of spending on social policies and services and a greater emphasis on the value of financial efficiency.

Such policy changes influence the standards that social policies set for service delivery, put existing occupational standards to the test or give rise to new occupational standards. For example, workers are expected to have a greater focus on the labour market attachment of their clients, to focus more on the financial efficiency of their services or to implement 'disciplinary' instruments, such as financial sanctioning. These new policy standards do not necessarily fit well with existing occupational standards, as the literature on social workers made responsible for implementing these policies has shown (Jordan, 2001; Evans, 2013; 2015).

Various authors have explored these potential tensions for the social work occupation, which, in many cases, has been a preferred supplier for various kinds of social policies (Clarke and Newman, 1997; Kirkpatrick et al, 2005). Evidence has become available of a growing discrepancy between the self-identity of social workers as critical agents in structural social change and policy development, and the actual role that they have come to play in the 'technical' delivery of neo-liberal social policies (see for example Garrett, 2009; 2014; Lavalette, 2011; Marston and McDonald, 2012; Rogowski, 2011 and 2016). Jordan (2001) discusses how social policy increasingly accentuates the promotion of employment, a domain in which traditional social work has not been very active and, indeed competent (van der Aa and van Berkel, 2015:266). Changes in the governance and management of social policy implementation potentially affect the organisational standards for service provision. These might include the redistribution of responsibilities for policymaking and implementation, for example between professionals and professional managers, along with the introduction of quasimarkets for service delivery. Additionally they cover the stimulation of inter-agency cooperation, for example among health, social care, housing and financial sectors, and overall the introduction of new management methods within agencies.

With respect to the notion of de-professionalisation simulating a competing standards narrative, an illustration can be found from a definition of performance management in the workplace. On the one hand, output targets, as well as the 
external definition of these targets by policymakers or managers, may conflict with occupational standards, may be at odds with professional ethics and may be experienced as an attack on professional discretion. On the other hand, performance management may go hand in hand with deregulation and less bureaucratic control, thus actually increasing room for occupational standards (Hill and Hupe, 2014; Kirkpatrick et al, 2005; Newman, 2005). Rather than be seen as an attack on 'pure professionalism' (Noordegraaf, 2011) at the cost of occupational standards and professional autonomy, the exact impact of these changes needs to be conceptualised, depending on the nature of the changes themselves, as well as on the existing working and occupational contexts in which they are introduced, resulting in many professionals adapting creatively to new expectations.

The emergence of the professions as distinctive occupational groups proclaiming the exclusive competence over a particular field has often been identified as the product of specialisation, the division of labour characteristic of modern forms of production and knowledge (Weber, 1987). Thus the emergence of the professions is seen as an integral part of the process of rationalisation: the increasing complexity and extensiveness of knowledge and information leads to specialisation and the division of labour. De-professionalisation could then be measured as a contrasting trope concept founded on the intricate processes of professionalisation that emphasise the 'labour of division' (Fournier, 2000) along with 'incommensurability' characteristic of the professions as described by Weber. Incommensurability suggests that the social position and status of a profession may be such that it is not able to be judged by the same standard as anything else, or indeed has no common standard of measurement. This idea can be understood in terms of creating boundaries between the sphere of competence of the professions and other spheres of activity. In terms of the attempt through various 'defensive strategies' to place professional activity apart from, outside of, the sphere of ordinary relationships and activity, and in particular, outside of the market, incommensurability supports the view that professions may thus be better seen in terms of the labour of division than as an outcome of the division of labour. In other words, they are not the technical outcomes of the intellectual division of labour but are constituted and maintained through processes of isolation and boundary construction.

As more boundary layers are created to establish professionalisation so there would appear to be a skilled effort on the part of outsiders (members of the public, private service providers, government) to question and re-evaluate professional knowledge. More broadly, there has been a wide repudiation of the 'experts', most notably in the 2016 US election and Brexit referendum. Conservative Government politician Michael Gove's statement that 'people in this country have had enough of experts', said in June 2016 amidst the EU leave debate, was a more fine-grained attack on the conventional rhetoric of the establishment, This may have sounded like an attack on expertise as such but may be more a critique of modern technocratic government, a claim that the public are sick and tired of we-know-best lectures 
from economists and 'professional politicians' (Enough Said, Mark Thompson, 2016). The difficulty that ordinary people have in making sense of the language of elite policymakers is a real issue and language can be seen as within the purview of experts and sometimes used to control us. What researchers in an Ipsos MORI survey identified as 'a presumption of complexity' meant that many respondents thought that it was hopeless to even try to understand an issue in question often leaving politicians and 'experts' becoming vulnerable to provocation with their position challenged.

Professionals working in education, health and social care today are challenged interminably over some of their decisions, the quality of service they provide, and the organisational structures in which they operate. This critique takes on an existential tone, as one senior political expert claimed that 'the most important factor to tackle inequalities in education is teacher quality' (Milburn, 2016). Whereas a process of separation and boundary creation continues to consolidate, an unravelling, rather less sophisticated de-professionalisation narrative moves in an opposing direction. Parents may disapprove of their child's lack of progress in a particular school or what they may perceive as bullying by a peer group, and hence threaten legal action against the school. Social workers may be criticised following the action of taking a child into care or for failing to obtain a favoured adult placement. Here de-professionalisation can be used as a term to represent a process of disaggregation, dismantling or 'chipping away' of an established position of authority, even when such disapproval might apply only within a specific context to any one or group of individuals representing a profession. In summary the concept of de-professionalisation can be defined in the following multi-dimensional way:

- to remove from professional control, influence, manipulation; destabilisation of their mode of professionalisation and of their professional ties (Demailly and De La Broise, 2009); such a weakening that can be regarded as unalloyed characterised by a sharp diminution of autonomy at work and a powerlessness collectively to conceive of any positive re-constitution of a lost professionalism (transfer of power dimension)

- to cause to appear unprofessional; discredit or deprive of professional status; also privately experienced as a weakening of status, respect or tendency away from a position of strength or equal status; associated with measures for lessening the need for specialist knowledge and expertise (see for example, Rogers and Pilgrim 2014 pp.107-111) (status and market strength dimension)

- as the obverse of professionalisation, in which it is assumed that there is a plurality of professionalisation processes (Demailly, 2003; Kuhlmann and Saks, 2008), and that the social construction of individual and collective autonomy at work takes a multiplicity of forms, de-professionalisation can be regarded as a function or by-product of a normally hierarchical process where certain jobs become vulnerable, subordinate and professional identity scapegoated, replaced 
by insecurity and a lack of belonging (transformative-contextual dimension)

- as an inversion of a specific mode of professionalisation, it originates in a loss of autonomy in the practice of a profession and subordination to external supervision (even when the imposition of external control is presented as a transfer of responsibilities to the actor in question) (Adcroft and Willis, 2006; Frostenson, 2015) (managerialism dimension)

- as taking place within the historical trajectory followed by and in the space occupied by each group's particular mode of professionalisation. The spatiotemporal framework that forms the context of this process can be considered at various sociological levels (macro, meso or micro) depending on whether one is referring to public policies, organisational change or daily work routines (reconstituting professionalities dimension)

The final dimension points to what has been denoted as 'de-professionalisation of society' (Demailly and De La Broise, 2009), a process that is changing the mode of bureaucratic professional regulation characteristic of European societies. This mode of producing and regulating public policies did, after all, grant an important role to professional groups (represented by their associations and trade unions). It has been argued that the state, on the one hand, and the market, on the other, seem to be sharply reducing the role of occupational groups in the regulation of public policies and to be depriving that role of its legitimacy.

Somewhat distinct from the above is a definition of de-professionalisation based on the notion of 'deskilling' (see Braverman, 1974; Edgell, 2012, pp.56-73). This evolves from scientific management or Taylorism, and focuses on the impacts of breaking down a professional task (or work process) into elements creating a more atomised position in the workplace (Heywood, 2000, p.133). A topical example of breaking down a work process into a linear narrative-form is provided through 'partnership structures' which have characterised the UK's policy, implementation and professional practices towards disadvantaged children and families, for example Whole Family Approaches (WFA), Sure Start. The argument here is that the value of 'work processes' trumps the perceived contribution of individual professionals as they are viewed as prerequisite to achieving a superior performance or outcome potential. An overall effect of reliance on these partnership or multi-disciplinary structures may be to weaken or diminish the role of specific professionals. For instance, in delivering WFA there may be a statutory or policy requirement for partnership in specific areas of practice. The chosen 'model' includes a series of activities collectively defined as 'participation, engagement and a multi-disciplinary focus', and these might include: 'to enable a process of engagement with the family'; 'assessment and review'; ' to develop multi-agency involvement as regards decisionmaking; 'to strengthen coordination of services; 'to promote effective informationsharing'; and 'to produce an intervention or package of support which is flexible, targeted and coordinated'. Similarly there are different 'work processes' introduced 
to establish and measure impact and outcomes, and these provide an evaluation framework for managers and professionals to reflect on. WFA was framed as a policy response to a numbers of factors - inadequate range and level of service, poor coordination, problems of access for families, and insufficient adaptability. Whereas organisational or legislative change appeared as the preferred solution earlier on, a change in the 'cultural system' (Boyle et al, 2010) setting legitimate goals, and the technology that determines the means available for reaching them appears more instinctively relevant today. The above approach - of breaking down a work process into elements - contrasts with the more unifying process demonstrated by creating a 'professional project' - see for example, MacDonald; 1995, pp.187-208; where there is a starting point, overall objective and sub-goals and steps outlined towards a monopolization of professional knowledge.

Braverman's 'deskilling' thesis draws upon Marx's theory of work in industrial capitalism in that he starts from the proposition that in such a society workers are constrained economically, by the absence of alternatives, to sell their labour to employers who are similarly constrained to seek a profit or go out of business. This is the capitalist mode of production, at its core is the unequal relationship between employer and employee, and Braverman's aim is to examine 'the manner in which the labour force is dominated and shaped by the accumulation of capital' (1974, p.53). While Marx's empirical reference point was Britain in the nineteenth century, Braverman's was America in the twentieth century - respectively the first industrial capitalist society and the most advanced. Braverman's ambitious analysis of the development of the capitalist mode of production over the past hundred years or so was predicated on the Marxian assumption that human labour power is unique in that it is 'intelligent and purposive' (ibid, p.56). These distinctive characteristics make human labour exceedingly adaptable, with unlimited potential for production.

From the standpoint of the capitalist, this is good news, but the downside is that, in the context of the inherently 'antagonistic relations of production', there is 'the problem of realizing the 'full usefulness' of the labour power' that has been purchased (ibid, p.57). Thus, if all the capitalist really buys is potential, it is imperative to exert control over the labour process in order to maximise the productive potential of labour and therefore profits. This applies equally to professionals as providers of labour where the focus is on making full use of their knowledge and skills - productive potential - by controlling the work process. Capitalists turned therefore to developments in management and machinery, which not only enhanced the control of labour but also progressively deskilled the worker.

It follows that the primary new managerial responsibility under scientific management was the 'gathering together of all the traditional knowledge which in the past had been possessed by the workmen and then classifying, tabulating and reducing this knowledge to rules' (Taylor, 1947 (1911):36). All this knowledge was then centralized in a planning department, and managers, armed with the knowledge of the best way of performing a task, could specify how it was to be done 
and how long it should take. Braverman summed up Taylor's systematic or scientific approach to management with reference to three related principles: 'the first principle is the gathering and development of knowledge of the labour processes', 'the second is the concentration of this knowledge as the exclusive province of management - together with its essential converse, the absence of such knowledge among the workers', and 'the third is the use of this monopoly over knowledge to control each step of the labour process and its mode of execution' (1974:119). Implicit in these principles is the separation of conception from execution, namely the transfer of all mental labour from workers to managers while simultaneously simplifying and standardizing the tools and tasks that the worker is instructed to use in order to undertake a de-skilled task within a designated timeframe that is 'the manager's brains are under 'the workman's cap' (cited by Montgomery, 1987, p.45).

\section{Summary}

\section{Ideological reference points where the notion of de-professionalisation takes} shape include:

- Neo-Liberalism

- Taylorism/Post-Fordism

- Life-Long Learning

- Equality

\section{Theoretical definitions of de-professionalisation centre around the following} narratives:

- As an output of a process, or as the antithesis of professionalisation, which is an attempt to translate one order of scarce resources, special knowledge and skills, into another, social and economic rewards (Larson, 1977)

- Public service standards have been changing profoundly as have been expectations regarding public services through the lens of street-level bureaucracy (Lipsky, 2010; Hupe and Hill, 2015)

- Lipsky emphasised the common characteristics of street-level bureaucrats despite the diverse nature of the public services workforce to which this term refers

- It is a wrong to assume a notion of de-professionalisation across disciplinary boundaries, as while professional workers have seen changes that have constrained their work, they have also seen changes that have increased their power and status (Evans, 2015)

- General changes occurring in social policy fields emphasise the conditionality of welfare state arrangements; and especially since the economic crisis of 2008, the reduction of spending on social policies and services and a greater emphasis on the value of financial efficiency (Garratt, 2009; 2014; Lavalette, 2011; Rogowski, 2011; 2016) 
- It has been regarded as a contrasting trope based on a concept of professionalisation which emphasises the idea of 'labour of division' (Fournier, 2000) along with that of 'incommensurability' (Weber, 1987) where professions are constituted and maintained through processes of isolation and boundary construction

- As a critique of experts, or of expertise, beginning a process of disaggregation/ dismantling, as many professionals today are challenged over their decisions, quality of service they provide and organisational structures in which they operate

\section{In summary the concept of de-professionalisation may be defined in the following multi-dimensional way:}

- to remove from professional control, influence, manipulation; destabilisation of their mode of professionalisation and of their professional ties (Demailly and De la Broise, 2009), such a weakening that can be regarded as unalloyed deprofessionalisation, can be characterised by a sharp diminution of autonomy at work and a powerlessness collectively to conceive of any positive, reconstitution of a lost professionalism

- to cause to appear unprofessional; discredit or deprive of professional status; also privately experienced as a weakening of status, respect or tendency away from a position of strength or equal status; associated with measures for lessening the need for specialist knowledge and expertise (Rogers and Pilgrim, 2014)

- as the obverse of professionalisation, in which it is assumed that there is a plurality of professionalisation processes (Demailly, 2005; Kuhlmann and Saks, 2008), and that the social construction of individual and collective autonomy at work takes a multiplicity of forms, de-professionalisation can be regarded as a function or by-product of a normally hierarchical process where certain jobs become vulnerable, subordinate and professional identity scapegoated, replaced by insecurity and a lack of belonging

- as an inversion of a specific mode of professionalisation, it originates in a loss of autonomy in the practice of a profession and subordination to external supervision, even when the imposition of external control is presented as a transfer of responsibilities to the actor in question (Adcroft and Willis, 2006; Frostenson, 2015)

- as taking place within the historical trajectory followed by and in the space occupied by each group's particular mode of professionalisation, The spatiotemporal framework that forms the context of this process can be considered at various sociological levels (macro, meso or micro) depending on whether one is referring to public policies, organisational change or daily work routines.

- Notion of deskilling (Braverman, 1974) draws on Marx's theory of work in industrial capitalism.

- Direction/form of work 'processes', for example, Whole Family Approach, 
Sure Start and their impact on organisational culture may be perceived within managerialist ideology as more salient compared with the measured 'outputs' of individual professionals

\section{Section C. Reviewing the evidence: de-professionalisation as defined through a lens of 'cuts to services', job insecurity and globalisation}

\section{The austerity agenda}

The election of the Conservative-led Coalition Government (2010) followed by a second election of the Conservative Government 2015 have become characterised by an 'age of austerity', where public spending has been very substantially reduced in pursuit of deficit reduction; alongside an ideological commitment to reducing the size of the state. In Europe the single market, with its ruthless enforcement of 'open borders', has resulted in the rise of EU citizens migrating and the social disruption caused by deregulation, privatisation and post-2008 continent-wide austerity cuts. Inequality has increased, as have numbers of children in poverty. According to Department for Work and Pensions (DWP) figures quoted by the Child Poverty Action Group, there were 3.9 million children living in poverty in the UK in 2014-15, amounting to $28 \%$ of all children in the UK. No amount of focus on efficiency savings, partnership working and smart delivery should be allowed to disguise the fact that the loss of skilled workers, the closure of facilities and cutbacks to services including the destruction of local government in any recognisable form have been leading to a major crisis of local provision. At a time when austerity, insecurity and racism remain real threats to the lives of many people in the UK, austerity as defined by the difficult economic conditions created by government reductions in expenditure links directly to cuts in health and social care budgets. Such conditions have become an evermore trans-formative characteristic of public services. 'Austerity is not a short-term disruption to balance the books. It is the demolition of the Welfare State. We are not 'all in this together' and it's time for a re-think on the fundamental parameters around which our society is based' asserts Kerry-Anne Mendoza (2015). As a defining era of Welfare State development, 2010 marked the end of 13 years of New Labour Governments. Coming into government in the wake of the economic crash of the mid-2000s and in the middle of a recession, the Government introduced stringent austerity measures including some of the largest cuts in public finance ever seen, and some of the most extensive welfare reforms since the introduction of the Welfare State (see TaylorGooby and Stoker, 2011; Beatty and Fothergill, 2013; Lambie-Mumford, 2015). 


\section{Is de-professionalisation due to service cutbacks? Is it part of the neo- liberal extension of 'markets' agenda?}

Interrogating 'cuts to services' as socially and politically contentious places the notion of de-professionalisation at the heart of assessing the impact of the commercial model within the NHS. Effects on staff being able to fulfil their role to a high professional level have been evidenced from the NHS Ombudsman, Dame Julie Mellor who reported that inadequate staff numbers become responsible for a 'wall of silence' on causes of death in hospitals. Three quarters of hospital complaint investigations revealed that where patients suffered avoidable injury or death, there was a failure to identify serious deficiencies in care, leaving distraught families in the dark (Campbell, 2015a). Mellor said hospitals' inquiries into serious injuries or deaths too often failed to gather enough evidence owing to staff neglect, were inconsistent in how they looked for proof of error, and did not look closely enough at materials to see what went wrong. She blamed - but did not excuse- cuts in staffing for a failure to uphold service standards. Similarly cutbacks in NHS hospitals demonstrated that they are so full that patients are discharged too soon and the continued split between health and social care is tantamount to "political mal-administration', according to a House of Commons Public Administration and Constitutional Affairs Select Committee Report published in September 2015. This report asserted that the failure to join up health and social care services means that one in five patients are at risk of either getting stuck in hospital or being released before they are fit to go home creating so-called 'bed-blocking' which costs the NHS in England about $£ 820 \mathrm{~m}$ a year (National Audit Office [NAO], 2014). The Committee was responding to earlier revelations by the NHS Ombudsman that patients sent home too soon, were at risk of being readmitted as emergencies or even of dying, and that a lack of social care was often behind the delay in the discharge of medically fit patients.

Where are the deeper impacts of 'cuts to services' within health, social care and education? How have these cuts helped to downsize professional service-inputs in the form of efficiencies, pay cuts, rationing, reducing training and staff development, all of which potentially affect overall economic productivity? Pointing to examples of reported incapacity to deliver along with variations in overall standards nationwide has become a media-driven way of highlighting ineffectiveness (Kitzinger, 2000; Butler and Drakeford, 2005). For example we rely on migrant medical staff in our NHS because we have not trained sufficient numbers of our own young people. People have perhaps become manipulated by EU policy where the winners have been big business (a ready supply of cheap labour) and government (lower costs in terms of training doctors and nurses). Political will is needed to properly resource the NHS which is constantly described as being under pressure and under-funded; however it is a political choice that much of this situation results directly from the private finance initiative (PFI). PFI was first initiated by the Conservative Government of 
the late 1990s and enthusiastically endorsed by New Labour as a means of raising private finance to fund government projects such as hospitals, nursing homes, police stations and prison services. According to Department of Health estimates over 700 contracts had been signed by the end of February 2016. The concept is very much like taking out a fully serviced mortgage, where not only the interest is repaid but also the upkeep and maintenance. The total national cost of the PFI over the next 35 years has been estimated at $£ 300 \mathrm{bn}$, or nearly $£ 4,000$ per household.

There is a widespread belief that the sizeable cuts stemming from political tinkering and extension of 'markets' have destroyed Aneurin Bevan's original NHS principles of a safe, comprehensive, publicly funded, publicly delivered and publicly accountable integrated health care system (Campbell, 2015b; Dixon, 2015). What are some of the effects of the commercialised model forced on the NHS by the Coalition's Health and Social Care Act 2012? It is perhaps inevitable that outsourcing responsibility has the effect of reducing paid hours but not the workload, reducing wages, or employing under-qualified staff. The aim of the present Conservative Government would seem to offer a pledge to continue further reform and achieve a '7-day NHS' by 2020, promising to recruit 5,000 more GPs and 11,000 new staff in order to achieve this.

Yet probably the real story has always been the financial squeeze on the public sector to reduce the fiscal deficit by 2020-21. It has been reported that 'thousands of hospital beds are set to disappear, pregnant women will face long trips to give birth and a string of A\&E units will be closed or downgraded' (Campbell and Bawden, 2016) as part of controversial plans to reorganise the delivery of healthcare in England. Publication of the forty-four regional plans has demonstrated 'an unprecedented centralisation of key hospital services' as a result of the Conservative Government's Sustainability and Transformation Plans (STP), which are at the heart of the new NHS funding package. The thinking behind the changes is that some NHS services can be rationalised and managed more efficiently, helping to improve patient care, tackle understaffing and working towards the NHS's target of making $£ 22 \mathrm{bn}$ in savings by 2020. The NHS Chief Executive Officer Simon Stevens has made several bold speeches, focusing on the Government's national Five Year Forward View delivery plan, to promise a brave new NHS world by 2020 through 'integrated organisations'. This will involve dissolving the split between commissioners and providers of health and social care, and by introducing new models of care, accountable care organisations and innovative STPs.

\section{De-professionalisation as evidenced throughout health, social care and education}

'Cuts to services' in health, social care and education have embodied deprofessionalisation in ways which have been associated with reducing the number, 
type and range of 'professional' staff employed, for example fewer qualified teachers employed in free schools, more use made of teaching assistants; also more health support workers as opposed to fully trained nurses employed in both 'hospital' and 'community' settings (Siddique, 2015). The impact of service cuts has borne an inevitable effect of reducing professional influence, for example by curtailing LA responsibilities in relation to child protection, children in need, care leavers and disabled children through the Children and Social Work Bill 2016 which introduces a fast-track process for the removal of many duties seen as significant to the formal rights of children, young people and families (see later section: 'Politicians Critique Social Work Training'). Professional influence can be removed further following a children's social care policy objective which places greater reliance on the need to strengthen capacity for developing Local Authority adoption services and which uses new enhanced powers of an Ofsted inspection regime to regulate child and adult care homes. This model of working appears to value disproportionately the idea of having in post an 'effective manager' far more than any results achieved from the one-to -one intervention of single professionals.

There is ample evidence that 'cuts to services' have been shaped by an ideological adherence to managerialism methods (see for example, Rogowski, 2016). For instance, throughout the UK university sector it has become a ubiquitous credo to employ more 'managers' who promote and defend the 'vision' of a university, and who focus for example on the need for 'cultural change', 'consumer focus', 'value for money' along with 'efficiency and effectiveness'. And such individuals often become more valued, in an institutional context, in terms of their overall contribution than those undertaking the 'bread and butter' academic tasks of teaching, research and income generation. In schools throughout the UK the framework provided by GSCE results as an analogue for school standards may exist as a poor measure for reflecting what a good education should provide. Arguably a more creative, less managerial approach would advocate a less narrow, more challenging curriculum with a broader range of objectives - intellectual, social, creative and moral reflecting the whole range of student achievement. A mismatching occurs where there may be individuals who are incentivised towards achieving high skills but whose livelihoods depend on working within the public services arena.

De-professionalisation attributes arising as a consequence of managerialism have become evident in the process of carrying out legal aid work, an activity protected now only for the 'highest priority cases' and which uses increasingly paralegal staff rather than social welfare lawyers. A priority case is defined as 'where there is a risk of serious physical harm or loss of home, or where children may be removed from a family' (Howard, 2016 ). Within local authority child protection services it is clear that partly due to the number of Sure Start children's centre closures there has been a soaring number of children being removed from their families and placed in care. Department for Education figures have showed that the number of closures has risen every year since 2010. Sure Start children's centres give help and 
advice on child and family health, parenting, money, training and employment; also they provide early learning and full day care for pre-school children. Such figures indicate that there were no children's centre closures in 2010, 12 in 2011, 27 in 2012, 33 in 2013, 85 in 2014 and 156 in 2015. With the right to private and family life being enshrined in the Human Rights Act it has meant that the use of section 20 of the Children Act 1989 (voluntary arrangements to protect children) has resulted in an increasing number of actions brought against local authorities under the Human Rights Act 1998. The outcome has been rising levels of damages awards causing greater risk aversion, increasing care applications and draining local authority budgets of scarce resources that ought to be going into early help, family support and preventive work. The removal of all public funding for private family law proceedings must be part of this problem as is the extended use of paralegals, trained in subsidiary legal matters but not fully-qualified as lawyers. They are being deployed to provide a 'quick-fix' solution to demonstrate an under-reported $£ 2$ bn financial saving (Graham Cole Chair, Lawyers in local Government Child Care lawyers Group 30.11.2016) ignoring both the short- and long-term social costs. It is unsurprising therefore that when vulnerable families in difficulties cannot access professional legal advice and representation, their situation deteriorates and children are put at risk.

The UK educational landscape has witnessed a slow growth of school academy trusts, who are at liberty to employ people to teach with as many or as few qualifications as the new 'executive heads' deem fit so long as such individuals have the 'right skills'. As their business model demands 'innovation and creativity' continually finding ways to cut costs and save money, as the supply from central government is reduced, employing fewer teachers on lower salaries and employing more poorly paid teaching assistants becomes likely. It has been authentically reported that all schools across England will suffer steep budget cuts up to 2020 despite the Conservative Government's new 'fair funding', according to an analysis released by teaching unions including the National Association of Head Teachers (NAHT) and the National Union of Teachers (Adams, 2017). This study suggests that $98 \%$ of schools face a real-terms reduction in funding by 2019, with an average loss for each primary pupil of $£ 339$ and $£ 477$ for every secondary pupil. The funding formula redistributes funds between urban and more rural schools, a post-code lottery in effect, where in some areas the Department for Education data found an average loss of $£ 655$ for every pupil by 2019-2020, some even higher - up to $£ 834$ in real terms. The result is that heads have been forced to cut staff, cut the curriculum and cut specialist support; in addition to overcrowded classrooms and teaching assistants not being replaced.

According to published DfE figures almost a third of teachers who began teaching in 2010 have quit the classroom within five years of qualifying. Of the 21, 400 teachers who began their teaching careers in English state schools in 2010, $30 \%$ had quit by 2015. A joint report by the National Union of Teachers (NUT) and 
the Association of Teachers and Lecturers (ATL) concluded that staffing problems mean schools are relying on supply teacher agencies and teachers covering roles outside their specialism; also that the quality of provision is being lowered, with growing teacher workload being blamed for the flight from the profession (Weale, 2016). This undermining of the integrity of the teaching profession has been accompanied by transformative managerial changes to schools following the introduction of single academies. Such school academies form a bedrock of Government policy, along with grammar schools; and continue to be set up and are largely unaccountable. This represents a pursuit of the neo-liberal model which seemingly fails to respect adequately the democratic wishes of voters by taking away local authority control, thereby emasculating the notion of the public sphere. Putting schools in the hands of others mainly with business interests and as a replacement for parent governors may allow such schools to indulge their own prejudices as long as high test scores are achieved. It may not be the case however that a public service ethos vanishes entirely as there remains ample evidence that, where school governance and leadership are strong, such 'independent' features strengthen 'community interest' as for example, many schools

buy excellent HR, financial and school improvement advice ... [and] are able to call on the support of a network of experienced, expert advisers. (Rustin, 2016)

This 'market ideology' bridges the huge commercial costs and can cause chaos, endangering the quality and safety of health care, as a direct result of ongoing NHS fragmentation and privatisation. Government initiatives such as PFI are now seen as having been wasteful as they are run for private profit and accumulate huge public debt, NHS services and assets, including blood supplies, nurses and other care professionals, scanning and diagnostic services, ambulances, care homes, hospital beds and buildings - which the British public own - are being handed over to UK and foreign private companies. Privatised services cost the NHS and taxpayer far more than when provided by our publicly owned and publicly run NHS. That is because public health systems don't need to pay dividends to shareholders, don't have the added costs of private sector loans, and don't have privatisation's heavy and unnecessary marketising costs of contracts, billings and all the extra administration involved (see for example, Demello and Furseth, 2016; Greer, Wismar and Figueras, 2016 ; Klein, 2006).

One example of the impact of 'cuts' - and its association with a deprofessionalisation critique - is the notion that UK community and social services could not cope with more hospital discharges at week-ends, and that there is mounting evidence that fewer fully qualified professional staff are employed to work outside hospitals and that there is a shortfall. This represents a diminution in the number of district nurses, CPNs, care workers; and NHS data show that the number of GPs in England rose only by just 108 in 2015 despite the Conservative 
Government's high profile pledge to expand the family doctor workforce by 5 , 000 by 2020 (Clay, 2016). There were 4l, 985 GPs in September 2016 compared with 41,877 in the same month of the previous year. The rising costs of providing healthcare in coming decades could force ministers to increase the proportion of GDP going into health from the $6.9 \%$ expected in $2020-21$ to $12.6 \%$ by $2066-67$. That $12.6 \%$ would equate to about $£ 228 \mathrm{bn}$ in today's prices, according to the Office of Budget Responsibility (OBR). The 2\% reduction in GDP funding imposed on the NHS by the Conservative Government since 2010 has given rise to reports that there are now people on hospital trolleys waiting for a bed who are not the worried well accused of blocking up Accident and Emergency Departments (A\&E) but individuals who have already been assessed as needing beds. These beds are full not just because people cannot be moved out of hospital but because the number of hospital beds has been steadily reduced over the last 20 or more years, so that the UK now has 2.8 beds per 1, 000 of population, compared with 8.6 in Germany and 6.2 in France. The OBR prediction is that the NHS's budget will need to increase by $£ 88$ bn over the next 50 years to keep pace with the rising demand for healthcare.

As a society we may appear to be becoming more tolerant of poor standards in for instance delivering adult social care and mental health services. People who are fit for medical discharge are waiting for social care packages and there has been a $£ 4$.6bn cut in social care funding between 2010 and 2016. Lowly- trained care workers are sometimes paid below the minimum wage and examples have been reported of companies paying for 'live-in' care at under $£ 4$ per hour - that is the company pays only for the actual care-giving time and not for being 'on call' and availability in the domiciliary setting (Brindle, 2015) According to some recent research, 'flying 15-minute undignified care visits' are still being commissioned by 18 English councils (Leonard Cheshire Disability Organisation, 2016). Cuts to care of the elderly are now taking A \& E to a 'tipping point' according to England's care regulator. A report by the Care Quality Commission (CQC) showed that hospitals were ending up dangerously full, and have seen 'bed blocking' hit record levels, because of a widespread failure to give elderly people enough support to keep them healthy at home. A worsening lack of both at-home care services and beds in care homes was described as forcing hospitals to admit more patients as emergencies and deepening their already serious financial problems.

'The difficulties in adult social care are already affecting hospitals. Bed occupancy rates exceeded 91\% in January to March 2016, the highest quarterly rate for at least six years. And in 2015/16 we saw an increase in the number of people having to wait to be discharged from hospital, in part due to a lack of suitable care options'. (CQC Report State Of Care October 2016).

The former Conservative Health Secretary Stephen Dorrell stated that the government's policy of giving social care less and less money was 'insane economics 
and bad social policy' and undermined its claim to be backing the NHS. The CQC disclosed in the same report that about 800,000 patients were registered with a GP practice that its inspectors judged to be 'inadequate' on safety grounds. Such safety failings included poor management of medicines, inappropriately trained staff and premises that were unsuitable.

A further report published around the same time by Age UK bemoaned the fact that annually thousands of older people end up in hospital with potentially lifethreatening infections because GPs and other community-based NHS services do too little to keep them well (Age UK, 2016). Integration apparently will not solve this problem as, it has been concluded, that little will be gained from pooling resources between secondary and primary care (quoted from Simon Stevens NHS Chief Executive in an article by Felix Clay 'NHS boss calls for new deal to care for the old', The Guardian, 2016). Combining this cost with that of social care it has been shown that the UK spends far less overall, on both social care and healthcare, as a percentage of GDP; $9.4 \%$ in 2010, the highest ever, falling to $9.1 \%$ in 2011 and 2013. This is in stark contrast to the US at $17.1 \%$, less than France at $11.6 \%$ and less than the financially prudent Germans at 11.3\%. Appearing before the Health Select Committee in January 2017 Simon Stevens argued that the NHS had fewer medics, beds and scanners per head than other countries in Europe and contradicted the suggestion that NHS spending was in line with the average for OECD countries, which he said included nations such as Mexico. Between 1980 and 2013 the UK has on average spent only $6.9 \%$ of GDP on health and social care representing the lowest spender of the world's 21 richest countries (Pritchard, 2016). Social care funded by local councils has experienced an overall budget cut of 40\% since 2010 and continues to be under severe pressure.

A continual dispute has reigned over the actual depth of the cuts, particularly as regards health and social care, The above Age UK report claimed that $£ 470$ million is equivalent to the expected fall in the social care budget by the end of 2016. However the Department of Health has disputed this claim but Age UK goes on to state that the social care budget has shrunk by $£ 1.85$ billion over the last decade. The Local Government Association, Kings Fund health Think Tank and Age UK together have consistently been critical of the 2\% levy on council tax as unlikely to raise the sums required asserting that this is no substitute for central government funding for such key care. Simon Stevens, appointed as Chief Executive Officer to the NHS, has urged political parties pre-2020 to find 'a settled and durable new political consensus' on social care funding (Clay, 2016) having identified that around 185, 000 hospital beds had been lost because a lack of social care prevented patients being discharged, up 70\% since 2012. In England it is estimated that roughly two-fifths of care homes' residents are private, with another two-fifths funded by the state. The remaining residents include those who pay fees but are topped up by local authorities and residents who are funded by the NHS. Some local authorities are paying just $£ 330$ a week for residents, the equivalent 
of less than $£ 2$ per hour. Industry research has shown that private residents now pay $40 \%$ more on average than publicly funded residents for like-for-like service (Kelly, 2015).

It is widely recognised that there is under-funding of social care for both care homes and home care. (Chief Executive of one of UK's largest Care Home suppliers)

\section{More emphasis on parenting and alternative types of intervention as a form of social policy in place of professional services}

The Conservative Government's 'life chances strategy', intended to focus on supporting children during the early years and improving parenting, was expected to be published within 2016, acknowledging that parenting support programmes have become a growing feature of changes to service direction and a substitute for other professional services. It has emerged since that, with a change of Prime Minister, the DWP is to drop this important strategy in favour of a wider scheme on social justice to be outlined in a Government Green Paper in early 2017. The outlined intention is to focus not just on the very poor but also on Teresa May's favoured demographic - the 'just about managing' households. A major plank of the strategy will be about addressing joblessness in families, as part of how the Government views effective parenting, and which it believes would be the biggest step towards improving social mobility for children (Mason, 2016).

The philosophical or theoretical underpinnings of parenting support as a policy field serves to reveal its dominant professional orientation, becoming 'either a benign project of support or part of a more controlling educative or retraining exercise' (Daly, 2015 pp. 597-608). Some countries tend to regard parenting support as the province of 'professionals'. For example in the Netherlands parenting support is delivered by pedagogues and/or people trained in social work or youth work. However the degree of professionalisation of parenting support is less in England, especially because parenting programmes, which can be delivered by people with relatively little training, have been so predominant there (ibid, pp.602-603). Parenting classes had been advocated by then Prime Minister, David Cameron who suggested that all parents should be offered them as a measure to help alleviate child poverty, often replacing professionals who may currently provide family support.

Parenting support is multi-dimensional and has capacity to play host to varying objectives. Daly and Bray (2015, pp. 633-644) argue that it has become a popular policy solution as it has the advantage of being relatively easily generalisable especially in the form of programmes, and aligns with current developments of the welfare state, towards activation, provision of support through services and an interest in localism.

To take the case of the Coalition (and Conservative) Government's Troubled 
Families Programme (TFP), the content and form of parenting support offered varied considerably. Local authorities across England were enlisted to deliver the programme which, although it carried no new legislation or statutory guidance, was expected to be delivered using a 'family intervention' approach. This approach advocates using a single key worker who can 'grip' the family, their problems and the surrounding agencies' (DCLG, 2012, p.18) to work with them in a 'persistent, assertive and challenging' (DCLG, 2012, p.23) way which will encourage them to take responsibility for their behaviour and change their ways. These workers are expected to be 'dedicated to the family' and able to 'look at the family from the inside out, to understand its dynamics as a whole; and to offer practical help and support' (DCLG, 2012, p.4). Where families did not engage with the programme, workers were encouraged by the government to, in some circumstances ask 'other agencies to accelerate threat of a sanction to exert maximum pressure on families to change' (DCLG, 2012:28). The TFP then, was positioned as a central government programme that would not only 'sort out ' troublesome families, but would also 'sort out' the public services that were currently working with the families (Crossley and Lambert, 2017). Troubled Families were officially defined as those who met three of the four following criteria: (i) are involved in youth crime or anti-social behaviour; (ii) have children who are regularly truanting or not in school; (iii) have an adult on out of work benefits; (iv) cause high costs to the taxpayer (DCLG, 2012:9).

At the time of launching the TFP the then Prime Minister David Cameron said that he wanted to put 'rocket boosters' under plans to 'turn around' the lives of the country's 'most troubled families'; and to underline the importance of strong parenting in preventing the kind of social problems that had led to riots in London and elsewhere. As for the variation in parenting support, at one end there was intensive home-visiting encompassing a range of types of engagement and goals for example, outreach and carrying out assessments where the home becomes the locus of intervention. At the other end of the scale was a much looser befriending of parents, often by lay volunteers (Casey, 2014; Crossley, 2016: 127-146). Also the Programme represented a consummate critique by the Conservative Government of the efficacy of social work as a profession, its values and its status as an organised group of workers advocating on behalf of children and families. The approach of using 'key workers' remains in keeping with the wide body of literature on the role of street-level bureaucrats (Lipsky, 1980) which includes other 'helping professionals' such as youth workers, teachers and police officers, in negotiating, resisting and adapting national policies for the citizens on the receiving end. However it became acknowledged in an unpublished Whitehall report (see Savage and Wright, 2016) that the TFP, as an interconnected government-controlled intervention as part of an 'underclass' discourse to tackle entrenched social problems to date had no discernible effect on unemployment, truancy or criminality. The proven ineffectiveness of this Programme appears alongside an oversight of cuts to benefits, soaring levels of food bank use and lower funding for all public services. 
Cuts to the number of permanent staff employed in children's services seem significant as is an effort to close some children's homes as part of a strategy to get more children cared for by foster families (O'Carroll and Halliday, 2016; Perraudin, 2016; Weale, 2016). Although social work services may be core to the field of parenting support a recent report has claimed that around $85 \%$ of sexually abused young people are not receiving help and treatment; and that only 1 in 8 child abuse victims ever come forward (Quinn, 2015). 50, 000 equals the number of cases of Child Sexual Abuse recorded in the 2 years to March 2014, the real figure could be up to 450,000, and the "police service has been dealing with the tip of the iceberg' (Office of the Children's Commissioner [OCC], 2014). This Report called for a strengthening of the responsibilities of those working with children, to ensure that professional bodies work together more effectively to identify problems and implement a 'whole-school approach to child protection' where all staff can identify the signs and symptoms of abuse. There has been a dramatic increase in the number of newborns subject to care proceedings as the level of services offered to help parents keep their children has dwindled. The quality and consistency of services that parents receive has been severely criticised as this seems dependent on wherever they are living, revealing territorial injustices in the Ofsted ratings of Local Authorities (Stein, 2015).

The issue of resorting to an increased use of foster carers has characterised current policy and the de-professionalisation question emerges when it becomes legitimate to ask: should foster carers be treated as 'professionals' and receive a fee for their service given the public demand for a high level of life-experience, knowledge and skill on the part of those providing foster care for children? The term 'foster carer' in the UK has replaced the term 'foster parent', in order to signal that this is a professional role (Ribbens-McCarthy and Edwards 2011, p.18). Debate continues as to whether foster carers are employed principally as substitute parents or as paid professionals with a legal status. 'Specialist fostering' involving for example groups of older /younger children, own race and transracial placements, and the viewing of foster carers as professionals opened new dimensions to the practice of foster care. For instance the structure and organisation of the services became important for the recruitment, training, deployment and retention of carers, yet there has been a paucity of formal research around this subject, particularly relating to its outcomes. The evolutionary history of adoption and fostering has been one of overlaps, leading sometimes to ambiguities and confusion about purpose, expectations, roles and relationships (see for example Triseliotis, 1997, pp.331-336). The early 1970s witnessed a form of fostering used either to divert children from institutions or to get them out of there and place them with families. The philosophy that informed it was associated with the notions of community care and normalization that were new at the time (see for example, Malin, Manthorpe, Race and Wilmot 1999; also Wolfensberger, 1972 and 1998). Besides viewing specialist fostering as being for the most troubled and troublesome children, its other key features were its 
contractual nature, time-limited with an average of two years; the payment of a fee to foster carers; the training and preparation of carers; the preparation of children before placement; and the provision of post-placement support to foster carers and children alike (Triseliotis, ibid, p.332 ). Over the years there have been unresolved issues about the role fostering should play in spite of signs of a slow drift towards professionalisation. It was reported that the number of those fostering in England remained roughly constant for 25 years at around 32, 000 (Triseliotis, 1995) but recent evidence shows that there has been a marked increase to between 45, 000 to 55,000 by 2016 (Bawden, 2016).

\section{Re-balancing the ratio of professionals to non-professionals delivering public services?}

De-professionalisation arises from a necessary re-balancing of workforce budgets as more health support workers are being employed by NHS England proportionate to professionally trained nurses (Catton, 2015; Campbell, 2015c). 'Bed-blocking' currently costs between $£ 800$ and $£ 900$ million annually (RCN, 2015; Campbell, 2015d) indicating that many chronically ill patients remain in hospital unnecessarily. While it is certainly possible to deliver 'better value' for the $£ 120 \mathrm{bn}$ spent on the English NHS, it will fall short of the $£ 22 \mathrm{bn}$ in 'productivity improvements' on which NHS CEO Simon Stevens' Five Year Forward View - and the Conservative Government's funding calculations - are based (Ham, 2016). The Government's decision in 2011 to withdraw its entire general grant to local authorities by 2020 will affect vulnerable groups most of all for example, older people and providing support to children and young people in care, leaving 'hundreds of thousands of elderly people without the care and support they need to live independently' (Meikle, 2016).

Nine out of ten hospital trusts are reported as having deficits from which they can't escape... [the Health Secretary] has never confronted NHS under-funding and now a threatening 'reset' letter has been sent (to all trusts) where fines will be imposed on those in debt. [This letter] warns that trusts will also lose 30\% of promised funds if they fail $\mathrm{A} \& \mathrm{E}$, cancer and operation waiting times, with a cap on hiring staff or temps. (Toynbee, 2016)

The need to employ large numbers of 'temporary' and more expensive agency nurses to care for those who remain in hospital unnecessarily has resulted in ballooning financial deficits in hospital budgets. Employment agencies charge exorbitant fees and official figures show that the $£ 2.72 \mathrm{bn}$ spent on agency and contract staff in the financial year 2015-2016 was £1bn more than planned. Most hospitals now have an increased reliance on temporary staff including locums because of personnel shortages: £4bn spent on agency staff (2015) compared to 
$£ 2.6 b n$ (2013-2014) and £3.4bn (2014) (McVeigh, 2016). Private companies appear to be being awarded huge health contracts at an ever-increasing rate.

The impact of restricted professional advocacy on behalf of youth services, including Connexions, and women's refuge services has likely contributed to difficult outcomes they currently face as both have felt the effect of severe cuts (Brignall, 2016). A survey by UNISON of 180 local authorities that provide youth services in the UK estimates that cuts in youth service spending, including that spent on staff, between April 2010 and May 2016 stand at $£ 387$ million, questioning the current rise in knife crime among young people and both the rise and huge disparity in youth unemployment that has occurred across the UK, for example $18.3 \%$ in 2015 in the north-east region. Other services that have come to rely more on volunteers and 'non-professional' staff as a result of unwelcome financial cuts include women's refuges which have been put at risk by benefit changes. For example it has been claimed that $17 \%$ have been shut down over the last five years and two-thirds are facing closure because of a change in the way that housing benefit is paid to supported and sheltered housing (Gayle, 2016). Professionals familiar with legislation and how the system works are urged to challenge this failure to exempt refuges from the reform. There was an intention to cap the amount of rent that housing benefit will cover in the social sector at the same level offered to private landlords in the same area. Nevertheless the Department of Work and Pensions (DWP) has concluded that a deferral of the reforms until 2018 would give women's refuges a period of grace while officials conduct a review into funding for the supported housing sector.

Other schemes reportedly have elected to employ 'a dedicated practitioner' in preference to a social work professional in order that they may 'work differently' but one suspects that at chief reason may be to cut corners over financial arrangements and/or to absorb staff more conveniently into the 'managerial model'. This has been the approach adopted by for example the Pause pilot project which is a national scheme to reduce pregnancy, mental health problems and drug addiction and designed to 'step into the lives of women made fragile by layers of accumulated anguish'; and to work intensively alongside them for 18 months on the practical and emotional challenges they face (Tickle, 2017). It is alleged that some prisons, for example those run by G4S, have set about reducing the number of higher paid, experienced, senior professionals to replace them with cheaper officers in order to make such prisons profit-making since their take-over in 2011. Similarly there has been both privatisation of the probation service and political attacks made on this 'social' service by a number of home and justice secretaries. Evidence has since been released that this service had not been failing and that many of its problems were the consequence of government mismanagement and misguided target-setting, rather than internal incompetence. According to Professor Mike Nellis:

'There were, back in 2014, a cohort of managers and officers perfectly capable of 
delivering an effective probation service, although many have now left their broken and demoralised profession, However the community rehabilitation companies that took over the probation trusts have been short-changed (as)..the Ministry of Justice overestimated the numbers they would get to supervise in order to attract their business .... "Payment by results" is a fiasco and the companies cannot afford to keep their third-sector partners on board'.

\section{Is de-professionalisation associated with 'under-performing' services?}

The headline 'hospitals under-performing due to a lack of health care professionals' was quoted from evidence following Care Quality Commission (CQC) inspections placing some hospitals in special measures, for example Addenbrookes's Hospital in Cambridge, where the CQC Report highlighted 'serious concerns' (Campbell, 2015e). These included a significant shortage of staff in a number of key areas, including critical care; staff having been moved from ward to ward to cover gaps in rotas, even though some lacked the necessary training, [and] too few midwives, coupled with a high use of agency and bank staff.

This form of what amounted to hospital 'blacklisting' may cause damage by contamination to the reputation of individual professional staff employed there albeit undeserved. The CQC Report suggests the need for an 'improvement director' but in the confusion it is not clear what exactly merits 'inadequate' patient care or indeed 'special measures'.

Previously a scandal in the UK that occurred in the mid-2000s in the Stafford hospital run by the Mid Staffordshire NHS Foundation Trust concerned the level of poor quality health care and brought to the fore this notion of 'under-performing services' due largely to staff malpractice. The main recommendations of the Francis Report (2013) which followed included:

- Foster a common culture shared by all in the service of putting the patient first

- Develop a set of fundamental standards, easily understood and accepted by patients, the public and healthcare staff, the breach of which should not be tolerated

- Provide professionally endorsed and evidence-based means of compliance with these fundamental standards which can be understood and adopted by the staff who have to provide the service

- Ensure openness, transparency and candour throughout the system about matters of concern

- Make all those who provide care for patients - individuals and organisationsproperly accountable for what they do and to ensure that the public is protected from those not fit to provide such a service

- $\quad$ Provide for a proper degree of accountability for senior managers and leaders 
to place all with responsibility for protecting the interests of patients on a level playing field

- Enhance the recruitment, education, training and support of all the key contributors to the provision of healthcare, but in particular those in nursing and leadership positions, to integrate the essential shared values of the common culture into everything they do

By mid-2016 it was reported that the tough inspection regime for hospitals introduced to prevent a repeat of the Mid Staffordshire care scandal had been relaxed as the NHS regulator adjusted to budget cuts brought in by the Secretary of State for Health. The CQC now will undertake 'fewer and smaller inspections of hospitals in England and rely more on information provided by patients and NHS trusts under a new five-year strategy' (Campbell and Johnson, 2016).. This change will likely see a rolling-back of the in-depth approach to assessing the quality and safety of hospital services since the Mid Staffordshire Report, which has evidenced scores of CQC inspectors spending up to a week examining how hospitals operate. As part of the new CQC strategy inspectors will be expected to concentrate on core services, such as A\&E and critical care, and no longer examine in detail how a wide range of departments are doing.

The CQC admitted it was having to scale back and rethink because it will be receiving 'fewer resources' - £32million less by 2019 than the £249million it currently receives from the Department of Health. The likely result is that fewer inspections will be carried out, hence more corner-cutting in staffing resource. This is saddening in a situation where CQC rates just $1 \%$ of care homes as outstanding and $40 \%$ as either requiring improvement or inadequate (Quinn, 2016). A later report from NHS England (NHS England, 2016) which examined a range of data and attributed new ratings claimed that almost nine in 10 NHS groups are failing cancer patients with low rates of diagnosis and treatment.

The fact that so many clinical commissioning groups (CCGs) in England have been identified as providing inadequate care to cancer patients through delayed diagnosis, first treatments and referrals is very concerning... The data shows that of 209 CCGs only 22 have been 'performing well', for example in the last 2 years the target to start treatment (for cancer) within 62 days has only been met once, with 2, 000 cancer patients now waiting longer to start treatment' (ibid, 2016)

The argument for 'under-performing services' is supported by evidence from the Social Mobility Commission in relationship to two-year olds not having their health and education needs routinely reviewed by a professional:

Despite this being a crucial period for families, there is still too little support for parents in the earliest stage of their child's life. With the socio-economic gap in 
outcomes emerging early, providing support to parents at this point could reap divisions for social mobility later on in life. (Social Mobility Commission, 2016)

This Report indicated that the number of full-time equivalent health visitors in England fell by 1, 000 in one year between 2015-2016, with the result that one in four babies born in the UK was not receiving mandatory checkups from health visitors during their first two years. This 'cuts to services' lens highlights a process of de-professionalisation through a reduction in service standards as a result of depleted staff numbers. A separate report on a hospital whose A\&E unit was threatened with closure on safety grounds admitted that four patients died after errors by staff in the emergency department and other areas. The Department of Health said the deaths showed that the North Middlesex hospital, which was described as seriously understaffed, had to urgently improve its quality of care (Campbell, 2016a).

The Royal College of Nursing stated in response that across England hospitals are feeling the strain of financial pressures and increased demand

beds being placed in corridors and patients treated in storerooms in order to move people out of A\&E...frail and elderly being moved around in the middle of the night and ambulances queuing outside A\&Es. (Whitehead, 2016)

A number of 'serious incidents' were uncovered according to a report by the Care Quality Commission into Brighton and Sussex University Hospitals NHS Trust (CQC, 2016) including so-called 'never events' where surgeons operated on the wrong part of patients' bodies and where it was suggested that not enough staff were available to ensure that patients were receiving safe care. Similarly a CQC Report on Winterbourne View (Flynn, 2012; Department of Health, 2012 ) which faced heavy criticism for poor quality care stressed the need for a 'bespoke commissioner' to ensure service delivery. This recommendation offered a 'managerialist' response counterintuitive to what the overwhelming body of evidence had demonstrated, that is a need to hire more professionally-trained care staff. In 2015 the Department of Health appeared to be asking all hospitals to draw up plans to reduce staff numbers in the wake of future Treasury cuts (Walker, Stewart and Taylor, 2016) prompting the RCN to respond that patients will suffer without the right number of skilled and experienced front-line staff in place. The cost-cutting 'sustainability and transformation plans' (STPs) announced in late 2016 were stated by NHS chiefs as intended to plug funding gaps and to provide a more regionally, coordinated approach to deliver health and social care. The tough inspection regime for hospitals introduced to prevent a repeat of the mid-Staffordshire care scandal has now been relaxed as the NHS regulator adjusts to budget cuts brought in by the Secretary of State for Health.

The Care Quality Commission NHS England has vowed to transform mental 
health services with an extra £lbn a year although there have since been some doubts that this sum is being ring-fenced (Quinn and Campbell, 2016). The present Conservative Government along with the previous Coalition have presided over the decimation of mental health services -'a car crash' according to Professor Sue Bailey, former president of the Royal College of Psychiatrists (Allan, 2017). The rise and rise of mental illness in the UK coupled with government cuts to mental health services have resulted in a balkanised system, divided and lacking integration, which cannot cope with current demands. Between 2010 and 2015, it has been reported that, funding for Child and Adolescent Mental Health Services (CAMHS) has been slashed by $\mathrm{f50million,} \mathrm{despite} \mathrm{massively} \mathrm{increasing} \mathrm{demand}$ (Orr, 2016). Furthermore Department of Health figures indicate that the number of mental health nurses working in the NHS has dropped by almost a sixth since the Conservatives came to power in 2010. While there were 45, 384 mental health nurses working in England in 2010, there were just 38, 774 in July 2016. According to Janet Davies, the RCN's Chief Executive:

'This represents a worrying downward trend that shows no sign of turning around, despite repeated Government pledges about equality for mental health care compared to physical health care. The loss of so many posts meant patients were at risk of receiving poorer care and of their recovery being jeopardised by having less time with trained nurses. Without the right number of nurses, people cannot get the care and treatment they need.'

The Government's national plan has a number of targets, for example people facing a mental health crisis will be able to get community care such as 'psychological treatments' 24 hours a day. Each area should have a multi-agency suicide prevention plan yet local plans are not specifically required to recruit additional trained professional staff for example, nurses, social workers.

We would like to ensure that every GP practice has easy access to trained mental health workers who can deliver therapies such as cognitive behavioural therapies. (Secretary of State in preamble to the Department of Health Mental Health Plan, 2016).

This objective has been expressed however as an aspiration rather than as part of a costed strategy guaranteeing a range of effective support to individuals. In reality with an ever increasing workload assigned to community teams and an inadequate number of skilled, qualified professionals to provide expert assistance, unpaid carers - whose contribution to the NHS is estimated annually at well over $£ 100$ bn by Carers UK - find themselves acting as 'lay' occupational therapists, psychologists, psychiatrists as they struggle to understand the complex symptoms and behaviour associated with such illnesses. Without this support there would be a permanent demand for the shrinking supply of mental health beds (see Needham and Glasby, 2014). 


\section{De-professionalisation, cuts in the number of fully-trained teachers and social inequalities?}

The de-professionalisation agenda can be highlighted further through 'cuts to services' experienced in many schools across the UK. Ensuring that low-income communities have access to high quality teaching places more responsibilities on schools to solve society's ills. As we shy away from family policy and dismantle elements of the social work system a greater onus becomes placed on schools and granting them institutional autonomy. A Labour Party view expressed by Tristam Hunt, Shadow Education spokesperson before the 2015 election, was that the Conservative Government had created a 'schools can-fix it narrative' where labour market changes, housing problems and catchment areas appear to have been ignored (Hunt, 2016). The Harvard sociologist, Robert Putnam echoes similar sentiments:

Schools work as part of a much broader social ecology of churches, clubs, sports leagues and work placements. A rich network of civic capital - used to be - offered to our kids trusting interactions with non-parental adults that socialised them and ensured failure did not have to be fatal... development of character, resilience and grit, family structure and economic inequality are main factors in inequalities. (Putnam, 2015, pp.135-190)

Funding for schools education in England has continued to drop in real terms as it fails to match increased need from a fast-growing population of school-age children. In particular cuts to school support include mental health services and specialist teacher input for children and young people with special needs (Weale, 2015). Instead relentless forced academisation and the burgeoning of free schools, unaccountable locally and of hugely variable quality, show that some employ no qualified staff (Millar, 2016), There are several reasons why there's a teacher shortage in schools, for example supply teaching is currently dominated by costcutting private supply agencies that pay up to $£ 60$ a day less than the national rates, often with zero paid into a teacher's pension scheme. Agencies send in teachers who may lack professional development opportunities, and possess few if any professional rights such as inhouse training. 'We need to re-professionalise the teaching profession' asserts Conservative Government Minister, Nick Boles inferring that some aspects of professionalism are failing to become valued and recognised (Lightfoot, 2016).

It has long been demonstrated that the best in-school predictor of long-term outcomes is the quality of teaching, for instance grammar schools are less likely or unlikely to employ untrained teachers. All the obsession with structures, with grammar schools and secondary moderns and so on would appear a complete red herring; instead it is the quality of teaching that matters, hence inequalities emerge from schools operating with untrained staff, asserts Government spokesperson on 
social mobility, Alan Milburn (Weale, 2016). The majority of supply teachers are aged 50 plus, with many close to retirement. In view of the fact that their experience and professionalism are not recognised, many appear to have voted with their feet and have left teaching. One conclusion is that there isn't a shortage of teachers as such, for instance in March 2010 the Coalition Government acknowledged that 404, 600 qualified teachers were not working in state schools. Private supply agencies cream off anywhere between one third and one half of the funding that schools pay for supply ensuring high profits to employment agencies. All that agencies may do is make a telephone call, a simple administrative task not requiring training.. Little if any ongoing professional development is provided for supply teachers (Knights, 2015).

\section{Summary}

\section{The austerity agenda}

Deficit reduction links to cuts in health and social care budgets.

Is de-professionaliation due to service cutbacks? Is it part of the neo-liberal extension of 'markets' agenda?

The argument that de-professionalisation is at the heart of assessing the impact of the 'commercial model' in the form of efficiencies, pay cuts, rationing, reducing training/staff development and potentially affecting overall economic productivity

\section{De-professionalisation as evidenced throughout health, social care and education}

Reducing the number, type and range of professional staff employed particularly within community and social services, for example more health support workers, poorly-paid care workers, more teaching assistants

Emphasis on 'professional displacement' - parenting classes in favour of family support services

Academies prefer to employ those with the 'right skills'

\section{More emphasis on parenting as a social policy in place of professional services}

Government's 'life-chances strategy' to emphasise supporting children during early years

Parenting support programmes/parenting classes

'Troubled Families' initiative to prevent 'social problems': assessment of parents, befriending of parents, setting targets/goals etc and to focus on unemployment, truancy and criminality

Increase the number of foster carers 


\section{Re-balancing the ratio of professionals to non-professionals delivering public services}

Evidence indicates employment of high numbers of temporary, expensive agency nurses

Some hospitals rely on temporary staff, for example 'bed-blocking' uses more health support workers

Women's refuges, youth services rely more on volunteers or non-professionals

\section{Is de-professionalisation associated with 'under-performing 'services?}

CQC reports show that some hospitals are under-performing due to a lack of health care professionals

Some 'professionals' lack the necessary training, for example for critical care, longterm and chronic illness such as Alzheimer's Disease

High use of agency and bank staff

'Blacklisting' destroys reputation of hospital and all staff working in it

Rolling back of rigorous inspectorate following Francis Report, 2013

De-professionalisation leads to a reduction in service standards due to fewer staff in post; higher number of serious incidents, deaths not gone properly reported; current plans to reduce numbers of staff to meet budget requirements

'Transforming Mental Health Services' (2016): no additional trained professional staff such as nurses or social workers; only ensure access to mental health workers who can deliver therapies (CBT); no overall costed plan; a further onus on unpaid carers

\section{De-professionalisation, cuts in the number of fully-trained teachers and identifying possible links to social inequalities}

Conservative Government's 'schools-can-fix-it' narrative impacts on distribution of social welfare support

Cuts to mental health services and specialist teacher input, for example young people with special needs

Preponderance of supply-teaching dominated by increased number of cost-cutting private agencies

Minister calls for 're-professionalising' of the teaching profession

It is the quality of the teaching that matters most and inequalities are perpetuated from schools operating with untrained staff 


\section{Section D. Case Study: The Strike by Junior Doctors}

To take an example of the lengthy strike action in NHS England led by junior doctors throughout 2016 and remaining still unresolved de-professionalisation exists as a metaphor to caricature in media representation both the action and its response, as follows:

1. The strike action has been viewed through the lens of 'cuts to services', for instance by the use of arguments that the new contract for a 7-day NHS will mean over-stretched services, and will affect patient safety deleteriously which contravenes values and ethics of medical professionals

2. Both the action and confrontations between junior doctors and the Conservative Government have had a demoralising personal impact on 'doctors as professionals' in carrying out their existing duties;

3. Junior doctors may have become scapegoated through government and/or management failings arising out of the operation of the internal market which elects to spend large sums on 'governance' - procurement and competitive bidding, inspectorates, performance measurement - rather than clinical and diagnostic expertise

4. The image of junior doctors has been negatively encapsulated following reporting of BMA negotiations as 'politically motivated' or 'politically expedient' - as opposed to 'principled' action - which is 'sometimes incompetent', primarily seen to be about status and pay and resulting in a potential loss of public trust.

\section{Professionals tarnished by conflict: The '7-day NHS' and the 'imposed contract'}

The politicisation of NHS service cuts has evolved around the continuing drama of alleged service deficiency or shortage associated with a series of strikes led by junior doctors creating a confrontation with the Conservative Government over an 'imposed new contract'. Much of the reported narrative of this dispute has been rooted in the fact that there will be threats to existing services - doctors argue that proposed 'reforms' equals patient safety compromise, loss of earnings and cuts to services, whereas the Conservative Government asserts that staff need to re-organise in order to get medical cover in NHS hospitals on to a more cost-effective footing and thereby fulfil a party manifesto promise to achieve delivery of a '7-day NHS'. Prior to the 2-day unprecedented strike which included emergency services (April 26th-27th 2016) the British Medical Association (BMA) claimed that junior doctors would be considering strike action indefinitely, a mass resignation, the possibility of junior doctors seeking alternative employment; recommending that trainees pursue 
careers outside medicine; along with unspecified 'alternative forms of permanent action' (Campbell and Siddique, 2016).

The Department of Health continued to respond in a virile manner by accusing the BMA of risking patients' safety in the campaign. Ben Gummer, Health Minister said:

This is evidence of an organisation in total disarray and the action proposed shows a regrettable disregard for patient care....for the JDC (junior doctors committee) this dispute is now clearly political, which makes it all the worse that by their actions the BMA are putting patients in harm's way.

For the junior doctors it would seem that a precondition of meeting with ministers is for the notion of an 'imposed contract' to be dropped, claiming that no patients will be at risk as senior consultants will provide full cover during strike periods. It has been their overwhelming view that senior figures in the medical profession shall 'stand up' to the Government because the dispute is a 'key battleground' in the service's future (Sparrow, 2016). An alternative perspective is one suggesting that it has been the doctors themselves who have failed to live up to the demands of their profession and that they are letting their profession down with their actions. "When someone is paid a high salary, that comes with the responsibilities of a profession' (Secretary of State for Health Press Release, March 2016).

'So demoralised, so alienated and so angry' are the junior doctors, remarked Nick Robinson (BBC Radio 4 Today Programme April, 26th 2016) 'that they are willing to walk-off the job, their reaction may be neither proportionate or appropriate, but is reminiscent of the miners' strike of 1980s in which the Government refused to back down.' The argument goes that if the Government lets the doctors win then others similarly dissatisfied will go out on strike, for example fire-workers, teachers and lecturers who were balloting for strike action at the same time. Ministers seem to fear that capitulation to British Medical Association (BMA) demands to change the terms and conditions that England's 45, 000 junior doctors work under from August 2016 might encourage other public sector trade unions (Elgot and Campbell, 2016; Clarke, 2016). The Government's 'utopian' plan for a 7-day NHS would require existing doctors to work longer hours - 'doomed to failure owing to a lack of doctors, finance and diagnostic -testing services' warns Prof Jane Dacre, leader of England's hospital doctors. 'Worsening shortages of NHS medics, and the inadequacy of support services vital to allow patients to be discharged mean the promise is unrealistic, especially with the NHS's $£ 2$ billion deficit' (Campbell, 2015f).

The affront to the medical profession is demonstrated by the fact that the Conservative Government tries to introduce a 7-day NHS without properly defining what it means by this. The existing position is that an unbroken emergency service is provided by various grades of NHS staff, including both consultants and junior doctors, who work unsocial hours, often staying on well beyond the ends of their 
shifts. In January and February 2016 the country saw the first walkouts since November 1975 as many of the NHS's 45, 000 junior doctors - defined as medics below the level of consultant - go on strike.

Figures released by NHS England showed that, on April 26th, 2016, 21, 608 junior doctors $-78 \%$ of those due to work - participated in the industrial action. It was stated that this was down from the $88 \%$ who did so on each day during the previous strike from 6-8 April. Such an unresolved dispute around junior doctor contracts of imposing unsafe hours inevitably distracts from the perceptible crisis in the NHS - around 'cuts to services' - including the overall lack of doctors. A possible perception is that de-professionalisation is a cover or compromise of the doctors' relationship with the public, for example by carrying out strike action which underminines trust and ultimately impacts on how doctors are viewed by the public. A GP registrar states:

'This is the saddest day of my professional life. The strike is now wholly unfortunate, regrettable and damaging. I would like to hope that all parties wish it had never come to this. No one will come out of it well. I don't support withholding emergency care. I don't think that it directly causes harm, or affects safety, but it affects our relationship with the people we serve. Our profession has to have trust with the society we serve at its heart, and while I agree there is a longer term view in all-out striking, for me a line is crossed'.

Studies of the effects of doctors strikes have shown that they can be made safe with appropriate safeguards, as their roles will be taken over by consultants, fully trained and the most experienced doctors. Is the Secretary of State stating that the consultant workforce is not up to the task? (Gani, 2015). Much reporting of the doctors' strike in the media has described it as a 48-hour withdrawal of emergency care by junior doctors, however the withdrawal has been between the hours of $8 \mathrm{am}$ and $5 \mathrm{pm}$. On those days the clinical care of patients and the emergency provision through A\&E was, to all intents and purposes, provided by consultants. It could be argued that the medical care would be of at least the standard usually provided, or even a higher standard since, by definition consultants have more experience than junior doctors. What will suffer, it has been claimed, is administration work, meetings and routine planned outpatient care where normally these are provided by junior doctors.

\section{Cooperation not confrontation: harm is one thing but are patients getting the best possible treatment?}

One obvious effect however is that the growing confrontation has left junior doctors feeling devalued, a further signifier of de-professionalisation. The initial ballot for strike action in January 2016 suggested that the proposed changes would lead to 
a limited service, poor conditions and long hours, and cuts in pay for week-end antisocial hours, resulting possibly in an overall indictment of their professionalism. For junior doctors safety has been declared to be the main issue as they are expected to work longer hours given staff shortages. 'Each one needs to work 1-3 hours extra daily because of staffing problems and under-staffing' (Toynbee, 2015). 'Overtime' payments have to be fought for and are only paid when hours exceed 87 hours per week. The Government wants them to work more nights and week-ends. From the perspective of some junior doctors and consultants the Conservative Government continues to refuse to negotiate and it appears that this has become a personal issue for the Secretary of State which he seems intent on winning irrespective of the effect it has on the public. Doctors claim that the British Medical Association (BMA) has been painted as a militant body trying to bring the Government down. Whatever the eventual outcome to date this dispute has represented a prime example of a 'leftright' confrontation between a professional narrative, for example a determination to provide a high quality service to patients and the public and the Government's public sector market reform narrative which includes asset-stripping, with a barely hidden agenda of handing hospitals over to corporate interests. This is mirrored by a scenario whereby ministers have become seemingly indifferent to reasonable grievance among public sector workers, seeing trade unions as guardians of a mediocre and financially unsustainable status quo.

In its unpublished risk assessment of the seven-day policy in August 2016, the Department of Health's own working group admitted that workforce overload means that it may simply not be possible to find sufficient 'skilled/trained staff' to safely deliver the new service; and that '[the plan's] objectives are not fully agreed upon' (Siddique, 2016). The BMA added that the documents relating to a '7-day NHS' showed that there was still a painful lack of detail. Also senior officials at the Department of Health feared that the '7-day NHS' might fail to deliver its stated aims, which include improving the quality of hospital care at weekends and reducing death-rates among those admitted for treatment as an emergency on Saturday or Sunday; and worried that Britain's decision to leave the European Union (EU) might affect 'the plan' because the NHS employs 55, 000 staff from around the EU. Soon after it was reported that some services are to be cut as part of wide-ranging national efficiency plans. For example some children's A \& E services would be closed as they lack the 'bespoke skills required' and fail to meet the quality guidelines established following the Francis Report of the Mid Staffordshire NHS Trust (2013). A newlyappointed Chair of the Royal College of GPs, Dr Helen Stokes-Lampard, warned that surgeries would have to stop seeing patients at some points during the week unless the Government abandons its 'unrealistic' drive to guarantee access to family doctors across the weekend. Her report suggested that a relentless rise in demand is prompting more GPs to retire early or move abroad leaving the profession facing a growing workforce crisis and patients with long waits for appointments. This conclusion casts grave doubt on the ability of the Government to fulfil another key 
election pledge - to increase the number of GPs in England by 5, 000 between 2015 and 2020 (Campbell, 2016b).

In August 2016 the BMA announced a new wave of strikes by junior doctors in England over their contract, beginning with an unprecedented five-day walkout in September followed by similar five-day walkouts in the ensuing months up until the end of the year. Hospitals began to make contingency plans for strikes each month, but admitted to having had little notice to prepare. The BMA stated that it had made repeated attempts over the past two months to work constructively with the Conservative government to address the outstanding areas of concern, including the impact on those junior doctors not working full-time, a majority of whom are women, and on those working the most week-ends, typically in specialities where there is already a shortage of doctors. There now seems to be evidence of a growing frustration across the NHS that this employment dispute has not been resolved effectively, particularly bearing in mind that there has not been any unanimous support for taking strike action among BMA members. Junior doctors have been advised consistently by the General Medical Council that they should call off their five-day strikes and that putting patients at risk of significant harm could lead to them being struck off. This statement was issued to doctors under the authority of the 1983 Medical Act suggesting that doctors could face sanctions if they acted unprofessionally.

Given the scale and nature of what is proposed, we believe patients will suffer. (GMC's Chief Executive)

The Patients Association also expressed concern over the strike action, saying it was 'gravely troubled' at the 'catastrophic impact this will have on so many patients' as Winter approaches. The head of the NHS, Simon Stevens has repeatedly asked the BMA to call off its series of planned week-long strikes, warning that hospitals cannot cope without 50,000 junior doctors and that seriously ill patients will be put at risk. However BMA leaders appear to be continuing to back the walkouts partly because they want to avoid junior doctors breaking away and forming their own union (Campbell, 2016c). In a scenario characterised by murky and messy industrial relations there arises a lack of cooperation and instead confrontation, where the junior doctors eventually may lose some public support. In this instance the argument for de-professionalisation resonates where a major part of the workforce continues to withdraw its labour and the quality of service therefore must become affected. In September 2016 the Conservative Health Secretary, Jeremy Hunt claimed to be surprised at the need for continued strike action and accused the BMA and junior doctors of 'playing politics', describing their response as 'disproportionate' given that they appeared to have accepted the new contract back in May. In turn doctors claimed that they are 'demoralised' and that their trade union has been 'demonised'; yet the dispute seems to have become intractable as 
both sides continue to claim that it all the other side's fault. Speaking on the BBC's Radio 4 Today programme in October 2016 the BMA's representative Dr Mark Porter stated that 'it is now time to address the real issues of demoralisation and alienation that doctors face today'.

We fundamentally do not think it's necessary to change the junior doctors' contract... it's time to give up the incrementalist approach of changing work practices as new overall funding is needed. (another BMA representative)

[The dispute] is not about the new contract, it's about pay. (BBC journalist)

Genuine efforts to resolve the dispute through talks have been met with an unwillingness to engage and, at times, deafening silence from the secretary of state, leaving junior doctors with no choice but to take further action. The government has consistently said this is about creating a 7-day NHS, when junior doctors already work weekends and it's been shown that the government has no answer to how it will staff and fund extra weekend care. This contract will be in place for many years, it will have a direct impact on patient care and whether we can attract and keep enough doctors in the NHS. (Junior doctors' committee chair)

\section{Summary}

\section{Professionals tarnished by conflict; the '7-day NHS' and the 'imposed contract'}

Action has been viewed through a lens of cuts to services, for example the claim that a new 7-day contract will mean overstretched services, affecting patient safety Confrontation between junior doctors trade union (BMA) and government have had a demoralising personal impact on 'doctors as professionals'

Claim that junior doctors have become scapegoated through government/ management failings arising out of the operation of the internal market, for example governance arrangements

Image of junior doctors negatively perpetuated as 'politically motivated' or 'politically expedient' - as opposed to 'principled action'

De-professionalisation represents a cover or compromise of the doctors' relationship with the public by carrying out strike action which undermines trust and ultimately impacts on how they are viewed by the public

\section{Cooperation not confrontation: Harm is one thing but are patients getting the best possible treatment?}

Workforce overload means that it may simply not be possible to find sufficient 'skilled/trained staff' to safely deliver the new service; and that there is also a lack of consensus over 'reform' objectives 
Junior doctors complain of 'incompetence' by their trade union introducing a further split with calls to set up an alternative organisation to represent trainee doctors Managers warn that hospitals cannot cope without the support of junior doctors De-professionalisation resonates where a major part of the workforce continues to withdraw its labour and the quality of service therefore must become affected

\section{Section E. Reviewing the evidence: De-professionalisation as defined both by financial cuts to staff training and by critiquing models of current training}

\section{A perfect realisation of the unrealised, profoundly compromised}

There is a view that service delivery in health and social care sectors in England currently relies far too much on the commitment of inadequately-trained staff given the depleted nature of social and community care provision and that this is due to financial pressures (Glasby and Daly, 2014, pp. 277-297). Both in modern health and social care and for instance in law enforcement, related occupations require highly sophisticated skills based on advanced levels of education; and restricting training opportunities inevitably leads to an individual's incapacity to cope with growing job demands. 'There is more to contemporary nursing than wiping bottoms with a smile, and to policing than cracking miners' skull' (Dingwall, Guardian Letters 10th May, 2016). Today's nurses need the knowledge and skills to carry out complex technical and behavioural assessments and interventions. Police are dealing with cyber crime and the immense subtleties of terrorism and sexual abuse. Neither occupation can now be practised with a training based on hanging out with experienced practitioners, picking up tips, tricks and manoeuvres. That inflexible model just perpetuates poor habits and bad science. 'Graduate jobs' are not fixed for all time but evolve with the rest of the society and economy

\section{Reduced funding support to staff training}

There has however been a noticeable withdrawal of local authority, hospital trust and inhouse funding support for higher-level, clinical and specialist training. Most professions now recognise that learning and professional development are lifelong to be acquired with the aid of Continuing Professional Development programmes (CPD). Led by the Royal College of Nursing, the British Medical Association, the Royal College of General Practitioners and the Patients Association, a coalition of more than 20 charities, medical and professional bodies and trade unions released 
an open letter to the PM David Cameron in June 2016 saying that moves to drop funding for student nurses and midwives represented an 'untested gamble'. The proposals included dropping bursaries to support nurses during their training and switching them to student loans. The claim was that this may risk reducing the supply of future nurses, midwives and other health workers when they are desperately needed. Previously training for nurses had been treated differently to other higher and further education courses precisely to help revert the shortages. The organisations highlighted the "worrying lack of clarity or consultation about the effect that funding changes could have on those who need to train for more advanced or specialist roles, such as health visitors or district nurses.' (RCN letter led by professional bodies, 2016)

This warning came as an RCN survey pointed to a dramatic fall in the number of school nurses, with almost a third working unpaid overtime every day to keep up with their workload. The RCN stated that its research showed the number of school nursing posts had fallen by $10 \%$ since 2010, leaving 2, 700 school nurses now caring for more than nine million pupils, despite a rising incidence in issues, especially in mental health among children. More than two-thirds (68\%) of those surveyed stated that there were insufficient school nursing services in their area to provide the support that children and young people need, $70 \%$ stated that their work-load was too heavy, and $28 \%$ worked over their contracted hours on a daily basis. More than a third (39\%) said they had insufficient resources - including specialist training - to do their jobs effectively (McVeigh, 2016). Contemporary UK research conducted by the Alzheimer's Society revealed that only four in ten home care workers had specialist dementia training in spite of government promises that all staff would be specialist trained by 2018 (Alzheimer's Society, 2016). This study found that poor-quality home care was leaving many people spending the day in soiled clothing, going without food or water, and ending up in hospital. But inadequate care was not confined to home care as an allied study demonstrated that only a third of councils had enough nursing homes with specialist dementia support; and that less than $40 \%$ of care home staff in the UK are trained to deal with the challenging behaviour often displayed by residents with dementia.

Cuts to public sector provision and cuts to training budgets present a threatening back-drop to economic growth. Skilled graduates are increasingly in demand from employers, and the UK universities are working harder than ever to ensure graduates in every discipline pick up a range of skills useful to employers. The skills that higher education provides - the ability to think critically and to analyse and present evidence - aim to be lifelong and will be increasingly in demand as the number of high-skilled jobs increases. The UK Commission for Employment and Skills predicts that, between 2012 and 2022, some 2 million additional jobs are projected for occupations such as managers, professionals and associate professionals (Dandridge, 2016). A counterfactual argument has indicated that the UK government is being urged to end the political drive to get 
more people into university as there has been research to show that graduates in the UK are 'colonising' jobs in banking, education, the police and estate agency that were the preserve of school leavers in the past. This study has indicated that more than half of graduates take non-graduate jobs and has provided evidence that the number of newly-employed teaching assistants with a degree increased from $5.6 \%$ to $36.9 \%$ since 1979 (C.I.P.D, 2016).

\section{De-professionalisation as a feature of a market-led 'model' of delivery: What works?}

De-professionalisation as the impact of events or a process may be demonstrated through the trajectory of a political economy 'model' of delivering public services; where for example education policy has been progressively shaped by the needs or demands of a market economy. It asks whether spending on education or training is influenced by the needs and demands of business and industry, for example to improve literacy and numeracy or the use of new technologies. It aims to cut employers' costs, and leads to the gradual 'marketisation' of all services. Such a 'model' comes close to the theory of 'elite control', where for instance the NHS is largely the product of conflict and power struggles between a political and a medical elite and arguably will remain so in the light of policy changes brought about by the Health and Social Care Act 2012 (see for example Greer, Wismar and Figueras 2016, pp. 3-26). This is because the political economy 'model' suggests that most major policy decisions are subject to the backing of 'big business' or capitalist interests. This perspective falls in line with Marxist views of class-structured society in which a ruling class controls policy and makes most of, if not all, the big decisions (Blakemore, Warwick-Booth, 2013, p.165); and provides a raison-d'être for selecting the type of education and training found within both the public and private sectors of the economy.

As regards the social work profession, Tunstill (2016) asserts that 'there is a new and dangerously comprehensive quality to the current scope of [training] proposals under debate in the UK which makes them almost invulnerable to evidence-based critique, let alone revision' and goes on to describe a political party consensus about new contested developments, such as the introduction of an elite social work training route, Front Line (largely independent of the UK university sector). In excess of $£ 100$ million of extra funding has been given for fast-track training to expand the successful Frontline and Step Up schemes to help attract top-calibre graduates into social work. So that by 2018 one in four children's social workers will be qualifying in this way; and up to $£ 20$ million will be provided for a new What Works Centre to disseminate best practice (Taylor, 2016). This is intended as a new assessment and accreditation system for children's social workers, will be fully implemented by 2020 and replace the present Social Care Institute of Excellence (SCIE). The alleged 
target is to accredit around 27, 000 social workers for England. The General Social Care Council (GSCC) has been closed by the Conservative Government, transferring regulation to the Health and Care Professions Council (HCPC). The objective of singling out training opportunities for social workers working with children may contribute to disunity within the social work profession where for example, work with single adults and families is seen as of lesser importance due to the lower amounts of staff training resources allocated (Brindle, 2016).

At the local political level, the Conservative Government continues methodically to pursue the dismantling of local education departments, a move which whilst facilitating the contested schools academisation process, will, coincidentally expedite the continued outsourcing of all services for children and families. (Tunstill, 2016)

\section{The contentious issue of establishing 'appropriate training' for working in children's services}

There has been a significant drive to recruit trust sponsors from the charity and private sector to help develop innovative children's services. The allegation is that the Conservative Government's long-term strategy is for all schools and children's provision to be taken over eventually by 'high -performing' local authorities and 'teams of experts' and to give 'academy-style freedoms' to such high -performing local authorities (Taylor, 2016). Highly qualified graduates from 'good universities' are to be taught by academics 'in good universities' defined as having 'a strong academic reputation in social work theory and practice' so that social workers learn from the best practice in the country (Brindle, 2016; Murray, 2015). There is now an almost compulsory requirement of local authorities to buy in franchised packages, like 'Signs of Safety' and 'Attachment Measuring' packages with large sums haemorrhaging out of local authorities to buy this 'effectively privatised knowledge' (Tunstill, 2016). Some social workers may come to view this as a threat to the integrity of existing training programmes which have been validated and overseen by the profession's own association and which have shaped their own professional lives.

Perhaps an unintended consequence of the previous Labour Government's introduction of children's services departments has been the subsequent overshadowing of children's social care by the school system, often a poor selective relation to a more appealing universal system. A consequence has been perceptions of a relative neglect of the workforce in the area of under-5s childcare. 'The (Conservative Government's) flagship childcare policies, for example Sure Start Children's Centres are fragmented, uneven and are failing to deliver for families in poverty' quoting from a report authored by the Family and Child Care Trust (FACT) (JRF, 2016). This report places a good part of the blame on 'the poorly qualified inadequate workforce' and calls for 'a better qualified early years workforce to be 
paid in line with school staff, who earn 68\% more' (ibid, 2016). The tone of this Conservative Government's policies towards children seems to have less emphasis on offering training to professional staff and more on offering training to both natural and substitute parents.

The issue of poor evidence-gathering, case mismanagement and the need for professionals to challenge information arose in a Serious Case Review (SCR) conducted on behalf of Gloucestershire Council Children's Services into the circumstances that led to a boy being taken to hospital with bruising, fractured ribs and a perforated intestine (Tickle, 2016). This SCR concluded a 'complete lack of a child focus practice' and identified poor assessment practices along with the inexperience of both social work and medical professionals involved. A related report from Rotherham council said that it hopes to put the past behind it as it prepares to agree a new strategy that aims to 'put children at the heart of everything it does' (O'Carroll and Halliday, 2016). This self-proclaimed 'child-centred borough' has promised closure of two of its three children's homes along with greater provision and training of foster families.

As for the early years workforce parents have seen fees go up after a big fall in the number of childminder places, where there is now a greater use of untrained childminders. In a recent report from a Labour think-tank (Weale, 2016) the claim is that there are now 10,000 fewer qualified childminders and 23,000 fewer places provided by childminders in England and that costs have risen by 27\% since 2010. Among the issues contributing to the dwindling numbers has been the decline in the support and training that childminders receive from local authorities, hence an onus is now on childminders identifying suitable training and funding it themselves in order to compete effectively in the market-place.

\section{Politicians critique social work training}

The current Children and Social Work Bill, if it is passed, will enable local authorities to remove statutory protections from the most vulnerable children in custody and in care. Privatisation seems to pass for innovation. Considering the professional credentials of social work, Isobel Trowler, one of the two Conservative Government-appointed Chief Social Workers, is advising on how to implement a preferred definition of the social work task, through a Knowledge and Skills Statement (KSS). Trowler herself is a key promoter of the Bill and has co-founded Morning Lane, a private company working with a large number of local authorities (KPMG, which partners Morning Lane, has been awarded in 2016 a £2million government contract). Considerable disquiet has been publicly expressed by a range of social work organisations, including BASW, at the narrowness of the requirements of the KSS, and its focus on a narrow aspect of statutory social work activity. The Government recently set up 'independent reviews' of aspects of professional social 
work training in order to explore whether it may be 'ideally structured' to best serve the profession, namely Re-visioning Social Work Education (Croisdale-Appleby, 2014) and Making the Education of Social Workers Consistently Effective (Narey, 2014).

A predominant view of the Conservative Government has been that something urgent needs to be done about social work education, in particular as regards defining its outcomes. In Croisdale-Appleby's report he argues that the outcomes of social work education need to be expressed in a new way which reflects this thinking, namely: the social worker as a practitioner, the social worker as a professional and the social worker as a social scientist. He introduced these ideas by asserting that:

social work education is an extraordinarily complex subject because it draws upon a wide range of other academic disciplines, and synthesises from those disciplines its own chosen set of beliefs, precepts, ideologies, doctrines and authority ...

He proceeded to infer serious ambiguities set around social work theory concluding with a statement that 'social work education requires theory-informingpractice and practice-informing -theory to be inexorably linked.' Such statements might not be seen as contentious yet have contributed to creating an atmosphere around defining 'outcomes of social work education' which could place many practitioners on the defensive.

The Education Secretary who led the commissioning of these inquiries into social work education, Michael Gove, expressed a strong concern about 'raising the quality of social workers', along with their education and training, within children's social care services in response to the high number of children, around 600,000, in a single year - 2011/2012 - being referred to Local Authority services. Specifically Sir Martin Narey's Report was asked to consider the adequacy of education and training in equipping social workers with the capability of 'leading the assessment of the needs of these children and to make sure effective action is taken quickly to protect them from harm'; also that his recommendations should ensure that their education and training '[should] allow [social workers] to exercise their professional judgement in the best interests of vulnerable children'. Both reports focused on the need to separate out the initial qualification - readiness to engage in practice - from updating, for example Continuing Professional Development (CPD). Whereas such reviews may be welcomed for their intention to strengthen the training received by the profession their immediate effect may have been quite destabilising, leading some practitioners to question whether they have been adequately prepared for practice at this moment in time.

In the context of services for children and families there has long been considerable political and professional consensus as to the positive value of evidence-based policy and practice. When it comes to social work, the most significant development as far as children and families are concerned was the establishment of the Munro Review (2011) in the wake of the Baby Peter tragedy. 
It pointed out previous reforms led to too much bureaucracy, this hindering practitioners' ability to focus on the needs of children. Instead, it argued for the reduction in centrally imposed targets and bureaucracy with social workers being given more scope to exercise professional judgement. Paradoxically it recommended more 'determined and robust' management to achieve this even though determined and robust managerialism had led to social work's crisis (Rogowski, 2016, p.31). A leading academic in this field writes:

Over three decades, the children and families research community has enjoyed a respected high profile with its outputs, broadly deemed, by policy-makers, service providers as well as service users, to provide a legitimate source of data for informing service design and delivery. The 1989 Children Act is a respected example. The current Children and Social Work Bill, which (now) goes to the Lords for Report Stage however raises a number of serious challenges to this credibility...including that child protection services may be privatised. (Jane Tunstill blog 17/10/016 'A Pilot is a Pilot? Researchers and the Children and Social Work Bill')

There would appear to be an undermining of professional social work training in terms of sustaining their legitimate advocacy role in family support decisions. Tunstill claims that clauses 29-33 of the legislative bill establish a fast-track process for area-by-area derogation of children's social care legislation, and this issue has generated serious concern and robust opposition among professionals who work with children, young people and families, families themselves, and non-governmental organisations. In opposition to the changes being levied against social work education (and, as a consequence, displacement by a body of training emanating from the private sector) an argument has emerged towards highlighting the absence of any evidence-base for the hypothesis that current statutory requirements impede effective social work with children and families. It follows that, given the emphasis of the derogation clauses Bill on the importance of 'trialling new ways of working', there may be a particularly pressing need for researchers to analyse and interrogate the Children and Social Work bill from their specific perspective as methodology experts. The DfE is said to be promoting 'innovative plans to test out deregulation' - including how local authorities test deregulatory approaches to measuring the impact of training programmes. Within this context there remains a degree of general scepticism attached to understanding the 'outcomes' of social work training on the part of some civil servants and those in authority.

\section{Reviewing the viability and completeness of current training for health care professionals}

Critiquing the basic direction of training as a component of de-professionalisation 
applies similarly within health care where we have only to point to the high number of national and local reviews of nurse and paramedical training over the last 40 years since the 'political economy model' of delivering public services has taken hold (see for example DHSS, 1972; DHSS, 1986; DoH, 1988; Jay, 1979; Nursing and Midwifery Council UK, 2010, 2015). Perhaps this has been less so in the case of the medical profession which has customarily had greater autonomy. As to the current Conservative Government's requirement to deliver a '7- day NHS' there is a policy imperative to hire no only more junior doctors and consultants, but also $A \& E$ nurses and ancillary staff like radiographers and pharmacists to work at the week-end. However this would contravene a different remit within the NHS to cease recruiting health-care professionals from developing countries. A recent report has indicated a policy of hiring Indian GPs to plug gaps in services as professional staff shortages everywhere are grievous (Campbell, 2016d). The Royal College of GPs warned that doctors from outside the EU could not be 'parachuted' into the NHS without first undergoing proper training and assessment,

'These doctors are not trained to be GPs in the UK. Their training is entirely different. I have concerns for the doctors' safety and the patients' safety.' (Chair of British International Doctors Association).

The Conservative Government announced at its annual 2016 party conference a commitment to train an extra 1,500 doctors per year by 2025 representing an increase of $25 \%$ from 6, 000 to 7, 500 per annum in order that the country does not have to rely on doctors from overseas. The alleged aim would be for the NHS to be self-sufficient in doctors and that all trained doctors would be required to work for the NHS following graduation for a minimum of four years. How dependent is an English hospital on foreign doctors? It is said that about one third of hospital doctors did their training abroad but, as stated by the NHS Federation, the organisation has a significant shortage of practising doctors. There is broad evidence that it is difficult to recruit in areas such as radiology and intensive care medicine (Campbell, 2015g). In A\&E most doctors recruited have been based in the UK, although they may have been trained abroad and the UK is 'under-doctored' compared to other western European countries. The convention is for doctors to go abroad to develop their training and in reality they would expect the same freedoms as other professional workers and therefore not want to be prevented from going abroad immediately after training, according to BMA sources who state that 'lifting the cap' on the overall number of doctors being trained would be a good thing.

What about our reliance on overseas nurses and cuts to the number of UK nurses in training? More than 55, 000 EU nationals work as doctors and nurses in a health service that would collapse without them, argues journalist Polly Toynbee (2016). The reason we need so many foreign nurses is that after 2010, the number of UK nurse training places was cut, with the gap filled from abroad. In 2015 Health 
Education England was training 3, 100 fewer nurses than a decade ago - a 19\% cut. Add to that the attrition rate: only $60 \%$ of the newly-trained enter the NHS, as the long-enforced $1 \%$ pay cap means they can earn more in other occupations. Furthermore the Government has removed nursing bursaries with the intention of widening access to nurse training, whilst at the same time blocking visas to nonEU nurses. The immigration bill going through the UK Parliament will 'fine' the NHS for recruiting nurses from outside the EU and European Economic Area, and thereby will fix skills shortages. The stated intention of the charge is to encourage both private and public employers to train British- born staff and to use the money collected to train 3 million apprentices by 2020, but nurses and teachers are outside the apprenticeship scheme. The Government regulates their training and has not launched any major effort to increase the number of British recruits entering training or employment, or to retain existing staff (Mulholland, 2015).

The planned abolition in 2017 of bursaries for nurses in training means that, like other students, they will have to take out loans and accumulate large debts. The Department of Health claims that this would allow universities to create some 10, 000 more training places: currently they are turning away 37, 000 applicants, according to available Universities UK figures. But there is a fear that instead new trainees will be deterred.

'I worry about the older ones, as a third of our trainees are healthcare assistants who train up for a full nursing qualification. They have to give up their pay while they train as it is, and they will be reluctant to take on debts as well when they have families and high living costs in this area. Those with experience are the most valuable and we can't afford to lose them.' (Chief Nurse of a major English hospital)

There have been reported deep cuts - up to $45 \%$ - in nurses' post-registration specialist training signifying that closure of courses will create acute shortages in specialisms, such as A\&E, intensive care, diabetes and cancer and palliative nursing. Whereas we may be witnessing an NHS scenario where there are trained foreign nurses prepared to work for less than professional-style wages, this is not consistent with occupying a professional role and responsibilities.

The health and social care system is not only struggling to meet the care needs of our ageing population, it is completely unprepared for the consequences of looking after growing numbers of older people with extremely complex health problems (Lowton, 2016). Specialist health and social care services, currently in short supply on a national scale, along with a need for more knowledge and skills training for both professionals and carers are unable to respond to the increased demand and increasing complexity that, for example adult mental health conditions such as depression and anxiety will bring.

'I think the key difficulty for providing proper health services for these 'new' ageing 
populations in adulthood is that our definition of success in this context is so focused on the short-term. The current crisis in the NHS reflects our concerns about patients' immediate care needs rather than considering what our health and social care services will also require in the future in order to care for patients. We are unwilling or, perhaps, incapable - due to our parliamentary cycles and the current government's ethos of austerity - of looking ahead to see what type of support, intervention and care these 'new' ageing populations will need, and how we, as a society, can provide it.' (quotation from Professor Karen Lowton in an article by Amelia Hill, January 25th 2017)

This not only taps into the austerity agenda given that local councils are unable to fund the increased demand from older people requiring the highest levels of care, and where evidence shows that this number has risen by $50 \%$ in the last five years in some authorities, but also underlines the high value placed on social care services in terms of how a responsible government needs to act. Given that the rate is repeated over the next five years and that further funding would be required, national solidarity suggests that the health care demands of ageing populations are regarded as of major importance and therefore receive the kind of broad vision and diverse expertise that only well-resourced professionals are able to provide. In following a laid-down strategy most Chief Executive Officers (CEOs) now prefer to support interventions based on delivering a multi-disciplinary, flexible approach to health and social care; and which offer opportunities for deploying a range of staff acting in differing roles. As an example of inter-professional working the focus then would be on a 'trans-disciplinary approach' (Lacey, 2001) where sharing or transferring information and skills across traditional boundaries enables one, two or more members to be primary workers supported by others working as consultants. There is some evidence that this type of solution has been applied pragmatically during the junior doctors strike action when health professionals from several disciplines have 'stood in' to fill the gap left by doctors' absences (Campbell, 2016)e.

As trusts plunge deeper into debt, they have also been reproved by their regulator, NHS Improvement, for the rising pay bill. CEOs may choose rising debt as opposed to risking quality with an impact of a high use of expensive agency staff who still may not have undergone a particular specialist training programme. A relevant report commissioned by the British Medical Association (BMA, 2016), using a sample of interviewees - 237 doctors and 269 members of the public - concerned the adequacy of health professionals' training as regards 'end of life care'. The findings indicate a post-code lottery variation in the quality of care received; and specifically that doctors need training to help them handle 'difficult conversations' with dying patients and their relatives about the inevitability of death. This report reviews the viability of current training for health care professionals within this practice domain and urges doctors to be guided by their clinical judgement and to resist 'pressure' from relatives or a 'fear of failure' to continue treatment that would bring no benefit. 
It is not just the impact of the new staffing levels demanded by the Francis Report (2013) that has raised the reliance on agency nurses, up by $25 \%$, it would seem to be the better pay and conditions that agencies offer. It is thus ironic that the NHS has been accused of backtracking on improvements in patient safety made after the Mid Staffordshire scandal by reducing the number of trained nurses on wards because of its growing financial crisis. Cuts to nursing bursaries will come at a time when the NHS has been calling for increased 'compassion' in our healthcare system (see CQC reports post-2013). But are our healthcare professionals sufficiently trained in delivering compassion or should this attribute come naturally? For example following the Mid Staffordshire Hospital scandal the Secretary of State stated that

the goal of compassionate care should start to replace tick-box targets as the major focus on boards and wards, .. however the system can crush the innate values of compassion that NHS staff possess. (Hunt, 2014)

The then Prime Minister David Cameron reiterated this sentiment, asserting that '[The Conservative] Government has put compassion ahead of bureaucratic process-driven targets and put quality of care on a par with quality of treatment' (Cameron, in DoH, 2013). Nevertheless there is still some vagueness over the meaning of the term, and how it might be measured, taught and generated, marking it out in sociological terms as a somewhat problematised concept. If the emotion of compassion is seen as 'a deep awareness of suffering of another coupled with the wish to relieve it' (Chochinov, cited in de Zulueta, 2013, p.119) one argument for policy-makers use of compassion would be because it provides a convenient way of allocating blame, by which they are exonerated (Butler and Drakeford, 2005). The emphasis on 'compassion' tends to locate the causes of hospital scandals and other care short-comings in the failures of individual health workers, thus underplaying structural factors that implicate policy-makers such as the financial pressures and extreme under-staffing present within Mid Staffordshire hospitals. However despite the Report's caveat that cultures cannot be imposed hierarchically, the Secretary of State persisted in his view that organisational change can create the conditions amenable to the development of more compassionate care: 'Today is about tackling that culture challenge head-on so we build an NHS which supports staff to deliver the highest standards of safe and compassionate care...'

\section{Providing a consummate approach: A 'training gap' in schools?}

To take the example of schools there is evidence of de-professionalisation experienced through a 'training gap' where shortages have brought about a situation where teachers may lack a degree in the subject that they teach or they may only have been educated to A-level standard on the subject (Wintour, 2014). It has long been shown that it is the quality of teaching that matters most in tackling inequalities, 
hence schools operating with untrained staff mitigate against a social mobility agenda. There is a diversification in the nature and quality of teacher training across the UK, and the Conservative Government has expressed a preference for schoolbased schemes, such as School Direct to which candidates apply directly rather than university-based courses (Mason and Adams, 2015). There is no national or central planning of teacher supply and no fixed ratio of teacher: pupil required. With teaching recruitment definitely harder such deficiencies have resulted in reducing subjects in the curriculum, putting classes together and teaching children in much larger numbers (Elliott, 2016). A decision by former Education Secretary Michael Gove to relinquish central government responsibility for teacher supply in 2011 looks increasingly flawed:

the Government [has] largely abandoned the national teacher supply model, therefore it has no clear idea of how many teachers it needs and it has by and large abandoned planning. It assumes that schools can predict their supply needs, but they cannot. That's the strategy that's not working. (Millar, 2016)

\section{Summary}

\section{A perfect realisation of the unrealised, profoundly compromised}

Restricting training opportunities inevitably leads to an individual's incapacity to cope with growing job demands

Too much reliance on unpaid carers and commitment of inadequately trained staff, particularly in social care

\section{Reduced funding support to staff training}

A noticeable withdrawal of local authority, hospital trust and in-house funding support for higher-level, clinical and specialist training, dropped funding for student nurses

Most professions now recognise that learning and professional development are lifelong through Continuing Professional Development (CPD)

\section{De-professionalisation as a feature of a market-led 'model' of delivery such as 'what works?'}

De-professionalisation as demonstrated through application of a political economy 'model' of delivering public services shaping education policy

Proposals for reform of social work training appear invulnerable to evidence-based critique, for example fast-track training to expand Frontline and Step Up schemes; also 'What Works Centre' to disseminate best training practice 
The contentious issue of establishing 'appropriate training' for working in children's services

All children's provision to be taken over by 'high-performing' local authorities and 'teams of experts' and to give 'academy-style freedoms' to such high performing local authorities

Focus on highly qualified graduates from 'good universities', for example, buy-in of franchised packages such as 'Signs of Safety'

Threat to integrity of existing social work training

Greater use of untrained childminders; decline in support and training; poorlyqualified inadequate workforce for under-5s

\section{Politicians critique social work training}

The Conservative Government established 'independent reviews' of aspects of professional social work training with a degree of urgency (for example: CroisdaleAppleby, 2014; Narey, 2014) and particularly with respect to understanding and defining its outcomes

Secretary of State for Education expressed a strong concern about 'raising the quality of social workers', along with their education and training

\section{Reviewing the viability and completeness of current training for health care professionals}

High number of national and local reviews of nurse and paramedical training, both past and present, have been influenced by the 'political economy model' of delivering public services

National shortage of GPs may point to a need to fill gaps with doctors from abroad Greater use of a multi-disciplinary flexible approach where there is more joint working, individual professional displacement and mentoring across disciplines trans-disciplinary approaches

\section{Providing a consummate approach - a 'training gap' in schools?}

De-professionalisation points to the lack of commonality of standards such as the number of specialist trained teachers in schools

There is no national or central planning of teacher supply and no fixed ratio requirements as regards the number of teachers to pupils, also as regards the demand for extra teacher training

An increased use of teaching assistants - a formalised qualification? No common definition of the job, for example helping 'poor students' keep up with their peers 


\section{Section F. Reviewing the evidence: De-professionalisation as defined by a lowering of morale, and a demoralisation or denigration of the workforce}

The professions represent independent sources of power in our society, which is one reason that they are under such swingeing attack from the neo-liberals with their dogmatic assertion of the power of the 'market' over all else. If you can prevail with employing cheaper, untrained, lesser or differently trained staff, then an employer will go there. As for the professions, the problem is not so much with restrictive practices as with restricted access, as recent governments increasingly seek to shift power away from the professions and to monetise all relationships.

\section{De-professionalisation as displacement}

There is a mysterious gap between the welcome and widely shared concern that disabled and older people should receive good quality care and the lack of action to ensure this becomes a reality (Williams, 2012; Elliott, 2015). The recent decision to postpone the funding cap in the 2014 Care Act underlines the low priority policymakers attach to work with older and vulnerable younger people. This lack of funding for 'professional' social care is symbolic of the core problem, namely commodification, the fragmentation of the care relationship into standardised tasks that objectify the client. There is perhaps an underlying assumption by central government that, since social care will not contribute to export-led growth, it deserves to remain a low-status, low-paid activity. Professor Ruth Lister has drawn on feminist theorising around an ethic of care to uncover 'gendered moral rationalities' in which economic rationality itself can take second place to different forms of rationality, which prioritise caring over economic success. Social policies for instance that recognised the dignity of people living in poverty and the value of care-giving could represent small steps towards accepting a role for the state in acknowledging the psychological need for respect of one's dignity as a human being.

The vulnerability - or displacement - of social care 'professionals' can be seen in the Coalition and Conservative Governments' approach to Troubled Families which

uses family support workers, family intervention workers or key workers from a range of backgrounds. Some are from social work and youth work, some are nursery staff and some are teachers, some are police officers and housing officers. Their background is not as important as their skills and their tenacity. (Casey, 2014; DCLG, 2012; 2013)

Set up after the riots in 2011 the Government's $£ 1$.3bn scheme to help Britain's most troubled families was designed to give intensive support to 120,000 of 
Britain's most challenging families - the PM later announced an expansion to help 400, 000 more families until 2020, costing an extra $£ 900$ million. All families were identified by local authorities and each family was given a dedicated key-worker responsible for ensuring that they received appropriate help. The idea was to provide co-ordinated help to people who in the past would have been dealt with by a variety of government bodies such as the police, social services and Jobcentre Plus. Success was to be judged by different measures including reductions in truancy, criminal convictions and benefit dependency. Councils who took part in the initial $£ 400$ million scheme were paid when set goals were reached.

However a Government commissioned analysis by the National Institute of Social and Economic Research reporting in 2016 could find no evidence that the programme was having 'any significant or systematic impact' on employment prospects, performance at school, crime and anti-social behaviour or dependency on benefits. Similarly, the Conservative Government's rather over-enthusiastic support for the third sector agency 'Kids Company', widely reported in the media, was founded on an 'unorthodox' approach of dealing with 'troubled' young people through psycho-therapy, and for some represented a displacement of traditional helping professions. Here was an ethos that clinical phenomena are viewed behaviourally (gangs) or emotionally (depression) and understood not as failings of particular individuals or families. This perspective may have disturbed the world view of the political class but in practical terms resulted in denigrating the efforts of cash-strapped social service, health and youth workers (Butler, 2015; Weale, 2015). The Conservative Government chose to fund a virtually 'non-professional' service whose reported outcomes had always been questionable; and agreed to provide a $£ 3$ million 'rescue package' plus a further special grant of $£ 4.5$ million in 2014. Kid's Company was being funded regardless of officials repeatedly expressing concerns over financial sustainability and poor management practices.

\section{De-professionalisation as reducing self-esteem}

Such a shifting of authority or autonomy away from professional groups will likely have an insidious effect on morale, defined existentially as how an individual feels about their job, status and position, centring strategically on building confidence, enthusiasm and discipline within the workforce. Bourdieu's notion of cultural and symbolic capital may be relevant here as he claims that this can exist in the objectified state in the form of cultural goods; and in the institutionalised state such as educational qualifications (Bourdieu, 1984). When such values decline then the social dynamic depends on people possessing these qualities and valuing them. Bourdieu's concept of habitus can work in a way to explain how an individual becomes part of a recognised group; but it aligns embodied actions with social locations, and centres on how an individual feels about their sense of belonging 
(McKenzie, 2016, pp.31-32). De-professionalisation encompasses a lowering recognition of performance within an organisation's workforce often contrasting with how one might had been valued previously.

What you've got is a profession that is exhausted, battered and demoralised and this has come from an awful lot of changes from the DfE that were supposed to improve standards for children ... [and] they wonder why people don't want to come into the profession.

asserts a head teacher from a large inner-city comprehensive school who blames the growth of testing, children's mental health issues, compulsory academisation and the narrowing of the national curriculum as main reasons for teachers choosing to leave the profession.

In 10 years people will say academies should be locally accountable, and LEAs will be reinvented. (Wilby, 2016, quoting the Provost of Eton).

To illustrate the point about lowering morale take the example where a teacher may have been highly valued for a specific subject but once this subject becomes redundant or no longer in fashion, might experience difficulty in moving to an alternative and equally valued activity. There is a counter-argument that it should be a person's ability to transfer their teaching skills to another subject and to engage an audience which provides an essential professional quality (Dearing Report, 1997; Freidson, 2001). Confronting adversarial circumstances may not bring out the best in individuals and indeed can become corrosive of professional identity.

The Conservative Government appears to have ignored the views of teaching professionals through its 'forced academisation of schools' policy (Boffey, 2015). Local schools have been run by democratically elected local bodies since the school boards were created by the 1870 Education Act. That Act required the state, for the first time, to provide a school place for every child; and it is this aspect of democratic accountability which sustains the school system to uphold high standards, judged in part by teacher quality. The plan to force all schools into academy status can be seen as a ploy to hasten the unravelling of local democracy begun by Margaret Thatcher and pursued with varying degrees of enthusiasm by subsequent governments - both right and left - and not least by the present Government's squeeze on local financing. The choice concerns decision making and power vested in Whitehall, especially funding, and what role should be given to individual school representatives whether teachers or parents when it comes to understanding what schools and local communities want and need. Current proposals are to exclude those without specialist skills and knowledge from being parent governors, underpinned by the fallacious idea that local people don't share a strong interest in the direction of the school. As with the aforementioned example of the NHS junior doctors' strikes 
arising from what has been perceived as an overbearing political intervention, the result appears to have left a mutual disrespect, even animosity between the parties involved straining individual and group morale.

\section{De-professionalisation as an attack on social status or position}

In the Weberian tradition (Rogers and Pilgrim, 2014, p.108) professions develop strategies to advance their own social status. Collective social advancement rests upon social closure and it is clear that the medical profession in its fight with the Conservative Government has tried to use its special status as a profession to persuade the world at large, including courting the media, of their deserving case. The stand-off between the Secretary of State for Health, Jeremy Hunt and the BMA on pay and working conditions has in England become 'the main story' that is, a personality clash. The argument becomes: does the Conservative Government value junior doctors? Apparently not ...

it is simply unacceptable to devalue and denigrate doctors and the medical profession to the point where medicine in the UK is no longer a profession that the majority of doctors would recommend. (BMA spokesperson)

The purpose of the '5-day pause' of May 2016 to break the deadlock in this dispute has on the Government's part, a desire to ensure that doctors achieve a safe work environment, that their new contract is not discriminatory and above all to keep doctors remaining as workers in the NHS. For the BMA however the desired terms of reference appear to have been framed more broadly and includes consideration of how junior doctors might become better integrated in the NHS along with discussion of everything that demoralises them. Either way too much 'political' intervention would seem to have resulted in an attack on the morale of junior doctors. This 'political' move to impose a new contract has been met with ferocious opposition from medics, with many claiming that the move will jeopardise patient care and could lead to an exodus of expertise from the NHS.

'The thing I found most extraordinary of all was him standing up in the Commons and stamping all over us by imposing this contract while simultaneously announcing a review to improve doctors' morale.' (Junior Doctor, Oxford).

'Imposing a deal on junior doctors is wrong-headed, will inevitably damage morale across the NHS - and may damage patient care' (Chair of Royal College of GPs).

The NHS can barely staff a five-day routine service (emergency care is already 24/7). So stretching the same staff over seven days will make the service unsafe and a junior doctor's life intolerably stressful. A seven-day NHS cannot be delivered on a five-day budget' (Junior Doctor, Sheffield). 
One UK political party leader has claimed that the attack on the medical profession is about the future of the NHS:

That the government doesn't mind if the NHS collapses. The NHS has been brought to the point of collapse by deliberate under-funding, a hospital and bed closure plan, short-sighted manpower planning and cynical scare stories about safety....the result will be no recognisable NHS in a few years, not by accident but by design. (Campbell, 2016f)

Medical royal colleges have warned that imposing a new contract would further damage already low morale among junior doctors and make it harder to persuade newly qualified doctors to work in the NHS. A Guardian Healthcare Professionals Network survey showed that four out of five healthcare workers have considered leaving their job in the NHS and an overwhelming majority (84\%) of those have thought about it more in the past year - 'I worry about the long days....I'm so scared of making a mistake' (Campbell and Siddique, 2016). Increasing workloads, cuts to the health service, unreasonable expectations and long working hours are some of the factors they say are damaging the lives of NHS professionals at a time of escalated pressure. While the link between overstretched social care and extra cost for the NHS is not exact between 2011 and 2015 spending on social care has been cut in real terms by $8.7 \%$, During the same estimated period, according to some figures the number of $A \& E$ admissions of people aged over 90 had gone up by $61 \%$.

De-professionalisation defined as an attack on social status creating low morale possibly reached a watershed in late 2016 in the case of foster carers where it was reported that despite many being both highly experienced and qualified in the care of children over the years they had not being valued as such. For instance unlike caring professions such as nursing, foster carers cannot challenge decisions to cut fees or change working conditions because they lack any formal employment status.

They are self-employed, but by statute can only work for one provider. It's not a normal employment situation. (Chief Executive of UK Fostering Network Charity)

A fundamental disadvantage that they experience as substitute parents performing a professional role is that they receive no sick pay, no holiday pay and no pension rights. Around 60 foster carers voted to unionise and join the Independent Workers' Union of Great Britain (IWGB) in a bid to improve their working conditions. In addition to anger over welfare cuts, foster carers were said to have become increasingly fed up at their precarious legal status. Many felt that any attempt to challenge a decision or make a complaint would be ignored and could lead to them being deregistered by the local authority because they are not protected by whistle-blowing legislation

'Foster carers are rarely, if ever, informed about why a child is moved from their care and it can happen out of the blue ... No explanations are given. The council 
then subjects the foster carer to another 'official' review. The foster carer cannot be accompanied by a legal representative, to speak up for him or her, and is not allowed to see any evidence presented at that hearing. The foster carer can then be deregistered and banned from working with children or vulnerable people again.' (quote from a high court barrister working on behalf of foster carers)

Because they have no employment rights, foster carers cannot claim unfair dismissal. The current legal position in the UK may leave them highly vulnerable and as such children could be put at risk because of fear of the consequences of speaking out. Issues of accountability, complaints and low social status appear to have undermined the effectiveness of foster carers working in a professional capacity.

Foster carers should not have to continue working without any rights or protections. Carrying out the vital, often difficult, work we do on behalf of the state, and the communities in which we live, all foster carers deserve to be working under fair terms and conditions, with fair remuneration and support. (quote from an experienced foster carer)

A lack of morale sometimes can become evident from increased regulation within the workplace. For example, current regimes of performance measurement in the UK's higher education sector are said not only to lead to decreased professional autonomy (Frostenson, 2015) but also are unlikely to deliver any real improvement according to some research:

The most likely outcomes will be further increases in the de-professionalisation of academic staff and commodification of the work they carry out. Why? Firstly this is because the regimes of measurement reflect the triumph of a flawed postmodern philosophy which privileges and emphasises system deconstruction and economic functionality. Secondly, the regimes reflect a further instalment in the two-decade old story of New Public Management (NPM) and the transformation of the public sector through the importance of private sector practices and philosophies. Thirdly, the regimes will not deliver on their objectives because they are fundamentally flawed in terms of management process. (Adcroft and Willis, 2006)

Britain has now developed the most rigorous, costly and time-consuming system of assessments of any country in the world, and indeed one author commenting on universities several years ago wrote '... to an outsider, [the UK] seems obsessed by evaluations of every kind' (Smith, 2001). Performance measurement may enable greater transparency, and coupled with targets and self-evaluation equally may produce characteristics of role models to aspire to. At the same time such measures have the capacity to undermine or threaten the position or status of employees and place them on the defensive. This process can be used for self-improvement and 
professional development but also as part of a management 'stick and carrot'. Where some targets may be unrealistic and the dominant narrative is defined by attributes of the 'consummate professional' then a simulated reality may reflect also the role of the 'nearly-man' (someone who narrowly fails to achieve the success or position expected of them in their particular field of endeavour). Let us take for instance the versatile qualities to be demonstrated in a commonplace job advert for a leader in children's social care: '[Candidates] will also be able to role model the positive behaviours - trust, respect, innovation, commitment, integrity and flexibility'. How difficult is it to gauge these personal attributes and how easy is it to be seen to fall short of them?

\section{A gender gap?}

There may have been some evidence of a breakdown of tight gender divisions in the NHS but in social care a pervasive pattern of de-professionalisation as a result of poor working conditions becomes particularly noticeable due to its associated gender pay gap along with the feminisation of care work. This is portrayed for instance both through the culture of delivering home help or home care services, and through experiential accounts of the role of residential care workers and nursing auxiliaries over a long duration (Gray and Birrell, 2013; Manthorpe, 2002). A parliamentary Women and Equalities Select Committee Report published in early 2016 called for an effort to make all jobs flexible and to introduce an industrial strategy for low paid women's jobs to act on a pledge made by both Conservative and Labour Governments to close the gender pay gap (Allen, 2016). This Report said that all jobs should be 'flexible by default' unless there is a strong case for them not to be.

We are wasting women's skills and experience because of the way we choose to structure our labour market ... Part-time workers can be the most productive, yet reduced-hours working becomes a career cul-de-sac for women from which they can't recover. (Farrell, 2016)

The aim would be to make it easier for women to resume their previous careers after looking after children instead of taking lower paid jobs that do not make the most of their abilities. This Select Committee Report claimed that the debate about equal pay had focused too much on professional, well-paid jobs and not enough on 'highly feminised', low-paid work such as in the care sector, retail trade and cleaning. Women hold 59\% of minimum wage jobs and female part-time workers occupy $41 \%$ of those jobs, almost twice their share of all jobs. The argument was towards development of an industrial strategy for low-paid sectors to encourage innovation, higher productivity and better wages, starting with the care sector, where almost 80\% of employees are women (Select Committee Report, 2016). 


\section{De-professionalisation as evidenced by unfilled vacancies and poor recruitment}

Concurrent scenarios impacting both on social care and the social work profession provide statistics on the number of unfilled vacancies and of the poor morale within a national workforce (Skills for Care, 2013a, 2013b.). Andrea Sutcliffe, the CQC's Chief Inspector of adult social care, stated that there is a 'vital link' between providing high-quality care and having a registered manager consistently in post (see CQC, 2015; Quinney and Hafford-Letchfield, 2012). The Social Care Data Set showed that $64 \%$ of registered managers have been in their current post for at least 3 years, more than $12 \%$ of posts stand vacant and annual turnover is $24 \%$. Moreover, $49 \%$ (rising to $60 \%$ among nursing homes) are aged 50 or older, suggesting that half - some 10, 000 registered managers - will be retiring in the next 15 years or so (Skills for Care, 2015). A similar pattern of statistics is reflected throughout the nursing workforce in the UK where there are registered 23, 443 vacancies in England, Wales and Northern Ireland, according to 2016 figures. Comments below from experienced practitioners express the damaging effect on morale of current work practices and of Government plans to remove student nurse bursaries and to replace with loans:

The 'five Cs' that are instilled in nurses during their training: commitment, conscience, competence, compassion and confidence, but how can you show compassion when you're doing the work of several other people. On the worst days, I feel like I'm getting pissed on all the time.

A lot of time is taken up filling in the gaps with agency nurses who are new to the job, and there are many jobs they can't do. ... this means more work, as you may have six allocated patients in one shift, but you end up actually having more than ten. This isn't officially recorded - you just do it. But most of the time the gaps aren't even filled.

Economics and class relations determine an unfolding and rather disturbing narrative where stakeholders and shareholders own the "means of production', in this instance health and social care providers, working alongside professionals and occupations whose livelihoods depend inevitably on the decisions and choices of those who 'manage' an often fragmentary provision on behalf of the nation-state. A national survey (Murray, 2015) demonstrates the impact of unfilled vacancies and rising caseloads for social workers referring to 'hot-desking' lowering conditions under which social workers perform, which is not beneficial to their work with other colleagues. Many needed to sit in their car to make a confidential telephone call.

Such social workers experienced challenges to their work-life balance, whereby they are so busy they can't fit time off into their diaries, and much overtime went unpaid. This is aside from the morale-reducing aspects of the job commonplace from 'empathic distress' where the well-being of the helper can suffer. 


\section{Morale related to an ability to empathise}

Assuming an ability to empathise as being linked to morale, it is fundamental that the former is relevant to helping relationships and therefore is given primacy in all the varied counselling and psychotherapy theories and schools of training. It is often stated, implicitly or explicitly, that the more empathetic a person can be, the better the outcomes and levels of satisfaction will be in terms of helping relationships (Rogers, Bright and Davis, 2015: 18-19). However, it is important to note that empathy is, in fact, a multidimensional entity, with different emotional and cognitive facets. Davis (1980) identified at least three key components: perspective taking - the ability to imagine and adopt the perspective of other people; empathic concern - the ability to experience feelings of warmth, compassion and concern for others; and empathic distress - the experience of feeling anxiety and discomfort when hearing about the difficult experiences of others.

A number of authors have highlighted the risks of being emotionally over-involved with others in terms of compassion fatigue and burnout, and empathic distress may be a significant element in this. Research by Grant and Kinman $(2013,2014)$ provided some useful insights into the ways in which the different facets of empathy demonstrated by social workers impacted on their own well-being. They noted that the demonstration of both empathic concern and perspective taking appears to enhance resilience and well-being, while the experience of empathic distress has the opposite effect, with negative consequences for the psychological well-being of the practitioner (Grant and Kinman, 2014. p.28). Social workers need to go into the job with a realistic view of the challenges it will bring, but then need the right support as they progress. They become demoralised maybe because they are working with families at the extreme end of tension, family stress and breakdown. Demoralised feelings may be addressed through professional development and reflective practice. Great emphasis is placed on developing skills of reflection about, in and on practice, over many years in social work; and is considered key to Continuing Professional Development (CPD).

As we move to a profession that acknowledges lifelong learning as a way of keeping up to date, ensuring that research informs practice and striving continually to improve skills and values for practice...much emphasis becomes placed on the Professional Capabilities Framework. (Parker and Bradley, 2014, pp.xvi-xvii).

The Professional Capabilities Framework includes a preparation in knowledge or understanding relating to the 'level' of capability a social work student should be demonstrating at different points in his or her social work training, whether that be entry, assessment of readiness for practice learning, after the first placement or by completion of the programme (HCFC, 2012). 


\section{Demoralisation and workload}

Further evidence of poor morale comes from a survey of GP workloads:

An overworked, overstretched GP workforce is being buried under an avalanche of workload including pointless paperwork. Poor morale affects a majority of GPs who report that their services have worsened in the past year. From a survey of 2, 837 GPs 55\% expressed the view that there has been a deterioration of service in the past year claiming 'workload as unmanageable' or being 'starved of resources and staff' meaning that many patients can't get the appointments, treatment and services they deserve. (Campbell, 2015)

'If anyone says to you that staff morale is at an all-time low, you know you are doing something right' is an alleged claim made by the now retired Chief Inspector of Schools, Michael Wilshaw. Doubts were subsequently expressed about the extent to which Michael Wilshaw had been responsible for the alleged 'improvement' in Ofsted; but there had been none when it came to his reported role in the demoralisation of the teaching profession. His attributions of the improved rating of primary schools to 'Ofsted's hard work' were claimed as both too generalised and insulting to teachers; and that Ofsted was 'wasting about $£ 150$ million annually of taxpayers' money by creating a climate of fear in schools and colleges' (guardian. letters@theguardian.com 23rd December 2016). Teachers have begun to make a case for proportionate inspections based on dialogue and mutual trust to promote school improvement as opposed to the current audit-style approach of 18 criteria for judging leadership, nine for governance, nine for teaching, learning and assessment, and three for learning outcomes from 20 different groups of learners (boys, girls, ethnic groups and so on). Additionally the lengthy Ofsted inspection handbook contains criteria for evaluating provision for pupils' 'spiritual', 'moral', 'social' and 'cultural' development. Certainly the burdensome and ever-changing demands that some inspections have imposed on teachers continue to play their part in lowering morale. A survey conducted of teachers in schools showed that nearly half of teachers plan to leave in the next five years as a result of 'reaching breaking-point' over their workload (Lightfoot, 2016):

We are in the midst of a teacher recruitment and retention crisis brought on in large part by a culture of unmanageable workload. The biggest generator of workload, say teachers, is constant change caused by government policy.

Also demonstrated was a widening gulf between teacher morale within the two sectors, state and independent, with teachers in the latter much more likely to say they are happy in their work and much less likely to complain of unmanageable workloads. For instance class size was viewed as an important factor.

I was teaching classes of 31, now I have 11. That makes a big difference but it isn't the main reason why I am much happier now. In the state schools I was coming to 
see children as data walking round, they no longer seemed human. Here the teachers are nurturing each individual child and developing them not just academically but as people. You're doing everything for the sake of the child, not to tick a box for the school. I'm treated as a professional, my opinions are listened to and I feel much more appreciated. Here you gets thanks all the time.

An industrial strike carried out by teaching assistants in 2016 evidenced that many felt undervalued. The given reason was not only about low pay and job insecurity but about their nebulous status within schools and about their too varied workload where they were expected to respond without any further training (Harris, 2016). Their role would seem varied and they are required for many different purposes, for example shadowing teachers, working on specified structured programmes, helping less able students keep up with their peers; however there is no common definition of what their job involves. The Government claims that it spends around $£ 4$ bn on teaching assistants - approximately $10 \%$ of the overall educational budget - and each junior and secondary school has on average 10-15 teaching assistants. Nonetheless many claim that, in policy terms, they are neglected as needing extra staff training in order to support students with dyslexia and autism. Available Department for Education statistics show that the majority of teaching assistants are graduates; and that some schools cannot pay them enough to retain them, also that they lack a formalised qualification. There exists no overall national picture of the current work of teaching assistants as regards attitudes to workload and as one head teacher in the above survey asserted: 'We're not getting our best value yet'.

\section{Summary:}

Recent governments increasingly seek to shift power away from the professions and to give them restricted access.

\section{De-professionalisation as displacement}

Lack of funding for 'professional' social care services is symbolic of commodification, the fragmentation of the care relationship into standardised tasks that objectify the client

The Conservative government's approach to 'Troubled Families' tended to use family support workers, family intervention workers or key workers from a range of backgrounds such as teachers, police officers, housing officers, youth workers

\section{De-professionalisation as reducing self-esteem}

De-professionalisation encompasses a lowering recognition of performance within an organisation's workforce often contrasting with previous valuations

Major organisational upheaval tends to have a negative impact on morale, for example 
changes to school curricula, health service 'modernisation' plans; and particularly when professionals see their views /voice being relatively ignored

\section{De-professionalisation as an attack on social status or position}

Perceptions of too much 'political' intervention - for instance a long-standing confrontation has arisen between the Secretary of State for Health and doctors which has a rather different nuance to that evidenced between health service managers and doctors - seemingly to have resulted in an attack on the morale of junior doctors

De-professionalisation as embodied in increasing workloads, loss of autonomy in the practice of a profession and subordination to external supervision coupled with unreasonable expectations

Take the case of foster parents who have experienced devaluing of status, no legal rights as such; and cannot challenge decisions to cut their fees or change their working conditions because they have no official employment status - they have no employment rights and therefore cannot claim unfair dismissal

\section{A gender difference?}

Feminisation of parts of the workforce, for example home care services, residential care workers, nursing auxiliaries over a long period have experienced poor working conditions, leads to low morale

Many women have been forced to take poorly-paid jobs in the social care sector and this is tantamount to a waste of women's skills and experience

Need for an industrial strategy to encourage innovation, higher productivity and better wages?

\section{De-professionalisation as evidenced by unfilled vacancies and poor recruitment}

The ' 5 Cs' are instilled in nurses during their training -commitment, conscience, competence, compassion and confidence, but how can you show compassion when you're doing the work of several other people?

High number of vacancies reflected throughout the nursing workforce; also in the case of social workers there is an impact of unfilled vacancies and rising caseloads and challenges to work-life balance such as unpaid overtime

Morale related to an ability to empathise

Risks of being emotionally over-involved with others in terms of compassion and burnout, and empathetic distress may impact on a professional's own well-being Demoralised feelings may be addressed through professional development and reflective practice and seen as a key component of Continuing Professional Development (CPD) in social work training

\section{Demoralisation and workload}

Surveys reveal evidence of poor morale among, for example, GPs, teachers in schools 


\section{Section G. Reviewing the evidence: de-professionalisation as defined by low productivity where a rise in low-skilled jobs becomes blamed for static wages.}

Increases in productivity, which is output per unit of input employed, are as a result of deploying better raw materials, better trained or educated labour or better machines even if no changes in factor quantities or proportions take place. 'New ideas can raise efficiency by being applied to new products: imagination can design a better mousetrap, with no change in the quantity, quality or proportions of factors' (Lipsey; 1979, p.232). Productivity was envisaged as the 'main problem' affecting the economy by the Conservative Chancellor of the Exchequer George Osborne in his budget speech of March 2016, where he highlighted the significance of a 'national living wage' necessary as the country's growth has been heavily biased towards lowproductivity jobs which do not pay very well. For most UK employers lowering the cost of production may be seen as an obvious benefit; however this usually produces a degrading effect upon the technical capacity of the worker.

In contrast the Labour Party leader Jeremy Corbyn pledges to introduce policies to increase work productivity - 'to rebuild and transform Britain so that no one and no community is left behind' (Elliott, 2015). This would be achieved by introducing sectoral collective bargaining, and mandatory collective bargaining for companies with more than 250 employees, thereby demonstrating a commitment to workers' rights, social justice, government investment in our manufacturing sector and public sector, and good quality jobs (Trade Union leader Len McCluskey's speech at the Trade Union Annual Conference 2016). As to the reality, economic growth in the UK has remained slow, and despite bank bailouts, spending cuts, wage freezes, and pumping millions into financial markets, ordinary workers have enjoyed much less of its benefits (Davies, 2015; Chakrabortty, 2016).

However a slightly different economic direction augured in a speech by the new Conservative Prime Minister Teresa May at her first Party Conference endeavoured to claim the political 'middle ground' by referring to enhancing individual worker productivity with a need for an 'industrial strategy'. The PM announced the industrial strategy in January 2017 and spoke of a ten-point plan to revive the economy, to embrace a more productive, trade-focused strategy, with an emphasis on developing education, training and lifelong learning. The strategy would be interventionist in purpose but the intention was not for the state to become an agent of public reform. Businesses would be incentivised to invest in skills in a big way, for example through a lowering of tax rates. As the planned split from the EU would make hiring from overseas tougher there would be different sector deals to up-skill groups of workers. Technological change has shifted the distribution of income from labour to capital: according to the OECD, up to $80 \%$ of the decline in labour's share of national income between 1980 and 2007 was the result of the impact of technology. A particular hallmark of the Government's industrial strategy 
will be for British universities to focus more on 'technical skills' as skills training would be at the heart of the strategy. More 'face time' with tutors would represent a changed culture in vocational education; and different sectors of the economy and workforce would be singled out for special treatment, for example automotive engineering. The approach would involve greater investment in infrastructure, in training and skills by setting targets; and by implication a concerted effort to stop employers paying low wages through continuing to employ cheap foreign labour.

The Chancellor, Phillip Hammond has stated:

The problem is not highly skilled and highly paid bankers, brain surgeons, software engineers. You will not find, if you walk around towns in Britain and ask people how they feel about migration, that they have a problem with people with skills and high earnings coming to the UK ... They recognise that those people are a positive contribution to the UK economy. The issue that we have to deal with is people with low skills competing for entry-level jobs, the pressure on wages at the lowest end. (Treanor, 2016)

For example in the health and social work sector - where approximately $9 \%$ of the 4.1 million employees are non-UK nationals - a residential care home employer may, at the present time, choose to employ a majority of cheap, relatively unskilled workers regardless of potential disbenefits to the client group being served. Could this action be seen as de-professionalisation by the backdoor? The present Government's view, it would seem, is that growth should not be based on low-paid, low-skilled migrant labour. For GDP per capita to grow this would require economic expansion emanating from an improvement in productivity, not simply from bringing ever larger numbers of low-skilled people into the economy. The national living wage, a policy introduced by the Conservative Government, fits with the new PM's rhetoric about boosting the prospects for the poorest and is set in relation to median wages targeting $60 \%$ of median UK pay by 2020 . Note that the minimum wage for over-25s rose by 50p an hour in April 2016, to $£ 7.20$, as a result of this policy.

\section{Low productivity resulting from deskilling}

De-professionalisation as an applied concept featured within the sociology of work can be linked to 'progressive deskilling' (Braverman, 1974:, Wood, 1982; Garson, 1988) which in turn equates to low productivity as characterised by an organisation where the acquisition of any new skills by individual employees is not viewed relatively as of paramount importance by those in management or positions of authority. Despite the centrality of the concept of skill in the sociological analysis of work and its widespread use in everyday discussions of occupations, there is little 
agreement about how best to define and measure this familiar idea (Vallos, 1990). Braverman's historical account of deskilling is the leading and most powerful version of the 'pessimistic position' which tends to use a definition of skill emphasising the skill content of a job and the amount of task-specific training required to do it as he argues that much work has been deskilled, in contrast to an 'optimistic position' where exercising responsibility and obtaining increased educational qualifications are salient factors, that is to say up-skilling (Edgell, 2012, p.56). For the capitalist there is an imperative to exert control over the labour process in order to maximise the productive potential of labour and therefore profits; such that employers turned to developments in management and technology. A growth of entrepreneurial activity can be associated with increased productivity and output and the 'professional as entrepreneur' should not be discounted (see for example, Brockling, 2016, pp. 66-80). This author defines entrepreneurship as:

to reform or revolutionise the pattern of production by exploiting an invention or, more generally, an untried technological possibility for producing a new commodity or producing an old one in a new way, by opening up a new source of supply of materials or a new outlet for products, by reorganising an industry and so on. (ibid, p.70)

Schumpeter, a leading economist, depicts the entrepreneur as someone breaking loose from familiar routines and blazing trails on their own. The crucial quality for him was not inventiveness but the ability to establish 'new combinations' in production and distribution. For this reason he emphasises the role of power in entrepreneurial activity. Enterprise is a 'special case of the social phenomenon of leadership' (Schumpeter, 1928, p.412)

The leader type is characterised for one thing by a special way of looking at things. Less by intellect than by will, by the power to grasp very particular things and see them as real. Also by the capacity to go it alone and go before the others, to not feel uncertainty and resistance as opposing grounds, and so essentially by his effect on others; what we can call 'authority', 'gravity', 'command'. ... he is the special trailblazer of the modern human and the capitalist, the individualist way of life' (Schumpeter, 1934, p.134).

With authoritarian monetarist economics, the current scenario presents a UK economy requiring further stimulus and investment. Low productivity links with low pay and how it interacts with working hours, and is reflected in the extent to which staff may fail to take ownership of their work. What brings average productivity down is a higher proportion of people in low-paid work, and a longterm failure to invest in capital equipment. Only by analysing the economy sector by sector will it be possible to identify where attention is needed, either by better training or legislation to outlaw poor employment practices. As Henry Ford knew, as 
with an under-performing factory, if you mothball a workforce then a company will lack paying customers for its products. The cause of diminishing opportunities for even skilled work is the concentration of the benefit from automation into the hands of the elite. Business heads' rewards are now disproportionate to their workforce. Equalisation in pay levels, coupled with redistributive taxes, could allow provision of a basic income sufficient to permit a shorter working week. As technology advances, it means that we have become much more efficient at producing the goods and food we need; however these benefits have been retained by an ever decreasing minority, while the incomes of the majority have stagnated, or even regressed.

\section{Has the deskilled worker an incentive to acquire 'new skills'?}

In contrast we consider de-professionalisation as resonant of evoking images of lacking an opportunity to demonstrate initiative, control or authority. For the 'deskilled worker' - where there may be a disincentive to acquire new skills engaged in an innovative and successful organisation this feature may become part of the conversation around lower productivity or it may not. It has been claimed that one aspect of globalisation of the workforce has been its contribution to the growth of the 'precariat' - a term describing an emerging class of people facing lives of insecurity, moving in and out of jobs that give little meaning to their lives (Standing, 2011). An epidemic growth of workforce insecurity goes hand in hand with the way companies or organisations have become 'commodities', to be bought and sold through mergers and acquisitions. The frenzy with which firms are now traded, split up and repackaged is a feature of global capitalism. And corporations are increasingly owned by foreign shareholders, led by pension and private equity funds.. Companies want more flexible labour forces so that they can respond quickly to external threats.

Commodification has also made the division of labour within enterprises more fluid. If activities can be done more cheaply in one location, they are 'off-shored' (within firms) or 'outsourced' (to partner firms or others). This fragments the labour process; internal job structures and bureaucratic 'careers' are disrupted, due to uncertainty over whether jobs people might have expected to do will be off-shored or outsourced. For example the care industry in the UK is estimated to employ 160, 000 workers on zero-hours contracts while the public sector, especially the health service, has increasingly adopted flexible contracts, indicating that insecure employment has become a permanent and growing feature of the jobs market (Inman, 2016). In its 2017 outlook, the Chartered Institute of Personnel and Development (CIPD), which represents people working in human resources, forecasted slower economic growth, fewer new jobs and downward pressure on pay which would compound challenges from low productivity and uncertainty about Britain's future relationship with the EU. The argument goes that this disruption 
feeds into the way skills are developed. The incentive to invest in skills is determined by the cost of acquiring them, the opportunity cost of doing so and the prospective additional income. If the risk increases of not having an opportunity to practise skills, investment in them will decline, as will the psychological commitment to the company. In short, if firms become more fluid, workers will be discouraged from trying to build careers inside them (Standing, 2014, pp. 49-52):

Precarious unemployment in the neo-liberal framework has been viewed as a matter of individual responsibility, making it almost 'voluntary'. People came to be regarded as more or less 'employable' and the answer was to make them more employable, upgrading their 'skills' or reforming their 'habits' and 'attitudes'. (ibid, p.77)

An alternative suggestion is that businesses would rather employ cheap labour than spend more on new kit, which explains why investment in the UK as a share of GDP is still well below where it was before the 2008 recession. The argument for higher investment as the bedrock of a more successful economy is that it boosts productivity, leading to higher wages, a bigger tax-take and smaller deficit. Investing in skills and infrastructure, investing in growth, leading to a more competitive market had been suggested as hallmarks of the Conservative Government's Productivity Plan, according to the then Business Secretary of State, Sajed Javid, in a speech delivered in December 2015. However evidence from the 'budget watchdog' (Elliott, 2015) showed that productivity would not get better soon and this was similarly the case during the political campaign running up to the EU referendum in June 2016.

\section{And inequalities grow ...}

The Left's view has been that relentless cuts will not help Britain's long-term economic prospects nor produce successful growth; instead they will impact negatively on the integrity of public services. Their view is that since 2010 the Chancellor of the Exchequer has been committed to a self-defeating goal of massively reducing the public sector from $43 \%$ to $36 \%$ in 5 years, pushing forward his plan in the short-term interests of an elite class of tax avoiding private businesses and multi-national corporations. 'The UK's top executives will have made more money over the first two and a half days of 2017 than a typical worker will earn all year, according to an analysis that lays bare the gulf between executives at Britain's biggest companies and the rest of the workforce' (Allen, 2017). Amid the political fallout from the Brexit vote the PM has tapped into voter frustration over inequality and since becoming prime minister has promised to reform capitalism.

Nevertheless there is a current forecast of slower growth in the British economy and rising unemployment as austerity continues to bite. But it has been claimed that 
no economically successful country in modern history has voluntarily reduced its public services in this way as a supposed growth-promotion strategy. The Office of Budget Responsibility's (OBR) assumption of growth has been underpinned by the belief that labour productivity will grow briskly despite the fact that there has been no increase in productivity since the advent of the 2008 recession. We confront therefore the age-old dilemma or oppositional paradox. The Right believe that the economy will function better for everyone if Government is smaller, public debt is reduced and taxes and redistributions are curtailed. The Left's standard solution has been an activist government that taxes the wealthy, invests the proceeds in excellent schools, health care, housing and in other means that people need to become more productive, and redistributes to those in need. Public investment, social security and an industrial strategy all are features of a state-interventionist model, although some commentators view the notion of 'the state' - as in the creator of the welfare state after the second world war - now as almost invisible, even hostile to an association with social welfare principles and objectives (Chakrabortty, 2017).

The findings of a study by the Resolution Foundation (Elliott and Allen, 2017) demonstrate that falling living standards for the poor now threaten to bring the biggest rise in inequality since the Thatcher prime ministerial tenure, 1979-90. As inflation rises, as productivity flatlines and employment growth slows, inequality will be set to start rising again - incomes will fall for the poorer half of households, while they will rise by around 5\% for the richest fifth by 2020. This study has blamed the upcoming living standards squeeze on a combination of stagnating pay, rising inflation and the rollout of more than $£ 12 \mathrm{bn}$ of welfare cuts. Underscoring the challenge for the Theresa May Conservative Government as it seeks to redress deep regional imbalances in the UK, the Foundation highlighted also persistent major regional differences as regards inequalities between south-east England and the rest of the country. But tracking a rise in inequality as the standard explanation, as well as the standard debate, overlooks the increasing concentration of political power in a corporate and financial elite that has been able to influence the rules by which the economy runs:

The clash is no longer between left and right, but between a global financial elite and the rest of us. It is impossible to know when we will again reach a tipping point, but there can be little doubt it will come. Political economies that bestow most gains on small groups at the top are inherently unstable. The real question is not whether change will occur, but whether it will come through democratic reform or authoritarian mandate. (Reich, 2016)

\section{A dullened edge of professionalism?}

It is perhaps professions such as health care, social work and teaching and parts of the legal profession that have endured most trenchantly the negative impacts 
of a neo-liberal model representing a declining public service culture. The NHS is perhaps a leading example of where the creed of 'multi- or inter-disciplinary working' has been employed as a management device to achieve innovation, or more colloquially, 'to paper over the cracks on the ground'. 'Some evidence from the NHS shows that hiring has been driven by prevalence of low-skilled posts which often paid less than typical jobs before the 2008 financial crisis, pushing down on average rates of pay, growth and productivity. For instance an NHS bosses' letter (Campbell, 2015c) appeared to show a green light to row back on safe staffing by endorsing cutbacks on trained nurses and by implicitly preferring a 'multi-disciplinary approach' as a lower-cost alternative method for providing long-term care:

We would stress that a 1:8 ratio is a guide not a requirement. It should not be unthinkingly adhered to. Achieving the right number and balance of clinical and support staff to deliver quality care based on patient needs in an efficient way that makes the best possible use of available resources is the key issue for provider (hospital) boards.

This NHS managers' letter recommended that hospitals ask health professionals such as physiotherapists to help look after patients, and use technology to monitor their condition, to reduce the need for nurses on duty. It also urged hospitals to take 'a rounded view of staffing' showing they are making the best use of resources as well as providing safe care, listing a set of variables, including how ill patients are, adding:

In some cases these factors will mean a higher number of nurses per patient, and in other cases it will mean a lower or different configuration of staff can be justified.

\section{Summary}

Increases in productivity are as a result of deploying better raw materials, better trained or educated labour or better machines. Ordinary workers seem to have enjoyed few of the benefits of economic growth.

\section{Low productivity resulting from deskilling}

Braverman's historical account of deskilling is a leading and powerful version of the 'pessimistic position' which tends to use a definition of skill emphasising the skill content of the job and the amount of task-specific training required to do it. This author argues that much work has been de-skilled, in contrast to an 'optimistic position' where exercising responsibility and obtaining increased educational qualifications are salient factors, that is up-skilling (Edgell, 2012)

\section{Has the de-skilled worker an incentive to acquire 'new skills'?}

De-professionalisation evokes images of lacking an opportunity to demonstrate initiative, control or authority within the workplace A feature of globalisation of 
the workforce has been its contribution to the growth of the 'precariat' - a term describing an emerging class of people facing lives of insecurity, moving in and out of jobs that give little meaning to their lives (Standing, 2011)

\section{And inequalities grow ...}

The Office of Budget Responsibility (OBR)'s assumption of growth was underpinned by the belief that labour productivity will grow briskly despite the fact that there has been little evidence of an increase in productivity since the advent of the UK 2008 recession

\section{A dullened edge of professionalism?}

A multi-disciplinary approach as a preferred method given that hiring in the NHS has sometimes been driven by a prevalence of low-skilled posts which often paid less than typical jobs. As a leading financial analyst sums up: 'our world does not function effectively if it is always rigidly streamlined. Living in specialised silos might make life seem more efficient in the short-term. But a world that is always divided into a fragmented and specialist pattern is a place of missed risks and opportunities' (Tett, 2015).

\section{Section H: Discussion}

\section{What is the association of de-professionalisation with neo-liberalism?}

Ideological reference points where the notion of de-professionalisation takes shape include neo-liberalism which Davies (2017, p.5) has suggested represents an attempt to replace political judgement with economic evaluation, including, but not exclusively, the evaluations offered by markets. The central defining characteristic of all neo-liberal critique is its hostility to the ambiguity of political discourse, and a commitment to the explicitness and transparency of quantitative, economic indicators, of which the market price system is the model. 'Neoliberalism is the pursuit of the disenchantment of politics by economics' (ibid, p.6).

Quantification and measurement have their own affective and aesthetic qualities (Porter, 1995), but the example of market price indicates to an economic sensibility that ambiguity and performativity can be beneficially minimized or constrained. The disenchantment of politics by economics would involve a deconstruction of the language of the 'common good' or the 'public', which is accused of a potentially dangerous mysticism, As manifest in the work of Hayek (1944), this may be an attack on socialism and the types of state expertise that enact it, but it is equally apparent in a critique of the liberal idea of justice (Posner, 2002; Arblaster, 1985). For instance 
hospitals and schools may appear to be more valued by the public than fragmented community services; so, in line with consolidating the neo-liberal view, politicians and public service administrators may bolster this so-called normative judgement by resorting to methods of outcome measurement. The targets of neo-liberal critique are institutionally and ontologically various, where substantive claims about political authority and the public are critically dismantled and replaced with technical economic substitutes. However critics of neo-liberalism have noted that it did not seek or achieve a shrinking of the state, but a re-imagining and transformation of it (Peck, 2010; Mirowski, 2013).

The rise of American and German industrial capitalism had been achieved thanks to new economics of scale and organisational efficiencies associated with large corporations and hierarchical structures, including the birth of management, Science and expertise were now formally channelled into business. Technical advancements in the fields of statistics and national accounts, followed by the birth of macroeconomics in the 1930s, meant that 'the economy' had appeared as a complex object of political management. (Davies, 2017, p.7)

The point is that the ongoing growth of a 'social' realm, measured and governed by sociology, social statistics, social policy and professions, meant that the American and European states of the 1930s onwards had far more extensive capacities and responsibilities for audit, intervention and knowledge transfer than previously. The pragmatism of the neoliberal pioneers committed them to a reinvention of liberalism suitable for a more complex, regulated Fordist capitalism. Hayek's believe that 'the fundamental principle that in the ordering of our affairs we should make as much use as possible of the spontaneous forces of society, and resort as little as possible to coercion', is capable of an infinite variety of applications (1944, p.17). Victorian laissez-faire was only one empirical manifestation of the liberal idea. Restoring economic freedom would not be achieved simply through withdrawing the state from 'the market', but through active policy interventions, to remould institutions, state agencies and individuals, in ways that were compatible with a market ethos and were amenable to economic measurement. The state is therefore a powerful instrument of neo-liberalism, particularly insofar as it supports deregulated and flexible labour markets. The state is also a major provider and designer of public services and it appears fairly clear that the evidence around increased de-professionalisation lies at the heart of the UK austerity agenda symbolised by profound cuts to services in the form of efficiencies, pay cuts, rationing, reducing training /staff development and potentially affecting overall economic productivity.

Liberalism is associated primarily with the uncertainty of outcomes - 'to be neutral is to have no answer to certain questions' (Hayek, ibid, p.80). By contrast, political activity is interpreted as an instrument of planning, as a project of determining outcomes and reducing uncertainty. Most analyses of neo-liberalism have focused on its commitment to 'free' markets, deregulation and trade, but 
what is the nature of neo-liberal authority? On what basis does the neo-liberal state demand the right to be obeyed, if not on substantive political grounds? To a large extent, it is on the basis of particular economic claims and rationalities, constructed by economic 'experts'. The state does not necessarily cede power to markets, but comes to justify its decisions, policies and rules in terms that are commensurable with the logic of markets. The authority of the neo-liberal state is heavily dependent on the authority of economics to dictate legitimate courses of action. Understanding that authority - and its present crisis - requires us to look at economics, economic policy experts and advisors as critical components of state institutions. It is such 'experts' whose views might seem to matter more than those of 'professionals' employed by these organisations. As such it is the market-based principles and techniques of evaluation which determine therefore how much state organisations can afford to spend and by how much they may choose to reward their employees.

Moderate interpretations of neo-liberalism are grounded on the assumption that the state should fight deprivation but not income inequality, because the latter is understood as a precondition for economic prosperity (Beland, 2007). Social investment has become a social policy concept that can be seen as a way to find a new economic legitimacy to social programmes (Esping-Andersen, 2002; Morel et al, 2012; Mahon, 2013). Seen as part of the Keynesian policy paradigm as a means of increasing economic productivity, social investment was understood to play a positive role in economic regulation, especially during downturns when social benefits helped to maintain consumption. Rather than depicting social programs as a pure cost for the economy, as traditional neo-liberal thinkers do, social investment suggests that in a so-called knowledge society, investment in human capital (training and education) and social programs like universal access to child care and early childhood education are good for the economy.

Max Weber argued that modernity had a disenchanting impact in the way that much had been promised through positivist social science, characterised by primacy of observation in its epistemology, the role of theory, causality, laws and value freedom; and by bureaucratization. This approach subsumes the particular within the universal and reduces qualities to quantities. In Weber's analysis, modern science and bureaucracy lack any 'outward' or public sense of their own intrinsic value to humanity, making them cold, impersonal and anonymous forces - those same characteristics of markets that Hayek deemed valuable (Weber, 1991). The disenchantment of politics by economic ideology depends however for its progress on unspoken ethical commitments on the part of its advocates (Davies, 2017, p.11). For example, this becomes self-evident where the question of scientific and social scientific 'methodology' arises. In order for objective representations to be generated, certain presuppositions and practical procedures must be adhered to that have a normatively binding force. The stronger the claim to value neutrality, the more rigidly these procedures must bind, leaving value neutrality to become 
an ethos in its own right (Du Gay, 2000).

Although neo-liberalism as a creed may be preoccupied by a desire to maximise the potential of management in pursuing policy interventions, those in the Weberian tradition (Freidson, 1970; 2001) emphasise that the professions - who are charged with carrying out public policies - develop strategies to advance their own social status. This may involve persuading clients and potential clients about the need for the service they offer, cornering the market in that service and excluding competitors. Professionals are distinguished however by their concern to provide effective services to people rather than producing inanimate goods (Rogers and Pilgrim, 2014, p.108). What is distinctive about neo-liberalism as a mode of thought and government, however, is its desire to invert the relationship between technical rationality and substantive ethos. Where Weber saw modern rationalization and capitalism as dependent on certain ethical precepts, Hayek and his followers believed that various technical forms of quantitative evaluation could provide the conditions for and guarantee of liberal values. This technocratic turn diverts the attention of the liberal away from moral or political philosophy from credentialism and valuing of specialist knowledge and skills - and towards more mundane technical and pragmatic concerns. Prosaic market institutions and calculative devices become the harbinger of unspoken liberal commitments manifested through the employment of knowledge workers and entrepreneurial professions (Davies, 2017; Friedman, 2000).

Power has shifted too far towards big business and managerial unitarism since 1979. Politicians seduced by neo-liberal economics have enabled the dominance of a financial model of corporate governance serving shortterm profitability and shareholder value, detrimental to even minimalist industrial democracy. It now evident to parts of 'the establishment', not just to leftwing observers, that inequalities under British capitalism have contributed to exclusion and disadvantage. This disconnection influenced Brexit, though externalities of the EU and immigration were blamed. The main culprit is a failed 30-year domestic experiment with neo-liberalism and deregulated flexible labour markets'. (Dobbins, and Dundon, 2016)

\section{De-professionalisation, neo-liberalism and globalisation:}

An analytical framework for understanding the context in which a process of de-professionalisation exists assumes a neo-liberalist ideology characterised by rationalism, capitalism, technology and regulation (Scholte, 2005). These four interrelated factors are thought to have caused the expansion of globalisation. Those writing within the Marxian tradition (for example, Baumann, 1998; Edgell, 2012; Giddens, 1971) highlight the decisive role of capitalism, whereas neo-Weberians emphasise the influence of rationalism (Weber, 1976; Beder, 2000). By illustration, 
capitalism refers to a distinctive way of organising economic activity oriented to making a profit and this aspect of capitalism is regarded as a key force behind globalisation.

The unceasing concern to accumulate a surplus or fail constrains capital to seek out cheaper production sites and new markets for their products, which in practical terms means the world. (Edgell, 2012, p.222)

Whereas rationalism refers to a type of knowledge that is thought to have assisted the growth of global thinking and hence globalisation. Rationalist knowledge does not recognise boundaries based on nationhood, religion, ethnicity, and so on, and in this sense is thought to have encouraged globalisation.

Globalisation was initially seen as a threat to the welfare state. It was believed that the economic pressures generated by neo-liberal globalisation would inexorably lead to welfare state retrenchment or its dissolution and replacement by a lean 'competition' state (Cerny, 1997). Yet the global rediscovery of poverty (Noel, 2006), the challenges to territorially based conceptions of social rights posed by the increasing flow of migrants, not to mention the enhanced transactional spread of policy ideas and definitions of 'best practice' - or the reverse, a loss of autonomy in professional practice, unalloyed de-professionalisation (Demailly and De La Broise, 2009; Frostenson, 2015) - have put social policy issues on the global agenda. While neo-liberal ideas came to the fore in the UK during the 1980s, they have not been uncontested. For Deacon (2007) the battle over global social policy has come to centre on the contest between a neo-liberal emphasis on 'safety nets' for the very poor versus universal policies that include the middle class. He went so far as to suggest that:

powerful states (notably the USA), powerful organisations (such as the IMF) and even powerful disciplines (such as economics) contend with other powerful states (notably the EU, China and Brazil), other powerful organisations (such as the ILO) and other disciplines (such as social and political science) to engage in a war of position regarding the content of global policy. (p.16)

As such globalisation has become associated with the idea of de-professionalisation, defined as low productivity resulting from deskilling and where a rise in low-skilled jobs becomes blamed for static wages. Freedom of movement of labour is currently synonymous with freedom for employers to degrade pay and conditions at one end of the labour market, and freedom to asset-strip poorer economies at the other end. It does not have to be so but foreign workers would not be so attractive to employers if they could not be exploited and had to join a trade union. The position of using reserve armies of overseas labour objectively sustains exploitation and the neoliberal enterprise. 
Changes in the patterning of paid work - for instance, the combination of telephone, computer, and information and communication technologies in callcentres - has significantly augmented managerial power to a high degree; and this phenomenon can only be understood properly through the prism of globalisation. Faced with the imperative of globalisation, management constantly seek greater wage flexibility, functional and numerical flexibility. Thus, the competitive pressures associated with economic globalisation induce shifts in workforce composition and labour demand which naturally have additional impact throughout the care and education sector in the UK. It is not just routine work that is being deskilled and outsourced; the trend is for knowledge work to be Taylorized - transferring all discretion from workers to management along with the fragmentation and simplification of tasks. Contemporary globalisation has certainly put additional competitive pressure on capitalist enterprises to lower costs and be flexible in every sense, although there are major social costs and hence limitations to this neo-liberal economic project. A multi-layered perspective evaluating the effects of de-professionalisation in a specific sector will consider the changes in authority and autonomy from removing an area of activity from professional control and influence and the resultant destabilisation of a workforce (Demailly and De La Broise, 2009). Any measures taken by an employer to lessen the need within an organisation for specialist 'professional' knowledge and expertise may become experienced as a weakening of individual and collective status and may even lead to discrediting of the organisation at a national level, take for example the use of untrained workers in private G4S prisons or the reported abuse of elderly residents living in care homes.

De-professionalisation may be symptomatic of an audit culture (Power, 1999), directly linked to models of community sector funding and organisational sustainability. Critiques of neo-liberalism acknowledge the privileging of economic growth, competition and market forces whereby this ideology has been combined with managerial technologies, currently expressed in the quality systems regime which requires that organisation be continuously audited and assessed for conformance, and monitored and reviewed for effectiveness. The audit culture refers to the way in which techniques and values of accountancy have been transposed to fields beyond accounting, and have become a central ongoing principle in the governance, and management of human conduct (Shore, 2008, p.279). Shore argues that this creates new kinds of relationships, habits and practices. Thus issues of ethics and the moral behaviour of workers are not private or even organisational business, but become public through the adoption of numerous audit 'traces' (Power, 2014), including codes of conduct, risk management registers, critical incident logs, timesheets, continuous improvement records, training files, and so forth. Anthropologists Shore and Wright explain how,

Central to this process has been the re-invention of professionals themselves as units of resource whose performance and productivity must constantly be audited so that it 
can be enhanced. The discourse of audit has become a vehicle for changing the way people relate to the workplace, to authority, to each other, and most importantly to themselves. (Shore and Wright, 1999, p.559)

As was argued in the introduction (B. Theoretical Definitions), how workers experience and practice changing standards influences how professionalism is enacted. They have an imperative to act; and it is important to understand how front-line workers themselves deal with ambiguity and conflict concerning the standards for their work and what this implies for 'the fulfilment of the promise of professionalism' (Hill and Hupe, 2007). Dealing with and adapting to 'pressures 'resulting from changing standards requires workers to act either individually or collectively, the latter through for example political activism. 'Shielding, adaptation or resistance' are aimed at reconciling ambiguous standards with one's personal working identity and ambitions (Thomas and Davies, 2005). These reactions to external pressures on established professions, resulting from policy and management, have produced strategies 'to reconfigure and develop professionalism' (Noordegraaf, 2011). This becomes relevant to the de-professionalisation thesis as evidence shows that recent governments increasingly have sought to shift power away from the professions, giving them restricted access, for example through displacement measures by substituting family support workers for trained social workers, or 'qualified nursing assistants' in place of a registered nurse (Andalo, 2016). The deliberate reductions in local government funding in England since 2010 , including a $£ 4.6 \mathrm{bn}$ cut in social care funding, have become symbolic of a commodified fragmentation of the care relationship into standardised tasks that objectify the client.

\section{De-professionalisation in late modernity: A postmodern direction?}

According to Professor Ellen Kuhlmann, two key categories of professionalism serve to explore the mediating role of professions and reflexivity of change: namely, trust and knowledge. Both categories are cornerstones of professional power and also of the functioning of societies, and are embedded in new models of governance, specifically medical practice.

The developments enhance complex shifts in the balance of power in health care that move beyond the impact of marketisation and bureaucratic regulation and the discourse on consumerism. ... [This] has given rise to diverse patterns of professionalism in late modernity and opened windows of opportunity for the improved participation of citizens and accountability of professions without, however, radically reducing the power of the medical profession to shape and reshape these processes of change. (Kuhlmann , 2006, p.179) 
This form of power entrenchment may not apply so much in the case of other professional groups, for example teachers, social workers and allied health professionals who are possibly more vulnerable and where a similar process of deconstruction and questioning of identity emerges. Medical professionals perhaps need to understand that in the 21st century they are not the only people with education and skills, and that even they must adjust their expectations to allow the NHS to live within its means. A narrative constructed around a 'plurality of professionalisation processes and their obverse as an counterpart' (Kuhlmann and Saks, 2008) engenders a loss of autonomy and subordination to external supervision due to new public policy directions, organisational change or daily work routines. According to Professor Malcolm Williams, one of the ironies of postmodernism is that to describe what it is, is to describe a unified system of thought, or movement, referred to as a 'meta-narrative'. It sees all realities as socially constructed, as are the interpretations of those constructions, for example the notion of deprofessionalisation might involve the dismantling of a professionalisation process in a somewhat haphazard and disjointed fashion. In contrast the concept of a professional project conventionally works through different chronological stages towards professionalisation - the starting point, the overall objective, sub-goals, other actors and context (see Macdonald, 1995, pp.187-208).

This rejection of truth extends to all spheres, including scientific truths and, crucially, moral truths. Thus postmodernism is morally and culturally relativist, which means that postmodernists not only reject the idea that there is some objective, a-historical framework to which we can appeal in matters of knowledge or rationality, but also in terms of what is morally right or good. (Williams, 2016, p.167)

Within this melange of approaches used to encapsulate the meaning of deprofessionalisation it is relevant to consider how a de-construction process becomes demonstrated through a 'lived -in form' embodying a series of features like trust, knowledge, power or autonomy. As stated earlier the notion of trust as a 'signifier' of trustworthiness serves as part of the mediating role of professionalism and indeed may represent a cornerstone of professional power. When trust is seen as a dynamic rather than a static dimension of professionalism, then new forms of assessing the quality of provision and users' calls for informed and self-determined decisions are not necessarily signals of distrust. The regulatory power of trust in health and social care is directly related to the normative strength of an expert knowledge system (Allsop and Saks, 2002, p.6).

From a sociological point of view, Simmel was one of the first to identify trust as the 'most important synthetic force in society' (1950, p.326). In recent years different authors have confirmed its growing significance in modernisation processes (for instance, Coleman, 1990; Giddens, 1991) in society at large, and in changes in public services in particular. Coulson describes trust as the 'foundation of public sector 
management' (1998, p.3). Evidently trust became endemic to partnership-working as a background to New Labour 'Third Way' politics. This involved opportunity, responsibility and community as the central rhetorical trinity (White, 2004) to be based on ideas of asset-based egalitarianism, welfare contractualism, re-engineering public services, mutualism and the re-engagement of civil society. Partnershipworking among separate agencies was noted as laying emphasis on trust, mutual benefit and reciprocity as highly relevant, thereby potentially acting wherein the whole becomes greater than the sum of the parts. Considering trust as an endemic attribute, partnership is viewed as an organisational arrangement with normative rules, determining what behaviour is permissible and what constitutes a violation of trust (Gambetta, 1998, p.206). For instance, when trust breaks down there are consequences for how the public may perceive the actions of a professional group.

As an interactive category, trust has a considerable influence on the communication between professionals and clients and determines the quality and efficiency of the service provided. The capacity of trustworthy relations between physicians to enhance change is clearly borne out by the improvement of cooperation, and teamwork in health care. Nurturing a culture of trust at the organisational level can optimise the efficiency of the providers and their working methods (Kuhlmann, 2006. p.186). De-professionalisation becomes represented through a decline of trust where certain policies and organisational changes have negative effects on professional performance, according to Harrison and Smith (2004). These authors put changing patterns of regulation in health care in the context of modernisation processes, and explore four elements in relation to trust: 'surveillance' (inspection, monitoring and evaluating performance), 'bureaucracy' (governing performance with rules and procedures), 'instrumentality' (evidence-based practice) and 'consumerism' (empowering service users). Their conclusion is to view confidence, positioned at the centre of policy initiatives, and trust, positioned at the periphery, as opposite ends of the scale.

... the modernisation agenda privileges confidence over trust and neglects the relationship between trust, moral motivation and uncertainty. This has important consequences for service providers and service users. (2004, p.375)

Building trust in delivery of health and social care remains vital; and certainly this cannot be taken for granted. In the ongoing strike action carried out by junior doctors in the English NHS; de-professionalisation as a corrosive process represents a cover or compromise of the doctors relationship with the public which undermines trust and ultimately impacts on how they are viewed by the public. The pretence that the 'new' imposed contract will enable seven-day working undermines trust as, it is alleged, junior doctors already provide emergency care every day and without more doctors or increasing working hours this cannot be achieved. The medical profession now has to justify the placing of trust and compete for it with other 
experts with much competition taking place within the profession. Data show that physicians' qualifications and the traditional biomedical expert system - while still important - no longer guarantee a sufficient basis for trust building. Professionalism and managerialism are increasingly merging as more resources for building trust are developed. New tools of bureaucratic regulation and performance indicators fulfil this function as signifiers of quality integrated into individual professional practices. Such processes may be looked upon progressively or regressively, depending on whether such interventions are deemed as either valuable or obstructive - see for example the UK universities Teaching Excellence Framework (TEF) where evidence-gathering by higher education institutions relating to 'up-skilling of local communities is probably more relevant than ever' (Murphy, 2015, p.59-90)

Expression of a new technology of building trust via information under conditions of uncertainty and a 'risk society' (Beck, 1986) inevitably produces new dynamics and tensions reducing the existing power gaps in health and social care and giving rise to different social inequalities. For example unequal access of professions and occupations to the resources of 'legitimising information' via clinical, pedagogic or social scientific evidence may reinforce the division of labour or produce new divisions. This would become evident in expressing the notion of de-professionalisation as manifested through downgrading the quality and content of professional training programmes which require underpinning by evidence-based research in order to keep up to date. A high number of national and local reviews of nurse and allied health training, both past and present, have been influenced by the 'political economy model' of delivering public services, namely that which is shaped by the needs or demands of a market economy, business or industry. This includes national education policy which reveal for example, a changed focus as regards current plans for social work training and by implication a downgrading of professionally-constructed knowledge sources. Here government bodies, such as the Departments for Health and for Education, have become heavily involved

in setting out the knowledge and skills that social workers need for effective practice, [along with] a regulator with an undiluted focus on social work who has those standards in mind as they (including the two government appointed chief social workers) consider social work careers from initial education through to practice leadership. (quoted from letter by Edward Timpson MP, previously Conservative Minister of State for Children and Families)

A second attribute of professionalism, namely the 'knowledge-power knot' Kuhlmann, 2006, pp.199-217) establishes a link between power and knowledge based on formalised codes and rationalised technique; and became a key issue in the work of Foucault $(1979,1980)$ with his concept of governmentality. Several writers take this concept on board and focus on the capacity of knowledge technologies, via audits and suchlike, to govern at a distance and assess the activities of experts 
(Dean, 1999, Adcroft and Willis, 2006; Lehmann-Nielsen, 2015). Foucault (1980) writes that social analysis entails examining a

heterogeneous ensemble consisting of discourses, institutions, architectural forms, regulatory decisions, laws, administrative measures, scientific statements, philosophical, moral and philanthropic propositions - in short the said and the unsaid.

In particular he was concerned with mapping out discourses associated with particular social periods and places. This notion of discourse includes both forms of knowledge and the practices associated with that knowledge, hence providing a different way of looking at applied knowledge in professional work. Foucauldians (for example Lyotard 1984; Rosenau, 1991) appear to have no notion of a clear or stable power discrepancy between professionals and clients or between dominant professions and subordinate ones. Power is dispersed, it cannot be simply and easily located in any elite group. For instance, ways in which the person (the body and mind of the individual) is now described or constructed (measured, analysed and codified) are central features of contemporary society. Health and social care professions have had a central part in this regard with their interests in diagnosis, testing, assessment and observation and the treatment, management and surveillance of sick and healthy bodies in society. This idea of de-professionalisation resonates with the failure to endorse the notion of a self-conscious collective activity of professionals, to advance their own interests or to act on behalf of the capitalist state (Rogers and Pilgrim, 2014, p.111).

Whereas the social construction of individual and collective autonomy at work has taken a multiplicity of forms, de-professionalisation has come to be regarded as a function or by-product of a normally hierarchic process where certain jobs have become vulnerable, subordinate and professional identity scapegoated. The ambivalence incorporated in the concepts of consumerism and evidence-based policy and practice opens up various ways for a professional group to make use of new claims on legitimate knowledge without radically changing the balance of power. For instance consumerism and scientific- bureaucratic medicine introduce new criteria of legitimate knowledge and incite competition between different knowledge systems. Professional dominance is a key feature of the neo-Weberian model and focuses on ways in which different groups of professionals exercise power over others: they have power over their clients; they exercise power over their new recruits; and they seek to establish a dominant relationship over other occupational groups working wit the same clients (Rogers and Pilgrim, 2014, p.109). Building strategies to advance their own social status and to corner the market constitutes a progressive force, whereas in contrast a dissolution of this position may create uncertainty.

Bringing users into the matrix contributes to the extension of knowledge and 
confronts biomedical knowledge with new perspectives of lay knowledge. Titles and qualifications, which formerly gave access to market power and state protection, no longer guarantee these privileges. Against the backdrop of marketisation, for example as regards health and social care, there is an increasing need for reliable data to allow for informed decisions and to improve the safety of patients and the public at large. This offers opportunities and challenges as it creates an arena of competition where there are winners and losers. The explored changes in the building of trust confirm that nowadays the effectiveness and efficiency of the formalised expert system have to be justified using tools borrowed from management, and the 'embodied' knowledge of practitioners needs the proof of scientific bureaucratic medicine. Bringing together the different approaches and findings on knowledge and power reveals that medical and research knowledge in general is not just a powerful resource and a masquerade for professional dominance, but a 'creeper' that crosses boundaries capable of shaping and reshaping social structure, culture and action and even individual 'feelings' and agency' (Kuhlmann and Saks, 2008, p.206).

Increases in productivity are as a result of deploying better raw materials, better trained or educated labour or better machines. De-professionalisation evokes images of lacking an opportunity to demonstrate initiative, control or authority within the workplace. Hypothetically, the more that an agency becomes characterised as having a neo-liberal outlook or working within a political economy model the less it may tend towards recruiting 'over-qualified' employees and incentivising staff to pursue additional professional or specialist qualifications. What has been described is an intense bureaucratisation of the semi-professions. For instance, in the UK as regards nursing, this led to a decline in on-the-job skills, a rise in preoccupation with paperwork and procedures, and an atrophying of sympathetic and caring attitudes. The UK experience is typical as Project 2000 was an initiative to professionalise nursing, which moved training out of hospital-based nursing schools and into universities. However there were two pernicious effects: firstly, the new training has left some nurses more confident in theory than in practice; and secondly, the removal of student nurses from ward teams created a hole in the workforce that was filled by a new cohort of people called health care assistants.

Similarly the contemporary university is mired in auditing, regulation, waste and aimlessness, and its contribution to serious social innovation has deteriorated markedly. They are in reality teaching institutions, that is de facto colleges or institutes. They principally function to transmit knowledge, not to create knowledge. The miserable state of the universities reflects a larger social reality, as bureaucratic capitalism has replaced creative capitalism (Murphy, 2015). Most professions now recognise that learning and professional development are lifelong. There is a national social policy climate embracing a narrative where public services - be it health, social care, education, housing or prison services - have been gradually taken over by 'high performing' authorities and 'teams of experts'; granting autonomy and freedom to individual entrepreneurs to act on behalf of the 
state. This quiet revolution draws upon the language of outcome measurement, demoralised professional and occupational groupings and buttressed by unorthodox and contentious evidence.

\section{References}

Adams, R (2017) Thousands of schools in England face big budget cuts, unions warn. The Guardian, January 4th

Adcroft, A and Willis, R (2006) Postmodernism, De-professionalisation and Commodification (The Outcomes of Performance Measurement in Higher Education), Journal of Finance and Management in Public Services, 6, 1 43-60

Age UK (2016) The End of Formal Adult Social Care? (Author: Ben Franklin) London: Age UK Allen, K (2016) Women still far adrift on salary and promotion - average gender pay gap now $18 \%$ and widens after women have children. The Guardian March 8th.

Allen, K (2017) In just 28 hours, top bosses are paid more than a typical salary. The Guardian, January 4 th

Allsop, J and Saks, M (Eds) (2002) Regulating the Health Professions. London: Sage

Alzheimer's Society (2016) Dementia UK-Help Us Be There For Families. www.dementiauk.org

Andalo, D (2016) New nursing qualifications and apprenticeships boost care workers' credentials. Society Guardian, 3 November

Arblaster, A (1985) The Rise and Decline of Western Liberalism. Oxford: Blackwell

Arblaster, A (2002) Democracy. (3rd ed.) Milton Keynes: Open University Press

Baumann, Z (1998) Work, Consumerism and the New Poor. Milton Keynes: Open University Press

Bawden, A (2016) Foster carers vote to unionise over pay. The Guardian, September 21st

Beatty, C and Fothergill, S (2013) Hitting the Poorest Places Hardest: The local and regional impact of welfare reform. Sheffield: SHU, Centre for Regional Economics and Social Research. (www.shu.ac.uk/research/crest/sites/shu.ac.uk/files/hitting-poorest-placeshardest_ 0 . pdf)

Beck, U (1992) Risk Society: Towards a new modernity. London: Sage

Beder, S (2000) Selling The Work Ethic: From puritan pulpit to corporate PR. London: Zen Books Beland, D (2007) The social exclusion discourse: Ideas and policy change. Policy and Politics, 35, $1,123-39$

Beveridge Report (1942) Social Insurance and Allied Services. London: HMSO

Blakemore, Kand Warwick-Booth, L (2013) Social Policy: An introduction.(4thed.) Maidenhead: Open University Press

Bochel, H and Daly, G (eds, 2014) Social Policy. (3rd ed.) Oxford: Routledge

Boffey, D (2015) Schools 'must share teaching staff if they are to survive'. Head teachers' leader calls for a united solution to recruitment crisis. The Observer, May 3rd

Bonoli, G and Natali, D (2012) The Politics of the Welfare State. Oxford: Oxford University Press 
Bourdieu, P (1984) Distinction: A Critique of the social judgement of Taste. London: Routledge Boyle, D, Coote, A, Sherwood, C and Slay, J (2010) Right Here, Right Now. Taking coproduction into the mainstream. London: NESTA. www.nesta.org.uk

Braverman, H (1974) Labour and Monopoly Capital: The degradation of work in the 20th century. New York: Monthly Review Press

Brignall, M (2016) Huge differences in youth unemployment across UK. The Guardian, May 15 th

Brindle, D (2015) Fears of benefit cap for older people if councils take charge. The Guardian, 17 th December.

Brindle, D (2016) 'Bold reforms' but only in children's social work. The Guardian, January 27th

BMA (2016) End of Life Care and Physician-Assisted Dying. London: BMA. https://www.bma. org.uk/elcpad\%20report\%vol\% 203\% 20 March 2016 pdf

BMA (2016) Training Needed to Meet Patients'End-Of-Life Care Needs. 14 March. http:?//www.bma.org.uk BMA-Press Releases http:?//www.bma.org.uk>News> Media Centre. Press releases 28th September 2016

Brockling, U (2016) The Entrepreneurial Self: Fabricating: A New type of subject. London: Sage

Butler, I and Drakeford, M (2005) Scandal, Social Policy and Social Welfare. Bristol: The Policy Press

Butler, I and Drakeford, M (2011) Social Work On Trial: The Colwell Inquiry and the state of welfare. Bristol: The Policy Press

Butler, P (2016) Ministers ignored repeated warnings on Kids Company. The Guardian, February 21st

Callender, C (2012) Lifelong learning and training. in Alcock, P, May, M and Wright, S (Eds) 345-351, The Student's Companion to Social Policy (4th ed.) Oxford: Wiley-Blackwell

Campbell, D (2015a) Prestigious hospital in special measures over staff shortage: CQC says safety being put at risk at Addenbrooke's, The Guardian, September 22nd

Campbell, D (2015b) Seven-day NHS pledge doomed to fail, warns doctors' chief. The Guardian, October 14th

Campbell, D (2015c) NHS bosses' letter on staffing sparks fears for patient safety. The Guardian, October 16th

Campbell, D (2015d) Social care cuts leave 1 million pensioners struggling. The Guardian, October 21 st

Campbell, D (2015e) NHS 'wall of silence' hampers investigation of complaints. The Guardian, December 8 th

Campbell, D (2015f) Rationing in NHS hitting patient care, say doctors. The Guardian, December 9th

Campbell, D (2015g) Hospitals told to shed staff as NHS funding crisis deepens. The Guardian, December 15 th

Campbell, D (2016a) NHS plans to hire Indian GPs to plug gaps in services: Ministers have failed to develop home-grown staff. The Guardian, April 8th

Campbell, D (2016b) Hospital with troubled A\& E admits to four deaths after errors. The Guardian, June 18th 
Campbell, D (2016c) NHS chief says junior doctors' walkouts may put seriously ill at risk. The Guardian, September 8th

Campbell, D (2016d) NHS hospitals so full patients discharged too soon, say MPs. The Guardian, September 28th

Campbell, D (2016e) Mental health nursing numbers in sharp fall. The Guardian, November 2nd

Campbell, D (2016f) Top GP urges Tories to drop seven-day plan. The Guardian, December 15 th

Campbell, D (2017) Biggest headache for NHS boss is own plan. The Guardian, February 1st

Campbell, D and Bawden, A (2016) Thousands of beds to go in NHS shake-up: major centralisation in England. The Guardian, 19th November

Campbell, D and Johnson, S (2016) Hunt's cuts force NHS watchdog to reduce inspections: Hospitals and care homes to undergo less scrutiny. The Guardian, May 24th

Campbell, D and Siddique, H (2016) Junior doctors strike for first time in 40 years as lastditch talks end in deadlock: poll findings reveal 66\% public support for action. The Guardian, January 12th

Care Act (2014) London: The Stationery Office

Care Quality Commission (CQC)(2012) The State of Health Care and Adult Social Care in England in 2011/12. https://books.google.co.uk/books?isbn=0102981078

Care Quality Commission (CQC) (2015) Welcome to 2015! Care Quality Commission- Medium -CQC www. cqc.org.uk/content/welcome-2015 (CEO Andrea Sutcliffe quote)

Care Quality Commission (CQC) (2015) Report: Addenbrookes and the Rosie Hospitals Quality Report. 21st April. https://www.cqc.org.uk/sites/default/files/new_reports/AAADO111. pdf

Care Quality Commission (CQC) (2015) Annual Report 2014/15. Care Quality Commission July 21st, www.cqc.org.uk/content/annual-report-201415

Care Quality Commission (CQC) (2016) Shaping The Future: Consultation document. CQC. January 1st www.cqc.org-uk/sites/default/files/20160119_strategy \% 20 consultation _final_web.pdf

Care Quality Commission (CQC) (2016) CQC tells Brighton and Sussex University Hospitals NHS Trust to improve services. www. cqc.org.uk/cqc-tells-brighton-and-sussexuniversityhospitals-nhs-trust-improve-services. July 14th

Care Quality Commission (CQC) (2016) Brighton and Sussex University Hospitals NHS Trust. CQC. August 17th https://www.cqc.org.uk/provider/RXH

Care Quality Commission (CQC) (2016) State of Care Report warns adult social care is approaching a tipping point. CQC. www.cqc.org.uk//state-care-report-warns-adultsocial - care-approaching a tipping point. October 13th

Care Quality Commission (CQC) (2016) St George's CQC inspection report published?St George's Healthcare. November 1st

Care Quality Commission (CQC) (2016) CQC launches consultation on its next phase of regulation. December 20th www.cqc.org.uk/content/cqc-launches-consultation-its -nextphase- regulation 
Carter, P (2016) Interview: Peter Carter, former RCN Chief Executive, www.nursinginpractice. com/professional. August 11th

Casey, L (2014) The National Troubled Families Programme. Social Work E Social Sciences Review, 17, 2, 57-62

Cerny, P (1997) Paradoxes of the competition state: Dynamics of political globalisation. Government and Opposition, 32, 2, 251-274

Chakrabortty, A (2016) We're watching the death of neoliberalism - from within The Guardian, March 14th

Chakrabortty, A (2017) 'We need the state now more than ever. But our belief in it has gone' The Guardian, February 1st

Chamberlain, J. M. (2015) Medical Regulation, Fitness to Practice and Revalidation: A critical introduction. Bristol: The Policy Press

Chartered Institute of Personnel Development (CIPD) (2016) Graduates are 'colonising' jobs that don't require degrees, says CIPD. www2.cipd.co.uk/graduates-are-colonising-jobsthatdon't- require-degrees-says-cipd. October 11 th

Clarke, J and Newman, J (1997) The Managerial State: Power, politics and ideology in the remaking of social welfare. London: Sage

Clarke, J, Newman, J, Smith, N, Vidler, E and Westmarland, L (2007) Creating CitizenConsumers: Changing publics and changing public services. London; Sage

Clarke, R (2016) These leaks show Hunt's deception on the seven-day NHS. The Guardian, August 23rd

Clay, F (2016) 'We have to convert the pressure and frustration to a sense of possibility': NHS boss calls for new deal to care for the old The Guardian, January 19th

Coleman, J (1990) Foundations of Social Theory. Oxford: Oxford University Press

College of Social Work, England (2011) Professional Capabilities Framework. Available from: www.tcsw.org.uk/home

Coulson, M (1998) Collaboration and Trust in Health Care Innovation, in Calnan, M and Rowe, R Trust Relations in the 'New' NHS: Theoretical and methodological challenges. 'Taking stock of Trust' ESRC Conference. LSE

Croisdale-Appleby, D (2014) Re-visioning Social Work Education: An independent review. February, London: DfE

Crossley, S (2016) 'The Troubled Families Programme: In, for and against the state?' in Fenger, M, Hudson, J and Needham, C (eds), Social Policy Review 28: Analysis and Debate in Social Policy, Bristol: The Policy Press

Crossley, S and Lambert, M (2017) Introduction: 'Looking for Trouble?' Critically examining the UK Government's Troubled Families Programme, Social Policy and Society, 16, 1, 81-85

Daly, M (2015) Parenting Support as Policy Field: An Analytic Framework. Social Policy and Society, 14:4 597-608

Daly, M and Bray, R (2015) Parenting support in England: The bedding down of a new policy. Social Policy and Society, 14:4 633-644

Daly, M and Kelly, G (2015) Families and Poverty: Everyday life on a low income. Bristol: The Policy Press 
Dandridge, N (2016) Higher Education Roundtable on Social Action, 11 May \#iwill campaign, Universities UK

Dandridge, N (2016) Universities need to share ideas on how to help poorer pupils. www. yorkshirepost.co.uk//universities-need-to-share-ideas-on-how-to-help-poorer-pupils, October 10th

Davies, W (2017) The Limits of Neoliberalism: Authority, sovereignty and the logic of competition. (Revised ed.) London: Sage

Davis, M (1980) A Multidimensional approach to individual differences in empathy. JSAS Catalog. Of Selected Documents in Psychology, 10, 85

De Zulueta (2013) Compassion in 21st century medicine: Is it sustainable? Clinical Ethics, 8: $119-128$

Deacon, B (2007) Global Social Policy aAnd Governance. London: Sage

Dean, M (1999) Governmentality: Power and Rule in Modern Society. London: Sage

Dearing Report (1997) The National Committee Of Inquiry Into Higher Education: Report Of The Committee. London: HMSO

Demailly, L (2003) L'evaluation de l'action 'éducative comme apprentissage et négociation. Revue française de Pedagogie, 142, 1, 115-129

Demailly, L and De La Broise, P (2009) Les enjeux de la de-professionalisation; Études de cas et pistes de travail. Socio-Logos, Revue De l'Association française de Sociologie, 4.online. 7 May. http://socio-logos.revues-org/2305

Demello, S and Furseth, P (2016) Innovation and Culture in Public Services: The case of independent living. Cheltenham: Edward Elgar Publishing

Department of Communities and Local Government (DCLG) (2012) Working With Troubled Families. London: DCLG

Department of Communities and Local Government (DCLG) (2013) Troubled Families Programme receives extra $£ 200$ million boost. 24 June

Department of Health (DoH) (1988) Working For Patients. Cm 555. London: HMSO. http://www.gov.uk/government/news/troubled-families-programme-receives-extra200million-boost

Department of Health (DoH) (2012) Transforming Care: A national response to Winterbourne View Hospital. London: DoH

Department of Health (DoH)(2013) Prime Minister Responds to Mid-Staffs Public Inquiry Report. 14 April. https://www.gov.uk/government/news/prime-minister etc Department of Health (DoH)(2016) Implementing The Five Year Forward View For Mental Health. February 1st https://www.england.nhs.uk/wp./2016/02/Mental-Health-Taskforce- FYFVfinal.pdf

Department of Health (DoH)(2016) full CQC press release - Colchester Hospital. July 15thwww.colchesterhospital.nhs.uk/CQC\%20PRESS\%20RELEASE\%2014\%20July\%20 20 Department of Health (DoH)(2016)- GOV.UK

Department of Health and Social Security (DHSS) (1972) Report of the Committee On Nursing. The Briggs Report. London: HMSO. https://www.gov.uk/government/organisations/ department-of-health. December 15th 
Department of Health and Social Security (DHSS) (1986) Neighbourhood Nursing: A focus for care. (Report of the Community Nursing Review) London: HMSO

Dixon, J (2015) The NHS has social objectives as well as economic ones: Can we reconcile them? The Observer, November 8th

Dobbins, T and Dundon, T (2016) The Chimera Of Sustainable Labour-Management Partnership' British Journal of Management. DOI:10.1111/1467-8551.12128

Donaldson, Sir L. (2006) Good Doctors, Safer Patients: A Report by the Chief Medical Officer. DoH: London

Du Gay, P (2000) In Praise Of Bureaucracy: Weber, organisation and ethics. London: Sage

Edgell, S (2012) The Sociology of Work: Continuity and change in paid and unpaid work. (2nd ed.). London: Sage

Edmond, N and Price, M (Eds.) (2012) Professionalism in the children and young people's workforce. in Integrated Working with Children And Young People. London: Sage (pp. 29-45)

Elgot, J and Campbell, D (2016) Seven-day NHS 'might not cut deaths'. Report casts doubt on key point in dispute. The Guardian, February 16th

Elliott, L (2015) Poorest parts of Britain face 40\% public sector jobs cut. The Guardian, June 12 th

Elliott, L (2015) Corbyn has the vision, but his numbers don't yet add up. The Guardian, August 21st

Elliott, L (2015) Rise in low-skilled jobs blamed for static wages. The Guardian, September 24th

Elliott, L (2016) End drive to send more to university, say HR experts. The Guardian, February 10th

Elliott, L and Allen, K (2017) UK faces return to inequality of Thatcher years. The Guardian, February 1st

Esping-Andersen, G (2002) A child-centred social investment strategy. in: Esping- Andersen, G, Gallie, D, Hemerjk, A and Myers, J (Eds.) Why We Need A New Welfare State. Oxford: Oxford University Press, (pp.26-67)

Evans, T (2013) Organisational rules and discretion in adult social work. British Journal of Social Work, 43, 4, 739-758

Evans, T (2015) Professionals and discretion in street-level bureaucracy. in Hupe, H, Hill, $\mathrm{M}$ and Buffat, A (Eds) Understanding Street-Level Bureaucracy Bristol: The Policy Press (pp., 279-294)

Evett, J (2009) New professionalism and new public management: Changes, continuities and consequences, Comparative Sociology, 8, 2, 247-266

Farrell, S (2016) MPs report demands industrial policy to close gender pay gap. The Guardian, March 22nd

Flynn, M (2012) Winterbourne View Hospital: A Serious Case Review. Gloucester: South Gloucestershire Safeguarding Adults Board

Foucault, M (1979) About the concept of the 'dangerous individual' in 19th century legal psychiatry. International Journal of Law and Psychiatry, 1, 1-18

Foucault, M (1980) Power/Knowledge. Brighton: Harvester

Fournier, V (2000) Boundary Work And The (Un)making Of The Professions. in Malin, 
N (Ed.) Professionalism, Boundaries and the Workplace.. London: Routledge (pp. 67-86)

Francis, R (2013) Report Of the Mid-Staffordshire NHS Foundation Trust Public Inquiry. London: The Stationery Office

Freidson, E (1970) Profession Of Medicine: A study in the sociology of applied knowledge. New York: Dodd, Mead \& Co.

Freidson, E (2001) Professionalism: The 3rd Logic. Cambridge: The Polity Press (in particular Chapter 1: Professional Knowledge and Skill, pp.18-41)

Friedman, T (2000) The Lexus and the Olive Tree. London: Harper Collins

Frostenson, M (2015) Three Forms Of Professional Autonomy: De-professionalisation Of Teachers in a New Light, in Autonomy in Education. NordSTEP, Nordic Journal of Studies in Educational Policy. July 3rd. 1: 28464

Gambetta, D (Ed.) (1988) Trust: Making and breaking cooperative relations. Oxford: Blackwell Gani, A (2015) It's not just about pay, it's about the future of the NHS. The Guardian, October 17 th

Garrett, P.M (2009) 'Transforming' Children's Services: Social work, neoliberalism and the 'modern' world. Maidenhead: Open University Press

Garrett, P.M (2014) Children and Families (Critical and Radical Debates in Social Work) Bristol: The Policy Press

Garson, B (1988) The Electronic Sweatshop: How computers are transforming the office of the future into the factory of the past. New York: Simon \& Schuster

Gayle, D (2016) 'Women's refuges put at risk by benefit changes', says charity. The Guardian, May 18th

Giddens, A (1971) Capitalism and Modern Social Theory: An analysis of the writings of Marx, Durkheim and Max Weber. Cambridge: Cambridge University Press

Giddens, A (1991) Modernity and Self-Identity. Cambridge: Polity Press

Gilbert, N (2002) Transformation Of The Welfare State: The silent surrender of public responsibility. Oxford: Oxford University Press

Glasby, J and Daly, G (2014) Adult health and social care, in Bochel, H and Daly, G (Eds.) Social Policy. (3rd ed.) 277-297. London: Routledge

Grant, L and Kinman, G (2013) The Importance of Emotional Resilience for Staff and Students in the Helping Professions. York: The Higher Education Academy

Grant, L and Kinman, G (2014) Developing Resilience for Social Work Practice. London: Palgrave Macmillan

Gray, A.M and Birrell, D (2013) Transforming Adult Social Care: Contemporary policy and practice. Bristol: The Policy Press

Greer, S, Wismar, M and Figueras, J (Eds.) (2016) Strengthening Health System Governance: Better policies, stronger performance. Maidenhead: McGraw-Hill

Guardian.letters@The Guardian.com 23rd December, 2016

Ham, C (2016) Plenary 3: Delivering Better Value in the NHS/NHS Scotland Event. nhsscotlandevent.com/event/2016/plenary-session-3

Ham, C (2016) An Interview With Chris Ham, Chief Executive of the Kings Fund -BMJ Blogs blogs.bmj.com//2016/11/an-interview-with-chris-ham-chief-executive-of -the-kingsfund 
Harris, J (2016) Class action and special measures. The Guardian, G2 October 1lth Harrison, S and Smith, C (2004) Trust And Moral Motivation: Redundant resources in health and social care. Bristol: The Policy Press

Hayek, F. von (1944) The Road To Serfdom. London: Routledge

Health and Care Professions Council (HCPC) (2012) Standards Of Proficiency-Social Workers In England. London: Health and Care Professions Council. Available at: www.hpcuk. org/ publications/standards/index.asp?id

Heywood, A (2000) Key Concepts In Politics. Basingstoke: Palgrave Macmillan Hill, A (2017) 'New' adults will add to care crisis. The Guardian, January 25th Hill, M and Hupe, P (2014) Implementing Public Policy. (3rd ed.) London: Sage Howard, E (2016) Going into legal aid work now is career suicide. Society Guardian January 6th Hunt, J (2014) 'Francis Effect' on NHS care one year on from Mid-Staffordshire Inquiry. Press release via Department of Health (DoH) Gov.uk https://www.gov.uk/../francis-effectonnhs-care-one-year-on-from-mid-staffs-inquiry. February 6 th

Hunt, J (2016) Jeremy Hunt skips all 7 NHS crisis meetings in his department despite... 13 September. www.mirror.co.uk.News. Pre-release access request-NHS Improvement https://improvement.nhs.uk/Pre_Access_List_OPSIR_28_September_2016_pdf

Hunt, T (2016) Inequality: A problem schools alone can't fix. The Guardian, January 12th

Inman, P (2016) Workers on zero-hours lose $£ 1,000$ a year, a study shows. The Guardian,

December 30th

Jay, P (1979) Report Of The Committee Of Enquiry into Mental Handicap Nursing and Care. Vols I and II (Cmnd 7468). London: HMSO

Jordan, B (2001) Tough love: Social Work, Social exclusion and The Third Way, British Journal of Social Work, 31, 4, 527-546

Joseph Rowntree Fund (JRF) (2016) Children's centres on their own cannot protect families against poverty, www.nurseryworld.co.uk. Working Paper prepared by Prof. Eva Lloyd, University of East London

Joseph Rowntree Fund (JRF) (2016) Creating An Anti-Poverty Childcare System -Joseph Rowntree Foundation https://www.jrf.org.uk/file/48799/download? token=WExVHJF_\& file type...report by Adam Butler and Jill Rutter, Family and Child Care Trust

Kelly, S (2015) The 'atomised' council is here to stay, stripped back to the most basic services. The Guardian, December 2nd

Kirkpatrick, I, Ackroyd, S and Walker, R (2005) The New Managerialism and Public Service Professions. Change in health, social services and housing. New York: Palgrave Macmillan

Kitzinger, J (2000) Media templates: Patterns Of Association And The (Re) construction Of Meaning Over Time. Media, Culture E Society, 22, 1, 61-84

Klein, R (2010, 6th Edition) The New Politics of The NHS: From creation to reinvention. Oxford: Radcliffe Publishing

Knights, R (2015) The many reasons why there's a teacher shortage. Guardian.letters@ theguardian.com October 13th

Kuhlmann, E (2006) Modernising Health Care: Reinventing professions, the state and the public. Bristol: The Policy Press 
Kuhlmann, E and Saks, M (Eds.) (2008) Rethinking Professional Governance: International directions in health care. Bristol: The Policy Press

Lacey, P (2001) Support Partnerships: Collaboration in action. London; David Fulton

Lambie-Mumford, H (2015) Britain's Hunger Crisis: Where's The Social Policy? in Irving, Z, Fenger, M and Hudson, J (Eds.) Social Policy Review 27. Bristol: The Policy Press

Laming, H (2009) The Protection Of Children In England: A Progress Report. London: House of Commons

Larson, M (1977) The Rise of Professionalism: A sociological analysis. London: University of California Press

Lavalette, M (2011) 'Introduction' in Radical Social Work Today: Social work at the crossroads. Bristol: The Policy Press

Lehmann-Nielsen, V (2015) Law enforcement behaviour of regulatory inspectors. in Hupe, P, Hill, M and Buffat, A. (Eds.) Understanding Street-Level Bureaucracy Bristol: The Policy Press (pp.115-132)

Leonard Cheshire Disability Organisation (2016) Care Homes, Adult Day Care Centres. http: www/carehome.co.uk/care_search_results.cfm/searchgroup/36151005LEQA

Leonard Cheshire Disability Organisation (2016) file-datasets-IATI Registry. https://www. iatiregistry.org/dataset/lcd_admin-org

Lightfoot, L (2016) Nearly half of teachers plan to leave in next five years. Survey shows huge numbers of staff in England at breaking point over their workload. The Guardian. com/teacher-network. Guardian Teacher Network Survey, March 22nd

Lipsey, R (1979) An Introduction to Positive Economics. (5thed.) London: Weidenfeld \& Nicolson Lipsky, M (1980 and 2010 versions) Street-Level Bureaucracy: Dilemmas of the individual in public services. (30th anniversary expanded ed.) New York: Russell Sage Foundation

Lister, R (2015) Poverty Beyond The Statistics by Professor Ruth Lister. YouTube February 20th https://www.youtube.com/watch/=MuV99KqKU4u Uploaded by the British Academy;

Lister, R (2016) Poverty: Key concepts. London: Sage

Lowton, K, Hiley, C and Higgs, P (2017) Constructing embodied identity in a 'new' ageing population: A qualitative study of the pioneer cohort of childhood liver transplant recipients in the UK. Social Science \& Medicine, 172, 1-9.

Lyotard, J (1984\{1979\}) The Postmodern Condition: A report on knowledge. Minneapolis: Minnesota University Press

MacDonald, K.M (1995) The Sociology of the Professions. London: Sage

Mahon, R (2013) Social Investment According To The OECD/DELSA: A Discourse In The Making. Global Policy, 4 (2) 150-59

Malin, N, Manthorpe, J, Race, D and Wilmot, S (1999) Community Care for Nurses and the Caring Professions. Buckingham: Open University Press

Manthorpe, J (1999) Carers' perspectives: Do services support carers? in Malin, N, Manthorpe, J, Race, D and Wilmot, S Community Care for Nurses and the Caring Professions. Buckingham: Open University Press (pp. 138-144)

Manthorpe, J (2002) Community care and family policy. in Malin, N, Wilmot, S and Manthorpe, J Key Concepts and Debates In Health and Social Policy. Buckingham: Open 
University Press (pp. 110-122, )

Marston, G and McDonald, C (2012) Getting beyond 'heroic agency' in conceptualising social workers as policy actors in the twenty-first century. British Journal of Social Work, 42, , 6, 1022-1038

Mason, R (2016) Ministers to focus on struggling families. The Guardian, November 19th

Mason, R and Adams, R (2015) Tory education plans 'are election gimmicks'. The Guardian, February 2nd

McKenzie, L (2016) Narrative, ethnography and class inequality: Taking Bourdieu into a British council estate. in Thatcher, J, Ingram, N, Burke, C and Abrahams, J (Eds.) Bourdieu: The Next Generation. Oxford: Routledge (pp. 25-36)

McVeigh, T (2016) 'Reckless' cuts in student nurse funding attacked. The Times, June 19th Meikle, J (2016) NHS deficit hits $£ 2.3 b n$ as care demands rise. The Guardian, February 20th Mendoza, K (2015) Austerity: The demolition of the welfare state and the rise of the zombie economy. New York: New Internationalist

Milburn, A (2016) Chair of the Social Mobility Commission: State Of The Nation Report on Social Mobility In Great Britain. GOV.UK. https://www.gov.uk/state-of-the-nation-onsocialmobility-in-great-britain

Millar, F (2016) Teacher recruitment 'a mess' as every school slugs it out for itself. The Guardian Education. January 19th

Millar, F (2016) School reforms widen poverty gap, new research finds. Education Guardian. https://www.theguardian.com>Education. Free schools August 2nd

Millar, F (2016) education/Inequality in Education www. inequalityineducation.org/category/ education/ The Guardian, December 3rd

Mirowski, P (2013) Never Let a Serious Crisis Go to Waste: How neoliberalism survived the financial meltdown. London: Verso

Montgomery, D (1987) The Fall Of The House Of Labour: The workplace, the state and American labour activism, 1865-1925. Cambridge: Cambridge University Press

Morel, N, Palier, B, Palme, J (eds, 2012) Towards a Social Investment Welfare State? Ideas, policies and challenges. Bristol: The Policy Press

Morris, K, Featherstone, B, Gupta, A, Warner, J (2016) Let's stop feeding the risk monster: Towards a social model of child protection. Families, Relationships and Societies doi.10.1332/204674316x14552878034622

Morris, K and White, S (2016) Family Complexity and Social Work: A Comparative study of family-based welfare work in different welfare regimes. NORFACE: Workshop -Discussing Key Challenges to Today's Globalised World: Tensions Between Migration And the National Welfare State norface.net/2017

Morris, K, Laid, S, Archard, P and Clawson, R (2017) Working with the whole family: What case files tell us about social work practices. Child \& Family Social Work doi: $10.1111 /$ cfs.12349

Mulholland, H (2015) Nurse shortages are life-threatening. The Guardian, September 2nd

Munro, E (2011) The Munro Review Of Child Protection. Final Report. A child-centred system. Department For Education (DfE) Cm 8062. Norwich: The Stationery Office 
Murphy, P (2015) Universities And Innovation Economies: The creative wasteland of postindustrial society. Farnham: Ashgate

Murray, K (2015) 'We are not child-snatchers or do-gooders. The work we do save lives' The Guardian, December 9th

Narey, M (2014) Making the Education of Social Workers Consistently Effective. (Report Of Sir Martin Narey's Independent Review Of The Education Of Children's Social Workers) January. London: DfE. Policy-GOV.UK

National Audit Office (2014) Care Quality Commission: Recruitment and training of staff to build a new organisational culture. London: National Audit Office (NAO) July 22nd

NHS (National Health Service) available at: https:?/catalogue.ic.nhs.uk/publications/socialcre/staff/pers-soci-serv-staff-30-sep-eng-21010/per-soci-serv-staf-30-sep-2010-rep.pdf

NHS England (2016) Nine out of ten nhs groups failing on cancer care: Ratings show need for improvement. https://www-guardian.com.Society. NHS October 4th

NHS England (2016) NHS groups 'failing' cancer patients - Local Gov.co.uk -Yourauthority... https://www.localgov.co.uk/NHS-groups-'failing'-cancer-patients/41784 October 5th

Needham, C and Glasby, J (Eds.) (2014) Debates in Personalisation. Bristol: The Policy Press

Nellis, M (2016) Expanding Tagging Sentences. Scottish Government News. news.gov.scot/ news/expanding-tagging-sentences October 4th

Newman, J (2005) Bending bureaucracy: leadership and multi-level governance. in du Gay, P (Ed.) The Values Of Bureaucracy. Oxford: Oxford University Press (pp. 191-210)

Noel, A (2006) A new global politics of poverty. Global Social Policy, 6, 304-333

Noordegraaf, M (2011) Risky business: How professionals and professionals' fields (must) deal with organizational issues. Organization Studies, 32, 10, 1349-1371

Nursing and Midwifery Council of UK (2010) Standards For Medicines Management. London: NMC

Nursing and Midwifery Council of UK (2015) The Code: Standards of conduct, performance and ethics for nurses and Midwives. London: NMC

O'Carroll, L and Halliday, J (2016) Rotherham victims will ask court to force police to hand over abuse files. The Guardian, February 26th

Office Of The Children's Commissioner (OCC) (2014) 'I Thought I Was The Only One. The Only One In The World': Interim Report. November 17th www.childrenscommissioner.gov.uk

Office Of the Children's Commissioner (OCC) (2014) 'They Still Need To Listen More': A Report about disabled children and young people's rights in England. November 18th www. childrenscommissioner.gov.uk

Office Of The Children's Commissioner (OCC) (2016) Lighting Review: Children's access to school nurses to improve wellbeing and protect them from harm. September. www. childrenscommissioner.gov.uk Also CEO Anne Longfield's response to the Internal Review Of The Independent Inquiry Into Child Sexual Abuse, December 16th

Orr, D (2016) This is the NHS: Mental Health 'There is support out there - make use of it'. The Guardian, January 27th

Parker, J and Bradley, G (2014) Social Work Practice. (4th ed.). London: Sage/Learning Matters Peck, J (2010) Constructions Of Neoliberal Reason. Oxford: Oxford University Press

Perraudin, F (2016) Rotherham aims for re-birth as town that puts children first. The 
Guardian, May 31st

Posner, R (2002) Anti-trust Law: An economic perspective. Chicago: University of Chicago Press Power, M (1999) The Audit Society: Rituals Of verification. Oxford: Oxford University Press

Power, M (2014) Living in an Audit Society: Performance reporting after the global financial crisis.

Public Lecture at the Schools of Social Work and Human Services and Education. The University of Queensland. April 9th

Pritchard, C (2016) Professor Colin Pritchard, Bournemouth University, gives his views on the current problems facing the NHS www. dailyecho.co.uk/news/10583606 July 31st

Putnam, R (2015) Our Kids: The American dream in crisis. New York: Simon \& Schuster

Quinn, B (2015) Only 1 in 8 child abuse victims come forward. The Guardian, November 24th

Quinn, B (2016) Surgeons operated on wrong parts of patients, CQC finds: Culture of bullying at Brighton \& Sussex Trust. The Guardian, August 17th

Quinn, B and Campbell, D (2016) NHS vows to transform mental health services with extra £lbn a year. The Guardian, February 15th

Quinney, A and Hafford-Letchfield, T (2012) Interprofessional Social Work-Effective collaborative approaches. London: Sage/Learning Matters

Reich, R (2015) Saving Capitalism: For the many, not the few. Berkeley: University of California Press

Resolution Foundation (2017) As Time Goes By: Shifting incomes and inequality between and within generations. www.resolutionfoundation.org> Publications. 4th Report For The Intergenerational commission. February 13th

Ribbens-McCarthy, J and Edwards, R (2011) Key Concepts In Family Studies. London: Sage

Rogers, A and Pilgrim, D (2014) A Sociology Of Mental Health and Illness (5th ed.) Maidenhead: Open University Press

Rogers, J, Bright, L and Davies, H (2015) Social Work With Adults. London: Sage

Rogowski, S (2011) Managers, Managerialism and Social Work With Children And Families:

The Deformation Of A Profession? Practice, 23(3): 157-67

Rogowski, S (2016) Social Work With Children And Families: Reflections Of A Critical Practitioner. Abingdon: Routledge

Rosenau, P (1991) Postmodernism and the Social Sciences: Insights, inroads and intrusions. Princeton, NJ: Princeton University Press

Rothblatt, S (1997) The Modern University and its Discontents. Cambridge: Cambridge University Press

Royal College Of Nursing (RCN) (2016)?BMA letter to PM David Cameron regarding bursaries. Nursing Grants-rcnfoundation.org.uk www.rcnfoundation.org.uk Removing Nurse Bursaries - Latest Policy Updates - nuffieldtrust.org.uk www.nuffieldtrust.org.uk Ruch, G (2008) Post-Qualifying Child Care Social Work: Developing reflective practice. London: Sage

Rustin, S (2016) It's your school. It's personal: Meet the parents who are fighting back. The Guardian, July 12 th

Savage, M and Wright, M (2016) Cameron wasted $\mathrm{Elbn}$ on troubled families. The Times, October 18th 
Scholte, J (2005) Globalization: A critical introduction (2nd ed.) London: Macmillan Schumpeter, J (1928) Unternehmer. in Ludwig, E, Weber, A and Wieser, F (Eds.) Handwörterbuch der Staatswissenschaften, Vol. 8. (4th Ed.) Jena (pp.476-487)

Schumpeter, J (1934) The Theory of Economic Development. London: Harper Schumpeter, J (1976) Capitalism, Socialism and Democracy. London: Harper Select Committee Report (2016) Gender Pay Gap Reporting. Publications. Parliament -Parliament. UK https://www.publications.parliament.uk/pa/cm201516/cmselect/ cmwomeq/../584pdf

Shore, C (2008) Audit Culture And Illiberal Governance: Universities And The Politics of Accountability. Anthropological Theory, 8, 3, 278-298

Shore, C and Wright, S (1999) Audit culture and anthropology: Neoliberalism in British higher education. The Journal Of The Royal Anthropological Institute 5, 4, 557-575

Siddique, H (2015) Hospitals told to shed staff as NHS funding crisis deepens. The Guardian, November 15 th

Siddique, H (2016) Hospitals face 5-day walkout by doctors in contract fight. The Guardian, September 1st

Simmel, G (1950) The Sociology Of Georg Simmel. New York: Simon \& Schuster

Skills For Care (2013) Code For Conduct for Health Care Support Workers and Adult Social Care Workers in England. Leeds: Skills for Care

Skills For Care (2013) National Minimum Training Standards for Health Care Support Workers and Adult Social Care Workers in England. Leeds: Skills For Care

Skills For Care (2015) skillsforcare.org.uk - Skills for Care -Helping social care employers www.skillsforcare.org.uk/Standards and Legislation

Smith, D (2001) The changing idea of a university. in Smith, D and Langslow, K (Eds.) The Idea of a University. London: Jessica Kingsley (pp. 148-174)

Smith, J. (2004) Safeguarding Patients. Lessons from the past, proposals for the future. 5th Report of the Shipman Inquiry. Lonson: The Stationery Office Cm 6394

Social Mobility Commission (2017) The Class Pay Gap within Britain's Professions: The class pay gap and intergenerational worklessness. (authored by Friedman, S, Laurison, D and Macmillan, L) London: Social Mobility Commission. https://www.gov.uk/ government/?the-class-pay-gap-within-britains-professions. January 26th

Social Work Reform Board (2012) Building A Safe Confident Future: Maintaining momentum. London: DfE

Sparrow, A (2016) Junior doctors risk being struck off GMC. The Guardian, September 5th Standing, G (2011) The Precariat: The New Dangerous Class. London: Bloomsbury

Standing, G (2014) A Precariat Charter. London: Bloomsbury

Taylor, F (1947) Scientific Management. New York: Harper and Brothers.

Taylor, M (2016) Failing children's services to be taken over by rival councils under proposed changes. The Guardian, April 15th

Taylor-Gooby, P (2008) The new welfare state settlement in Europe. European Societies, 10, 1, 3-24

Taylor-Gooby, P and Stoker, G (2011) The Coalition Programme: A new vision for Britain 
or politics as usual? The Political Quarterly, 82, 1, 4-15

Tett, G. The Silo Effect: Why putting everything in its place isn't such a bright idea. London: Little, Brown

Tickle, L (2017) Mother courage: Trading pregnancy for help. Society Guardian, January 25th Toynbee, P (2015) Hunt's hit squad is a danger to our national health. The Guardian, September 22nd

Toynbee, P (2016) Saving his skin as he lets the NHS sink. The Guardian, July 26th

Toynbee, P (2016) Our nurses are being cast into a perfect Brexit storm. The Guardian, October 14 th

Treanor, J (2016) Chancellor insists foreign worker plan not aimed at banks. The Guardian, October 7 th

Triseliotis, J (1995) Adoption: evolution or revolution. in British Agencies For Adoption And Fostering, Selected BAAF Seminar Papers 1994/95 London: BAAF

Triseliotis, J (1997) Foster care and adoption. in Davies, M (Ed.) The Blackwell Companion To Social Work. Oxford: Blackwell Publishers (pp.331-336)

Thomas, R and Davies, A (2005) Theorising the micro-politics of resistance: New public management and managerial identities in the UK public services. Organization Studies, 26, 5, 683-706

Thompson, M (2016) Enough Said: What's gone wrong with the language of politics. Harmondsworth: Penguin

Tunstill, J (2016) Editorial: In defence of progressive social work. Social Work \& Social Sciences Review, , 18, 2, 3-6

Vallos, S (1990) The concept of skill: A critical review. Work and Occupations, 17, 4, 379-398

Van der Aa, P and van Berkel, R (2015) Fulfilling The promise of professionalism in streetlevel practice, 263-278 in Hupe, P, Hill, M and Buffat, A (Eds.) Understanding Street-Level Bureaucracy. Bristol: The Policy Press

Walker, P, Stewart, H and Taylor, D (2016) NHS bosses defend shake-up after planned cuts cause alarm. The Guardian, August 27th

Weale, S (2015) Without Kids Company I'd be dead or in prison. Its closure was a big shock to me. The Guardian, September 22nd

Weale, S (2015) Schools hit by record $£ 1$.3bn supply staff bill, says Labour. The Guardian, December 14 th

Weale, S (2016) Ministers childcare policies 'fail to deliver': demand for better paid and better qualified staff. The Guardian, January 27 th

Weale, S (2016) Parents see fees go up after big fall in number of childminder places. The Guardian, February 8th

Weale, S (2016) Third of new teachers quit within five years: Unions blame workload and constant changes. The Guardian, August 5th

Weale, S (2016) Grammar schools plan risks disaster, warns social mobility tsar. The Guardian, September 8th

Weber, M (1976\{1930\}) The Protestant Ethic and the Spirit of Capitalism. London: Allen \& Unwin Weber, M (1991) Science as a vocation. in From Max Weber: Essays in sociology (new edition) 
London: Routledge

Weber, S (1987) The limits of professionalism. in Weber, S Institution and Interpretation.

Theory And History of Literature, 31: 19-32, Minneapolis: University Of Minneapolis Press

White, S (2004) Welfare philosophy and the third way., in Lewis, J and Surender, R (Eds.)

Welfare State Change: Towards a third way? Oxford: Oxford University Press

Whitehead, S (2016) Pay the cost of caring: 'I love my job, but I'm tired'. The Guardian, June 25th

Wilby, P (2016) Eton's Provost: Social mobility improving, but real change is ... The Guardian, May 13th

Williams, M (2016) Key Concepts in the Philosophy of Social Research. London: Sage

Williams, P (2012) The role of leadership in learning and knowledge for integration: Nanaging community Care. Journal Of Integrated Care, 20, 3. 164-174

Wintour, P (2014) Labour: 430, 000 students taught by unqualified staff. The Guardian, December 30th

Wolfensberger, W (1972) The Principle Of Normalization In Human Services. Toronto: NIMR

Wolfensberger, W (1998) Social Role Valorization. (3rd ed.) Syracuse, NY: Syracuse University, Training Institute On Human Service Planning, Leadership And Change Agency

Women's Aid Federation Of England (2016) Support for Survivors: Refuge. Who can stay at a refuge?Women's Aid (@womensaid)?Twitter. SOS: Save Refuges, Save Lives-Women’s Aid https;//www. womensaid.org.UK. Campaign with us September

Wood, S (ed, 1982) The Degradation Of Work? Skill, deskilling and the labour process. London: Hutchinson 